\title{
Structure-Photochemical Function Relationships in Nitrogen-Containing Heterocyclic Aromatic Photobases Derived from Quinoline
}

\author{
Sophya F. Alamudun, Kyle Tanovitz, April Fajardo, Kaitlind Johnson, Andy Pham,
} Tina Jamshidi Araghi, and Andrew S. Petit*

Department of Chemistry and Biochemistry, California State University, Fullerton, California

$$
\text { 92834-6866, United States }
$$

*Author to whom correspondence should be addressed. Email: apetit@fullerton.edu

\begin{abstract}
Photobases are compounds which become strong bases after electronic excitation. Recent experimental studies have highlighted the photobasicity of the 5-R quinoline compounds, demonstrating a strong substituent dependence to the $p K_{\mathrm{a}}^{*}$. In this paper we describe our systematic study of how the photobasicity of four families of nitrogen-containing heterocyclic aromatics are tuned through substituents. We show that substituent position and identity both significantly impact the $p K_{\mathrm{a}}^{*}$. We demonstrate that the substituent effects are additive and identify many disubstituted compounds with substantially greater photobasicity than the most photobasic 5-R quinoline compound identified previously. We show that the addition of a second fused benzene ring to quinoline, along with two electron-donating substituents, lowers the $\mathrm{S}_{0} \rightarrow \mathrm{S}_{\mathrm{CT}}$ vertical excitation energy into the visible while still maintaining a $p K_{\mathrm{a}}^{*}>14$. Overall, the structure-function relationships developed in this study provide new insights to guide the development of new photocatalysts that employ photobasicity.
\end{abstract}




\section{Introduction}

Photocatalysts are of widespread interest to the chemistry community because of their important role in the transformation of solar light into chemical energy as well as the ability to systematically control catalyst reactivity using light. In processes like artificial photosynthesis, photocatalysts make possible redox reactions which require the overall transfer of multiple electrons and protons. This chemistry is driven by the rearrangement of charge in the photocatalyst after excitation to a state with significant charge-transfer character. This redistribution of charge in the electronic excited state allows electron or proton transfer reactions to occur which would otherwise be thermodynamically and/or kinetically unfavorable in the ground state.

Excited-state proton transfer represents a specific manifestation of photocatalysis that has also been applied to the optical control of enzymes as well as a probe of local molecular environments. ${ }^{1-3}$ Previous experimental and theoretical investigations of systems which exhibit excited-state proton transfer have primarily focused on photoacids, molecules which become stronger proton donors after electronic excitation $\left(p K_{\mathrm{a}}^{*}<p K_{\mathrm{a}}\right) \cdot{ }^{4-11}$ The gains in acid strength with photoexcitation can be very large, with examples reported in the literature of molecules whose $K_{\mathrm{a}}^{*}$ is 12 orders of magnitude larger than its $K_{\mathrm{a}} \cdot{ }^{9}$ Interestingly, photobases, molecules which become stronger proton acceptors after electronic excitation, are much less well represented in the literature despite their potential application in photocatalysis. ${ }^{12-19}$

Recent experimental studies performed in the Dawlaty lab have investigated the photochemical properties of a family of 5-R quinoline derivatives. ${ }^{20-25}$ These compounds were all shown to be photobases, with the magnitude of the photobasicity depending strongly on the identity of the substituent. Specifically, photoexcitation results in $\mathrm{K}_{\mathrm{b}}$ increasing by over 10 orders of magnitude when the substituent is the electron-donating $\mathrm{NH}_{2}$ group but only approximately 2 
orders of magnitude when the substituent is the electron-withdrawing $\mathrm{CN}$ group. This behavior has been attributed to the charge-transfer character of the singlet bright state responsible for the photobasicity, $\mathrm{S}_{\mathrm{C}}$. Specifically, the $\mathrm{S}_{0} \rightarrow \mathrm{S}_{\mathrm{CT}}$ transition results in an increase of electron density on the ring nitrogen atom and hence an increase in its basicity. Electron-donating substituents amplify the charge-transfer character of the transition, leading to larger $p K_{\mathrm{a}}^{*}$.

As a further step towards practical photocatalysts employing photobasicity, a recent study reported two iridium complexes containing a pendant quinoline ligand. ${ }^{23}$ This study demonstrated that the quinoline moiety maintained its photobasicity in the complexes and as such, represents the first rational design of a transition metal complex in which a ligand exhibits light-triggered proton removal functionality.

While these studies demonstrate the potential of applying photobasicity in photocatalyst design, only a very limited family of photobases has been systematically studied to date. In this paper, we report a computational investigation of structure-function relationships in the photobasicity of nitrogen-containing heterocyclic aromatics related to quinoline. We demonstrate that both substituent identity and position matter in determining the thermodynamic driving force for excited state protonation. We show that the substituent effects are additive, with a number of quinoline and isoquinoline derivatives with multiple electron-donating substituents identified to have $K_{\mathrm{b}}^{*}$ that are several orders of magnitude larger than that of the strongest monosubstituted quinoline photobase identified in experiment, 5-aminoquinoline. We demonstrate that the addition of a second fused benzene ring lowers the $\mathrm{S}_{0} \rightarrow \mathrm{S}_{\mathrm{CT}}$ excitation energy while also decreasing the extent of photobasicity; similar conclusions were recently drawn by Hunt et al. ${ }^{24}$ However, we identify a number of acridine and 1-azaanthracene derivatives which are both strong bases in the $\mathrm{S}_{\mathrm{CT}}$ excited state and have $\mathrm{S}_{0} \rightarrow \mathrm{S}_{\mathrm{CT}}$ excitation 
energies that are in the visible. Collectively, this work further refines the design principles necessary to develop new photocatalysts which employ photobasicity.

\section{Theoretical Methods}

Figure 1 illustrates the Förster cycle used to calculate $\Delta G^{*}$ and hence $\mathrm{p} K_{\mathrm{a}}^{*}$ from a series of quantities that are readily obtained from electronic structure calculations, specifically $\Delta G^{*}=$ $\Delta G+\Delta E_{00}^{\mathrm{B}}-\Delta E_{00}^{\mathrm{BH}}$. In this equation, the ground state $\Delta G$ is related to $\Delta G^{*}$ through the adiabatic $\mathrm{S}_{\mathrm{CT}}-\mathrm{S}_{0}$ energy gaps of the base and conjugate acid, $\Delta E_{00}^{\mathrm{B}}$ and $\Delta E_{00}^{\mathrm{BH}}$. More specifically, $\Delta E_{00}^{\mathrm{B}}=E_{\mathrm{S}_{\mathrm{CT}}}^{B}-E_{\mathrm{S}_{0}}^{B}$, where $E_{\mathrm{S}_{\mathrm{CT}}}^{B}$ is the electronic energy of the charge-transfer $\mathrm{S}_{\mathrm{CT}}$ state at the $\mathrm{S}_{\mathrm{CT}}$ minimum energy geometry while $E_{\mathrm{S}_{0}}^{B}$ is the $\mathrm{S}_{0}$ electronic energy at the $\mathrm{S}_{0}$ minimum energy geometry.

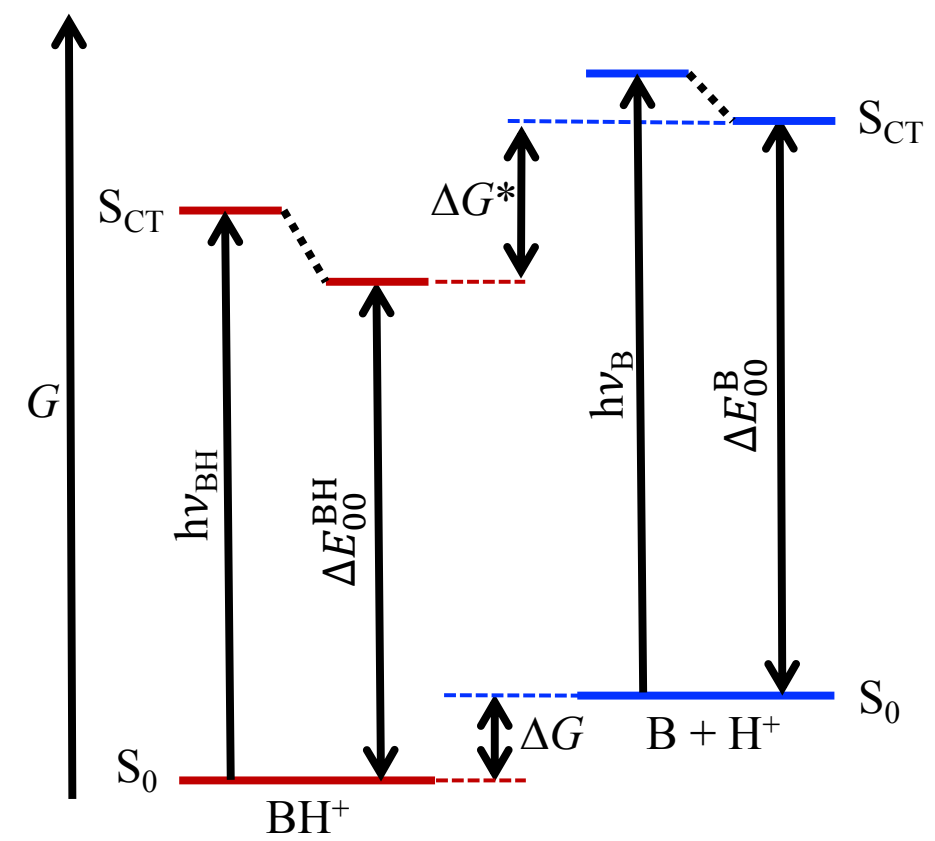

Figure 1: The Förster cycle used to calculate $\Delta G^{*}$ from $\Delta G$ and the adiabatic $\mathrm{S}_{\mathrm{CT}}-\mathrm{S}_{0}$ energy gap for the base and conjugate acid $\left(\Delta E_{00}^{\mathrm{B}}\right.$ and $\left.\Delta E_{00}^{\mathrm{BH}}\right)$. Vibrational relaxation on $\mathrm{S}_{\mathrm{CT}}$ is denoted by the dotted black lines.

The first step is calculating the ground state free energies of B and $\mathrm{BH}^{+}, G_{\mathrm{B}}$ and $G_{\mathrm{BH}}$, where the geometry optimizations and vibrational frequency evaluations are performed at the 
$\omega B 97 X D /$ def2-svpd level of theory while the electronic energies are subsequently evaluated using $\omega$ B97XD/def2-tzvppd. ${ }^{26,27}$ All DFT calculations employ a $(99,590)$ integration grid. Solvent effects are included using a polarizable continuum model (PCM); a conductor-like PCM (CPCM) for the geometry optimizations and an integral equation formalism PCM (IEF-PCM) for the single-point calculations. ${ }^{28}$ Both PCM models use a cavity constructed with Bondi radii and switching Gaussian surface charges. ${ }^{29,30}$ As in the experiments, the solvent used in these calculations is water. All electronic structure calculations were performed using the Q-Chem 5.1 software package. ${ }^{31}$

Figure 2 demonstrates that the calculated $G_{\mathrm{B}}-G_{\mathrm{BH}}$ is very strongly correlated with the experimental $\mathrm{p} K_{\mathrm{a}}$ of $\mathrm{BH}^{+}$for the family of 5-R-quinoline derivatives considered by Dawlaty and coworkers. ${ }^{20}$ Indeed, we take Figure 2 to provide a suitable calibration curve to convert $G_{\mathrm{B}}-G_{\mathrm{BH}}$ into $\mathrm{p} K_{\mathrm{a}}$ for other $\mathrm{N}$-containing aromatic heterocycles where the basicity involves a $\mathrm{sp}^{2}$ hybridized lone pair on $\mathrm{N}$. The desired $\Delta \mathrm{G}$ is then easily calculated from the $\mathrm{p} K_{\mathrm{a}}$ using $\Delta G=$ 2.303RTpK $K_{a}$. Finally, note that 5-bromoquinoline is excluded from the linear regression analysis presented in Figure 2 because it did not follow the same trend as the other 5-R quinoline compounds. 


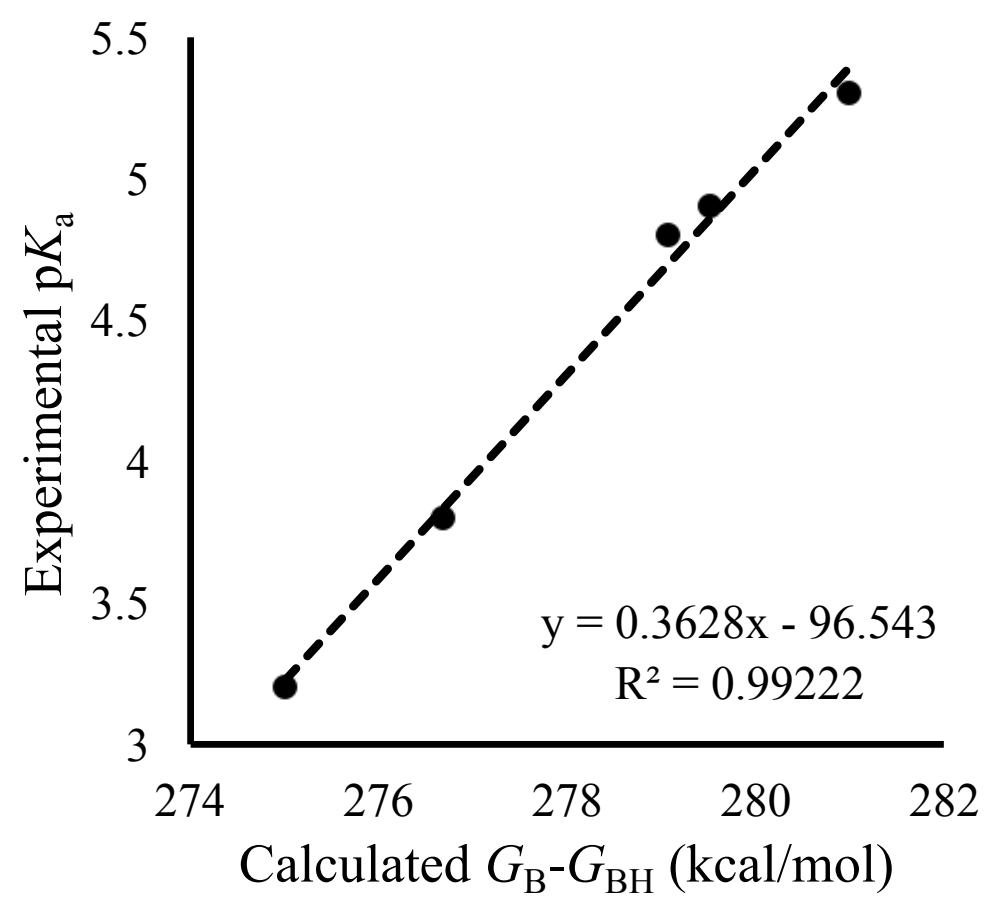

Figure 2: Correlation between the experimental $\mathrm{p} K_{\mathrm{a}}$ of the 5-R quinoline compounds studied by Dawlaty and coworkers and the calculated difference in free energy between the base and conjugate acid $\left(G_{\mathrm{B}-}-G_{\mathrm{BH}}\right) .{ }^{20}$ Note that 5-bromoquinoline was not included in the above analysis because it did not follow the trend formed by the other 5-R quinoline compounds.

The remaining quantities, $\Delta E_{00}^{\mathrm{B}}$ and $\Delta E_{00}^{\mathrm{BH}}$, are the adiabatic $\mathrm{S}_{\mathrm{CT}}-\mathrm{S}_{0}$ energy gaps for the base and conjugate acid. The excited state geometry optimizations are performed at the TD-

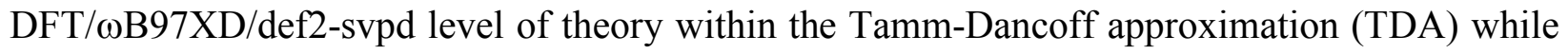

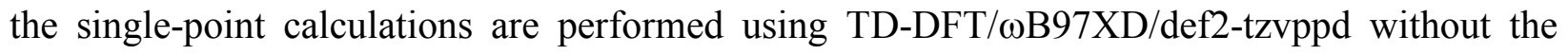
TDA. TDA is used in the excited state geometry optimizations to avoid numerical singularities that can arise when full TD-DFT is used to explore potential energy surfaces. ${ }^{32}$ All TD-DFT calculations used a $(99,590)$ integration grid. As above, solvent effects are included using PCM, with CPCM used in the excited state geometry optimizations and state-specific IEF-PCM used for the single-point calculations. ${ }^{33,34}$ The PCM models were parameterized for water with cavities constructed using Bondi radii and switching Gaussian surface charges. 
Our choice of the $\omega \mathrm{B} 97 \mathrm{XD}$ functional for this study is motivated in part because it is a long-range corrected functional. Long-range corrected functionals are known to reduce the selfinteraction error in DFT and provide an improved description of charge-transfer states in TD-DFT calculations. ${ }^{35}$ In particular, TD-DFT calculations performed using the $\omega$ B97XD functional have been shown to provide a reasonable description of the low-lying singlet states of heteroaromatics, in particular $\mathrm{S}_{\mathrm{CT} .}{ }^{36,37}$

Throughout this study, we identify $\mathrm{S}_{\mathrm{CT}}$ as the lowest-energy $\pi \rightarrow \pi^{*}$ bright state of the bases for which the ring nitrogen gains charge density and hence becomes more basic. Analysis of the electronic character of the excitations is performed using natural transition orbitals and Löwdin charge differences. ${ }^{38,39}$ The highest occupied natural transition orbitals (HONTO) and the lowest unoccupied natural transition orbital (LUNTO) associated with $\mathrm{S}_{\mathrm{CT}}$ are shown in Figure 3 for two representative compounds considered in this study; other examples can be found in the Supporting Information. In particular, Figure 3 shows that $\mathrm{S}_{\mathrm{CT}}$ is $\pi \rightarrow \pi^{*}$ with charge-transfer character, with electron density on the amine groups shifting into the rest of the molecule. We further ensure that the chosen state for the acid form of the compounds has the same electronic character as the base. For the majority of the compounds considered in this study, particularly those with strongly electron-donating substituents, $\mathrm{S}_{\mathrm{CT}}$ is identified as $\mathrm{S}_{1}$. State-tracking is used during the excited state geometry optimizations to ensure that the electronic character of the excited state is preserved. ${ }^{40}$ We additionally verify that the natural transition orbitals of the $\mathrm{S}_{\mathrm{CT}}$ state are consistent at the $\mathrm{S}_{0}$ and $\mathrm{S}_{\mathrm{CT}}$ optimized geometries. 
HONTO

5,6-Aminoquinoline

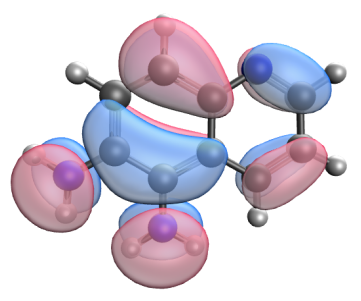

1,2-Amino-acridine

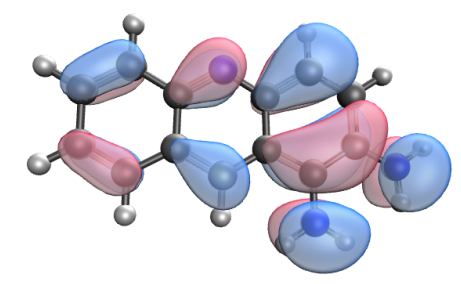

LUNTO
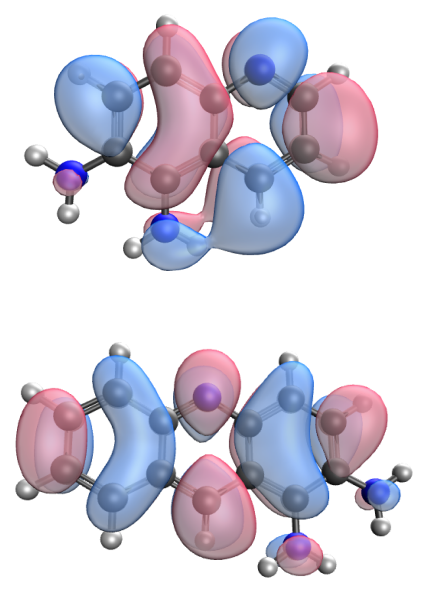

Figure 3: The highest occupied natural transition orbital (HONTO) and lowest unoccupied transition orbital (LUNTO) associated with the $\mathrm{S}_{\mathrm{CT}}$ state of 5,6-aminoquinoline and 1,2-amino-acridine. These orbitals were calculated at the $\mathrm{S}_{\mathrm{CT}}$ optimized geometry and plotted with an isovalue of 0.06 .

\section{Results and Discussion}

\section{Analysis of the Photobasicity of the Monosubstituted Quinolines}

Figure 4 shows that the calculated $\mathrm{p} K_{\mathrm{a}}^{*}$ for the 5 -R quinoline compounds depends strongly on the Hammett $\sigma_{\text {para }}^{+}$of the substituent. ${ }^{41,42}$ Specifically, electron-withdrawing substituents $\left(\sigma_{\text {para }}^{+}>0\right)$ lower the $\mathrm{p} K_{\mathrm{a}}^{*}$ while electron-donating substituents $\left(\sigma_{\text {para }}^{+}<0\right)$ raise the $\mathrm{p} K_{\mathrm{a}}^{*}$. The corresponding $K_{\mathrm{b}}^{*}$ span nearly 10 orders of magnitude, with $K_{\mathrm{b}}^{*}=2.69 \times 10^{-8}$ for 5 cyanoquinoline and $K_{\mathrm{b}}^{*}=205$ for 5 -dimethylaminoquinoline. Note that all compounds with $\mathrm{p} K_{\mathrm{a}}^{*}>14$ are strong bases in the $\mathrm{S}_{\mathrm{CT}}$ excited electronic state. In contrast with the excited state basicity, the variation in the ground state basicity is much smaller; $K_{\mathrm{b}}$ ranges from $1.67 \times 10^{-11}$ for 5-cyanoquinoline to $2.48 \times 10^{-9}$ for 5-aminoquinoline. Finally, Table S1 in the Supporting Information shows that electron-donating substituents decrease the vertical excitation energy of 
the 5-R quinoline compounds; the calculated $\mathrm{S}_{0} \rightarrow \mathrm{S}_{\mathrm{CT}}$ vertical excitation energy is $4.70 \mathrm{eV}$ for quinoline and $3.69 \mathrm{eV}$ for 5-methylaminoquinoline.

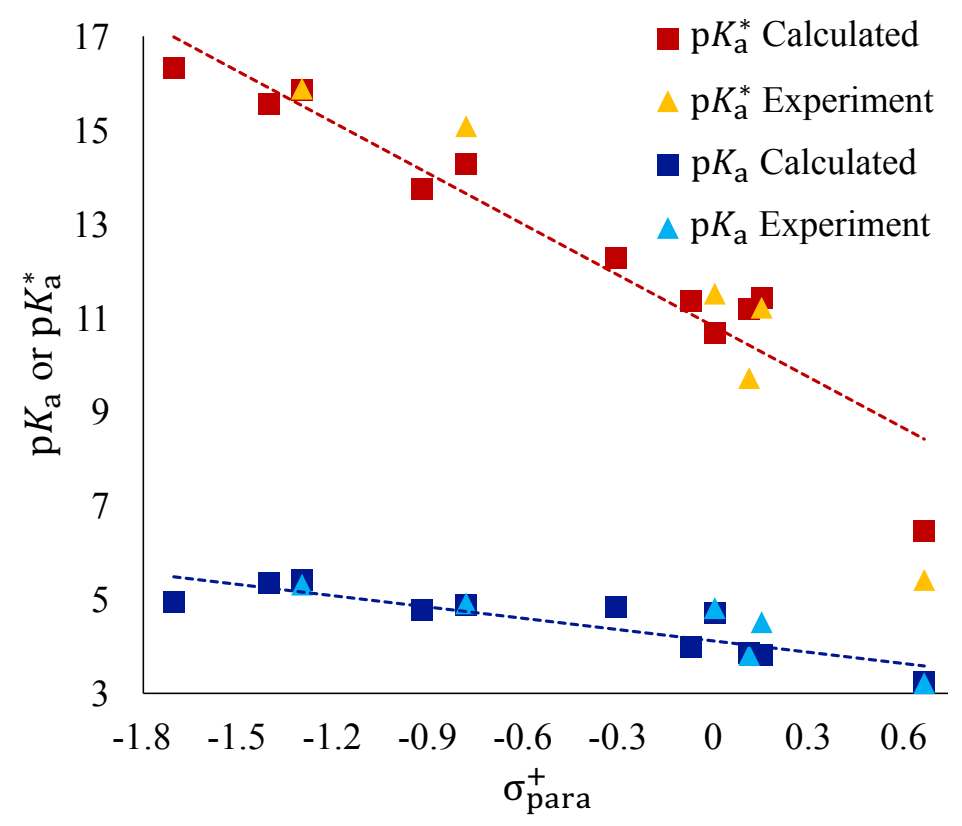

Figure 4: Dependence of our calculated $\mathrm{p} K_{\mathrm{a}}$ (blue squares) and $\mathrm{p} K_{\mathrm{a}}^{*}$ (red squares) on the Hammett $\sigma_{\text {para }}^{+}$of the substituent for the 5-R quinoline compounds considered in this study. The Hammett $\sigma_{\text {para }}^{+}$parameterizes the strength of electron-donating $\left(\sigma_{\text {para }}^{+}<0\right)$ or electron-withdrawing $\left(\sigma_{\text {para }}^{+}>0\right)$ character of the substituent. Where available, the corresponding experimental values reported by Dawlaty and coworkers are shown as triangels. ${ }^{20}$ The $\mathrm{R}^{2}$ values for $\mathrm{p} K_{\mathrm{a}}^{*}$ are 0.89 for experiment and 0.91 for theory whereas for $\mathrm{p} K_{\mathrm{a}}$ they are 0.76 and 0.75 .

Figure 4 additionally compares our calculated $\mathrm{p} K_{\mathrm{a}}$ and $\mathrm{p} K_{\mathrm{a}}^{*}$ (squares) to the experimental values reported by Dawlaty and coworkers (triangles). ${ }^{20}$ With the exception of 5bromoquinoline, the agreement between the experimental and calculated $\mathrm{p} K_{\mathrm{a}}$ is excellent; 5bromoquinoline was not included in the analysis shown in Figure 2 because it did not follow the same trend as the other 5-R quinoline compounds. The excellent agreement between the experimental and calculated $\mathrm{p} K_{\mathrm{a}}$ reflects our use of the calibration curve developed in Figure 2. While there are some discrepancies between the calculated and experimental $\mathrm{p} K_{\mathrm{a}}^{*}$, we clearly 
capture the same overall trend as experiment. Moreover, the agreement between experiment and theory is best for the strongly photobasic compounds with electron-donating substituents, the class of compounds of interest in this study. The errors that do exist between the calculated and experimental $\mathrm{p} K_{\mathrm{a}}^{*}$ primarily reflect errors in the calculated adiabatic energy gaps that result from our choice of using TD-DFT with a PCM solvent model to describe the electronic excited states. Nevertheless, Figure 4 demonstrates that our chosen computational approach captures the same trend as experiment for how photobasicity is modulated by changes to the molecular structure and hence is suitable for identifying the structure-photochemical function relationships of interest in this study.

Figure 5 extends our analysis of the photobasicity of monosubstituted quinoline to explore the effect of substituent position; the corresponding data is summarized in Tables S2-S6 in the Supporting Information. Compounds with the substituent on the nitrogen-containing ring are shown as squares whereas compounds with the substituent on the fused benzene ring are shown as triangles. The natural transition orbitals involved in the $\mathrm{S}_{0} \rightarrow \mathrm{S}_{\mathrm{CT}}$ transition, which are shown for representative compounds in Figures S2 and S3 in the Supporting Information, indicate that the transition is consistently $\pi \rightarrow \pi^{*}$ regardless of the substituent position. 


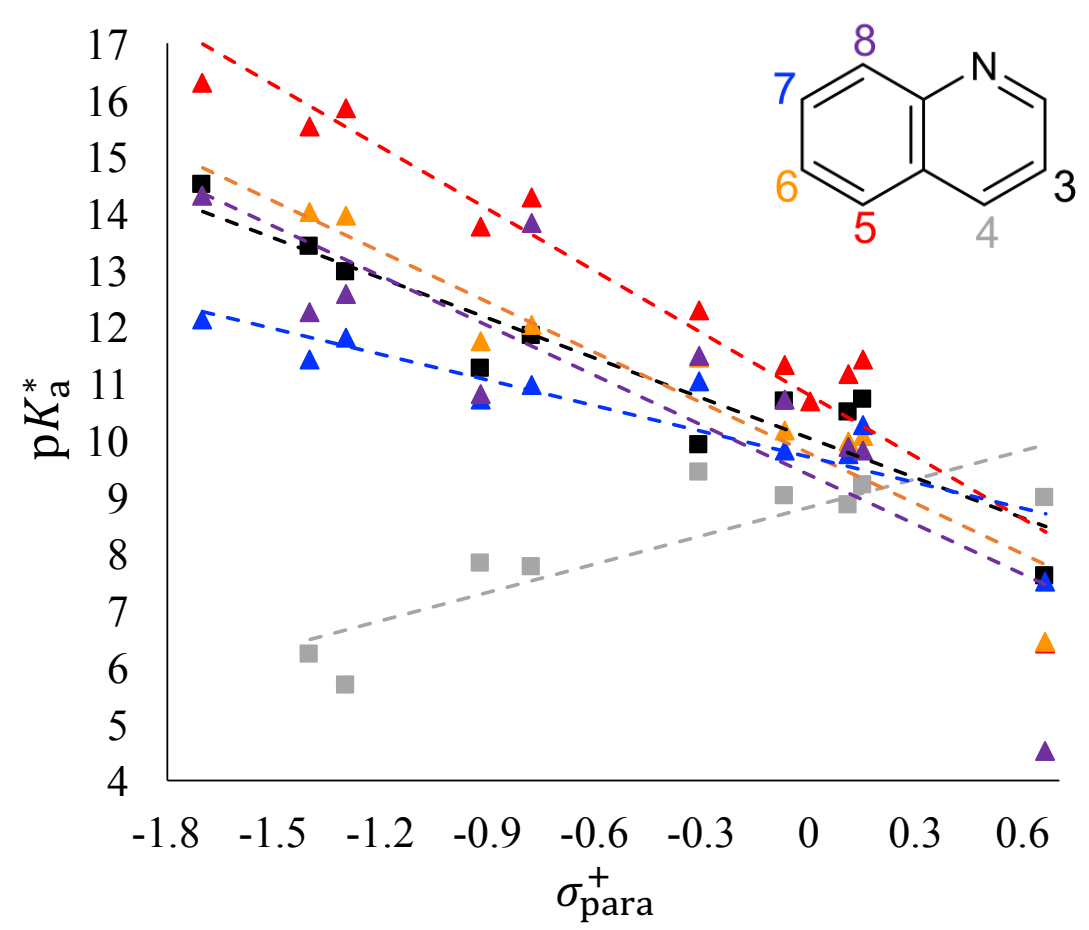

Figure 5: Calculated $\mathrm{p} K_{\mathrm{a}}^{*}$ versus the Hammett $\sigma_{\text {para }}^{+}$ parameter of the substituent for the monosubstituted quinoline compounds considered in this study. As shown in Figure $\mathrm{S} 4$ in the Supporting Information, $\mathrm{R}^{2}$ values from the linear regression analysis range from 0.92 for the 6-R quinolines to 0.69 for the $8-\mathrm{R}$ quinolines.

We focus first on the compounds with the substituent on the fused benzene ring. The 5-R quinolines (shown as red triangles) have the largest $\mathrm{p} K_{\mathrm{a}}^{*}$ and hence strongest photobasicity. This is especially apparent for the strongly electron-donating $-\mathrm{OH},-\mathrm{NH}_{2},-\mathrm{NHCH}_{3}$, and $-\mathrm{N}\left(\mathrm{CH}_{3}\right)_{2}$ substituents. Turning to the other substituent positions on the fused benzene ring, the 6-R (orange triangles), 7-R (blue triangles), and 8-R (purple triangles) quinolines show the same general trend as the 5-R quinolines, with the $\mathrm{p} K_{\mathrm{a}}^{*}$ increasing as the substituent is made increasingly electron-donating. The 6-R quinoline compounds have significantly larger $\mathrm{p} K_{\mathrm{a}}^{*}$ than the corresponding 7-R quinoline compounds; 6-dimethylaminoquinoline has $\mathrm{p} K_{\mathrm{a}}^{*}=14.32$ whereas 7-dimethylaminoquinoline has $\mathrm{p} K_{\mathrm{a}}^{*}=12.13$. 
The 8-R quinoline compounds exhibit a greater variability in their $\mathrm{p} K_{\mathrm{a}}^{*}$ than the 5-R, 6-R, and 7-R quinolines. In particular, 8-hydroxyquinoline, 8-aminoquinoline, and 8methylaminoquinoline have much lower $\mathrm{p} K_{\mathrm{a}}^{*}$ than would be expected based on the trend in the other 8-R quinolines. These three compounds each contain a substituent that is not only a strong electron-donating group but also a hydrogen bond donor. We therefore believe that the anomalously low $\mathrm{p} K_{\mathrm{a}}^{*}$ of these three compounds reflects the presence of intramolecular hydrogen bonding between the ring nitrogen and the neighboring $-\mathrm{OH},-\mathrm{NH}_{2}$, or $-\mathrm{NHCH}_{3}$ substituent. Protonation of the base results in the loss of this intramolecular hydrogen bonding, causing a reduction of the $K_{\mathrm{b}}$ and $K_{\mathrm{b}}^{*}$ relative to what is expected from the purely electronic effects of the substituent. Further support for this explanation comes from the fact that the syn conformer of 8hydroxyquinoline, which has the hydroxyl group oriented towards the ring nitrogen, is stabilized by $3.25 \mathrm{kcal} / \mathrm{mol}$ relative to the anti conformer. The observation that 8 -methoxyquinoline has a larger $\mathrm{p} K_{\mathrm{a}}^{*}$ than 8-dimethylaminoquinoline additionally suggests that steric repulsion between the protonated ring nitrogen and the neighboring substituent group in the conjugate acids provides an additional reduction in the thermodynamic driving force for excited state protonation; the anti conformer of 8-methoxyquinoline avoids this steric repulsion while simultaneously allowing the methoxy group to participate in $\pi$ conjugation with the rings. Figures S6-S8 in the Supporting Information show representative molecular geometries of 8-R quinoline compounds.

Figure 5 also shows the impact of substituents on the nitrogen-containing ring. The 3-R quinoline compounds (black squares) show a similar trend to the 6-R quinolines with a generally smaller photobasicity. Interestingly, the 4-R quinoline compounds (gray squares) show the opposite trend as the other monosubstituted quinolines, with $\mathrm{p} K_{\mathrm{a}}^{*}$ decreasing as the substituent is 
made increasingly electron-donating. Indeed, for 4-aminoquinoline and 4methylaminoquinoline, electronic excitation results in a decrease in basicity; for example, $\mathrm{p} K_{\mathrm{a}}=7.28$ and $\mathrm{p} K_{\mathrm{a}}^{*}=5.69$ for 4 -aminoquinoline. In contrast to their photobasicity, Tables S1-S6 in the Supporting Information show that 4-aminoquinoline and 4-methylaminoquinoline are the strongest bases in the ground state of all of the monosubsituted quinoline compounds considered in this study. Finally, Figure S5 in the Supporting Information shows that the effect of substituents on the $\mathrm{S}_{0} \rightarrow \mathrm{S}_{\mathrm{CT}}$ vertical excitation energy is much smaller for the 4-R quinolines than for the other monosubsituted quinolines.

As mentioned above, photobasicity in the quinoline derivatives has been attributed to the charge-transfer character of the $\mathrm{S}_{0} \rightarrow \mathrm{S}_{\mathrm{CT}}$ transition, with the ring nitrogen gaining electron density and hence becoming more basic. ${ }^{20,24}$ The extent of charge-transfer character in the $\mathrm{S}_{0} \rightarrow$ $\mathrm{S}_{\mathrm{CT}}$ transition can be quantified through the Löwdin charge difference on the ring nitrogen $(\Delta q){ }^{38,39}$ This analysis can also be performed at the excited-state optimized geometry resulting in $\Delta \mathrm{q}^{*}$. Figure 6 shows the dependence of $\mathrm{p} K_{\mathrm{a}}^{*}$ on $\Delta \mathrm{q}$ (squares) and $\Delta \mathrm{q}^{*}$ (triangles) for the 4-R, 5-R, and 6-R quinolines considered in this study. Figure S9 in the Supporting Information compares $\mathrm{p} K_{\mathrm{a}}^{*}$ and $\Delta \mathrm{q}$ for all of the monosubstituted quinoline derivatives.

For the 5-R and 6-R quinolines, Figure 6 shows that the $\mathrm{p} K_{\mathrm{a}}^{*}$ generally increases as $\Delta \mathrm{q}$ or $\Delta \mathrm{q}^{*}$ on the ring nitrogen becomes more negative. Indeed, linear regression analysis on the plots of $\mathrm{p} K_{\mathrm{a}}^{*}$ versus $\Delta \mathrm{q}^{*}$ reveals $\mathrm{R}^{2}$ values of 0.96 and 0.98 for the 5-R and 6-R quinolines. Figure $\mathrm{S} 6$ in the Supporting Information shows that the corresponding $\mathrm{R}^{2}$ values for $\mathrm{p} K_{\mathrm{a}}^{*}$ versus $\Delta \mathrm{q}$ are 0.89 and 0.92 for the 5-R and 6-R quinolines, respectively. This analysis demonstrates that, for a fixed substituent position, the thermodynamic driving force for excited-state protonation of the ring nitrogen is strongly correlated with the increase in the electron density on the ring nitrogen. 
This suggests that the degree of charge-transfer character of the $\mathrm{S}_{0} \rightarrow \mathrm{S}_{\mathrm{CT}}$ transition affects the strength of the photobasicity.

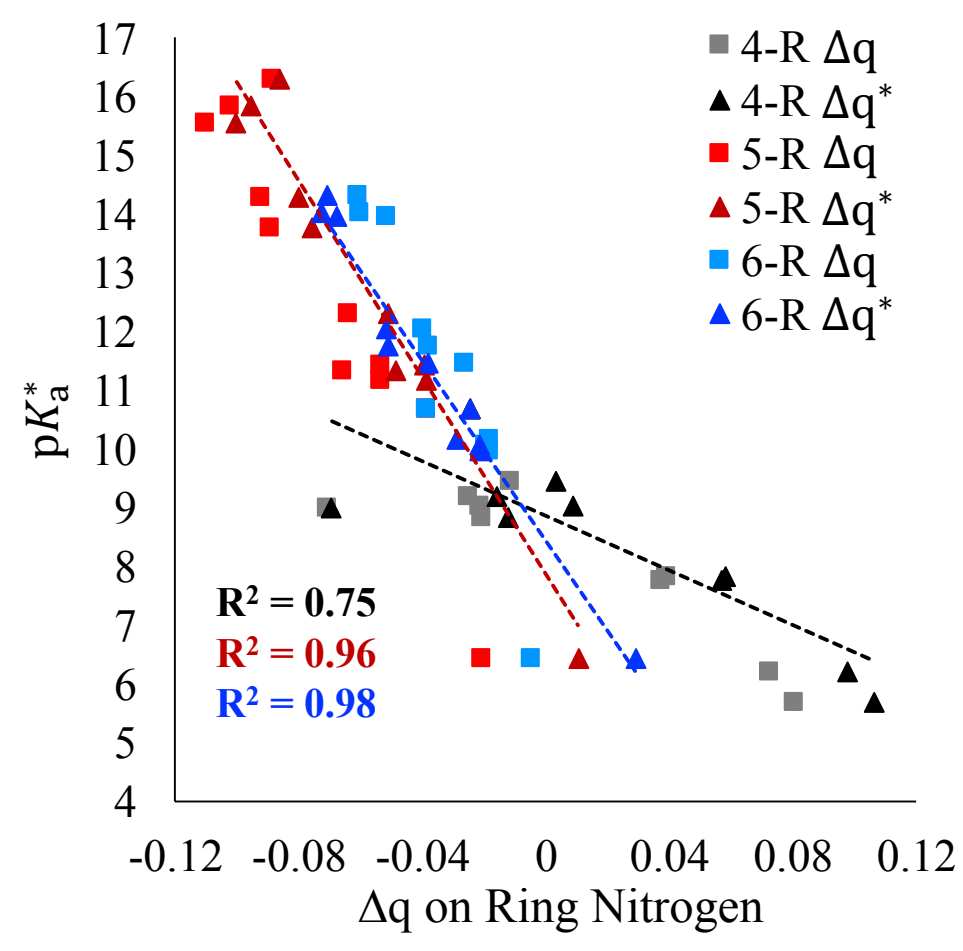

Figure 6: Plot of $\mathrm{p} K_{\mathrm{a}}^{*}$ versus change in charge on the ring nitrogen for the 4-R, 5-R, and 6-R monosubstituted quinoline compounds. The change in charge on the ring nitrogen are calculated at the ground state geometry $(\Delta \mathrm{q}$, squares) and at the excited state optimized geometry $\left(\Delta \mathrm{q}^{*}\right.$, triangles). The reported $\mathrm{R}^{2}$ values are from linear regression analysis performed on the $\Delta q^{*}$ data.

The 4-R quinoline compounds represent an interesting case because, as discussed above, they display the opposite trend as the other monosubstituted quinoline compounds. Figure 6 shows that many of these compounds have positive $\Delta \mathrm{q}$ and $\Delta \mathrm{q}^{*}$ on the ring nitrogen, suggesting that this atom loses electron density in the $\mathrm{S}_{0} \rightarrow \mathrm{S}_{\mathrm{CT}}$ transition and hence becomes less basic. Moreover, as shown in Table $\mathrm{S} 3$ in the Supporting Information, $\Delta \mathrm{q}$ and $\Delta \mathrm{q}^{*}$ become increasingly positive as the $\mathrm{R}$ group is made more electron-donating. This reflects the fact that Figure 5 shows that 4-aminoquinoline has a smaller $\mathrm{p} K_{\mathrm{a}}^{*}$ than 4-cyanoquinoline. Finally, note that while 
the 4-R quinolines exhibit the same overall trend in Figure 6 as the 5-R and 6-R quinolines, the slope is markedly smaller.

Before ending our discussion of Figure 6, we consider the magnitude of the $\Delta \mathrm{q}$ and $\Delta \mathrm{q}^{*}$ observed in the calculations as well as the extent to which the these quantities are predictive of $\mathrm{p} K_{\mathrm{a}}^{*}$. For all of the compounds shown in Figure 6, as well as those analyzed in Figure S6 in the Supporting Information, the magnitudes of $\Delta \mathrm{q}$ and $\Delta \mathrm{q}^{*}$ are modest, with the gain or loss of charge on the ring nitrogen less than 0.15 electrons. Moreover, vibrational relaxation on $\mathrm{S}_{\mathrm{CT}}$ does not always lead to an increase in the magnitude of the charge-transfer; for the 6-R quinolines $\Delta \mathrm{q}^{*}$ is more negative than $\Delta \mathrm{q}$ while the opposite is true for the 5-R quinolines. Additionally, Figures 6 and S6 contain multiple examples of compounds which have very similar $\Delta \mathrm{q}$ and $\Delta \mathrm{q}^{*}$ and yet significantly different $\mathrm{p} K_{\mathrm{a}}^{*}$. This shows that, aside from the observation that all strong photobases have $\Delta \mathrm{q}<0$, one should not use $\Delta \mathrm{q}$ or $\Delta \mathrm{q}^{*}$ as a proxy for $\mathrm{p} K_{\mathrm{a}}^{*}$ when predicting the photobasicity of a new compound. Moreover, the above analysis suggests that while $\mathrm{S}_{\mathrm{CT}}$ should have some charge-transfer character, with the ring nitrogen gaining electron density in the $\mathrm{S}_{0} \rightarrow \mathrm{S}_{\mathrm{CT}}$ transition, the thermodynamic driving force of the excited state protonation of these photobases cannot be solely attributed to the build-up of excess charge on the ring nitrogen.

Finally, we briefly describe the geometric changes that result from the vibrational relaxation on $\mathrm{S}_{\mathrm{CT}}$. For all of the compounds, the excited-state geometry optimization causes a distortion to the aromatic rings which results in a modest elongation of the molecules. The most pronounced geometric changes occur with the amine substituents which, as much as sterically possible, undergo planarization during the vibrational relaxation. This is most pronounced for the basic forms of the compounds; the amine groups are often planar in the ground-state 
optimized geometries of the acidic forms. Examples of this can be seen in Figures S7 and S8 in the Supporting Information for 8-aminoquinoline and 8-dimethylaminoquinoline.

\section{Expanding the Scope of Nitrogen-Containing Aromatic Heterocyclic Photobases:}

\section{Disubstituted Quinolines, Isoquinolines, Acridines, and 1-Azaanthracenes}

Figure 7 summarizes the diversity of compounds we considered in this study which are identified to be strong bases in $\mathrm{S}_{\mathrm{CT}}, \mathrm{p} K_{\mathrm{a}}^{*}>14$, along with their corresponding vertical excitation energies; the complete data set generated in this study is provided in the Supporting Information. We specifically focused on monosubstituted (squares) or disubstituted (triangles) quinoline (purple data), isoquinoline (green data), acridine (blue data), and 1-azaanthracene (red data).

Because we are interested in identifying compounds with the potential for use in photocatalysis, we focused exclusively on electron-donating substituents in developing this dataset.

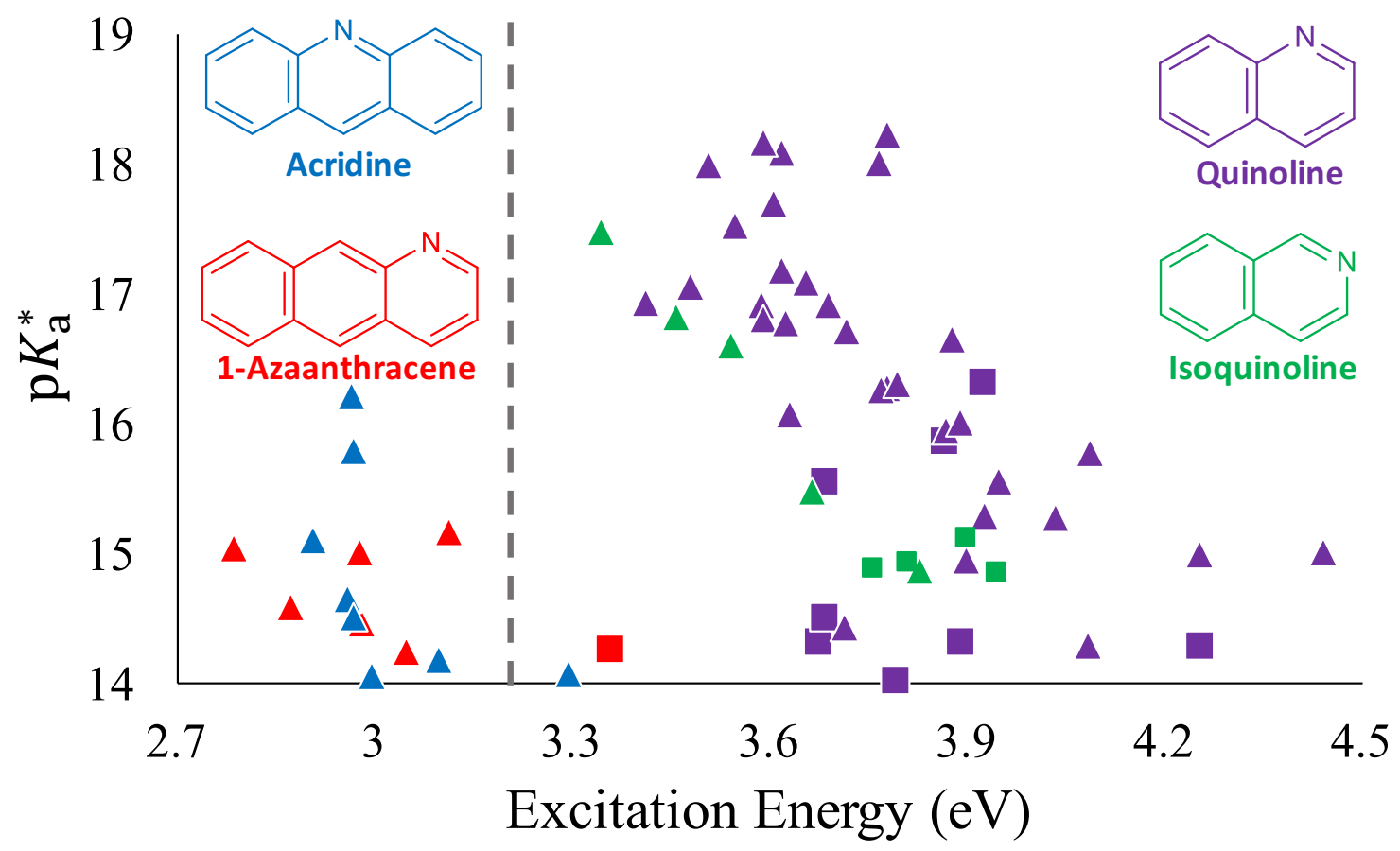

Figure 7: A plot of $\mathrm{p} K_{\mathrm{a}}^{*}$ versus $\mathrm{S}_{0} \rightarrow \mathrm{S}_{\mathrm{CT}}$ vertical excitation energies for the compounds identified in this study to be strong bases in the excited state. The monosubstituted compounds are represented by squares while the disubstituted compounds are denoted by triangles. The dashed gray line denotes the boundary between visible $(\mathrm{h} v<3.26 \mathrm{eV})$ and $\mathrm{UV}(\mathrm{h} v>3.26 \mathrm{eV})$ light. 
Focusing first on the disubstituted quinoline derivatives, Figure 7 demonstrates that the effects of electron-donating substituents on photobasicity are additive as many of the disubstituted quinoline compounds have significantly greater $\mathrm{p} K_{\mathrm{a}}^{*}$ than the monosubstituted compounds. For example, 5,6-aminoquinoline has $\mathrm{p} K_{\mathrm{a}}^{*}=18.16$ whereas 5-aminoquinoline and 6-aminoquinoline have $\mathrm{p} K_{\mathrm{a}}^{*}=15.85$ and $\mathrm{p} K_{\mathrm{a}}^{*}=13.96$ respectively. The disubstituted compounds with the largest $\mathrm{p} K_{\mathrm{a}}^{*}$ have both substituents in positions that Figure 5 identifies as being supportive of increased photobasicity. In particular, the strongest photobases have an amine group in the 5 position along with either another amine group in the 6 position or an electron-donating group in the 8 position which cannot engage in hydrogen bonding with the ring nitrogen. Tables S7-S8 in the Supporting Information further show that an electron-donating substituent in the 4 position continues to decrease the photobasicity in the disubstituted quinolines; the $\mathrm{p} K_{\mathrm{a}}^{*}$ of 4,5-aminoquinoline, 13.58 , is lower than that of 5-aminoquinoline, 15.85. Finally, note that Figure 7 demonstrates that, in addition to increasing $\mathrm{p} K_{\mathrm{a}}^{*}$, the presence of a second electron-donating substituent tends to result in a reduction of the vertical excitation energy. Nevertheless, all of these disubstituted quinolines are still predicted to absorb in the UV. The isoquinoline compounds are shown in Figure 7 to follow the same overall trends as the quinoline compounds, although the isoquinoline compounds tend to have a somewhat lower $\mathrm{p} K_{\mathrm{a}}^{*}$ than their quinoline counterparts. Electron-donating substituents in the 5 and 8 positions of isoquinoline (which are comparable to the 5 and 8 positions of quinoline) result in the largest $\mathrm{p} K_{\mathrm{a}}^{*}$ and lowest vertical excitation energies. In particular, 8-amino-isoquinoline is the most strongly photobasic monosubstituted isoquinoline compound with $\mathrm{p} K_{\mathrm{a}}^{*}=15.12$ while 5,8 amino-isoquinoline has the largest $\mathrm{p} K_{\mathrm{a}}^{*}$ of the disubstitued compounds at 17.48. Note that substituents in the 8 position of isoquinoline have a purely electronic effect on the photobasicity; 
because the ring nitrogen is now in position 2 , there can be no hydrogen bonding or steric interactions between it and a substituent in position 8. Similar to the 4-R quinoline compounds, Table S9 in the Supporting Information shows that increasingly electron-donating substituents in the 4 position of isoquinoline reduce the photobasicity; 4-methyl-isoquinoline and 4-aminoisoquinoline have $\mathrm{p} K_{\mathrm{a}}^{*}=9.23$ and $\mathrm{p} K_{\mathrm{a}}^{*}=8.06$, respectively.

With the addition of a second fused benzene ring, the vertical excitation energies of the acridine and 1-azaanthracene compounds are significantly reduced relative to that of the quinoline and isoquinoline compounds, with several examples in Figure 7 having vertical excitation energies in the visible region of the spectrum (to the left of the dashed gray line). As more fully shown in Tables S10-S12 in the Supporting Information, this reduction in the vertical excitation energy is accompanied by a general decrease in $\mathrm{p} K_{\mathrm{a}}^{*}$ relative to quinoline and isoquinoline. Nevertheless, Figure 7 shows 15 acridine and 1-azaanthracene derivatives with $\mathrm{p} K_{\mathrm{a}}^{*}>14,13$ of which are predicted to absorb in the visible. With the exception of 6methylamino-1-azaanthracene, these compounds are all disubstituted with two strong electrondonating substituents. In the case of the acridine derivatives, the strongest photobases are asymmetric, with an amine in the 1 position and the other electron-donating substituent on the same fused benzene ring in either the 2 or 4 position. The strongest such photobase considered in this study is 1,2-methylaminoacridine with $\mathrm{p} K_{\mathrm{a}}^{*}=16.21$. For the 1-azaanthracene compounds, the strongest photobases have the two substituents on the terminal fused benzene ring, with an amine group in the 6 position and another amine group in the 7 or 9 position. 6,9dimethylamino-1-azaanthracene, the strongest such photobase considered in this study, has $\mathrm{p} K_{\mathrm{a}}^{*}=15.17$ 
The relationship between $\mathrm{p} K_{\mathrm{a}}^{*}$ and the extent of charge-transfer character of $\mathrm{S}_{\mathrm{CT}}$ is further explored in Figure 8 for the disubstituted quinolines, acridines, and 1-azaanthracenes. Here, we see that $\mathrm{p} K_{\mathrm{a}}^{*}$ generally increases as $\Delta \mathrm{q}^{*}$ on the ring $\mathrm{N}$ becomes more negative. However, the relationship between $\mathrm{p} K_{\mathrm{a}}^{*}$ and $\Delta \mathrm{q}^{*}$ is too noisy to allow $\Delta \mathrm{q}^{*}$ to definitively predict the photobasicity strength. This is especially true for the disubstituted 1-azaanthracene data where a very narrow range of relatively small $\Delta \mathrm{q}^{*}$ values correspond to $\mathrm{p} K_{\mathrm{a}}^{*}$ ranging from 10.75 to 15.17 . Figure S27 in the Supporting Information demonstrates that, for the same set of compounds, the correlation between $\Delta \mathrm{q}$ and $\mathrm{p} K_{\mathrm{a}}^{*}$ is even less clear than the correlation between $\Delta \mathrm{q}^{*}$ and $\mathrm{p} K_{\mathrm{a}}^{*}$ in Figure 8. The variability present in Figures 8 and S27 reflects, as discussed above, the fact that the thermodynamics of the excited state protonation of these compounds is not fully controlled by the degree to which the $\mathrm{S}_{0} \rightarrow \mathrm{S}_{\mathrm{CT}}$ transition builds up electron density on the ring nitrogen. Finally, note that the correlations between $\Delta \mathrm{q}$ and $\mathrm{p} K_{\mathrm{a}}^{*}$ for the disubstituted quinoline, isoquinoline, acridine, and 1-azaanthracene compounds considered in this study are presented in Figures S13, S18, and S26 in the Supporting Information. 


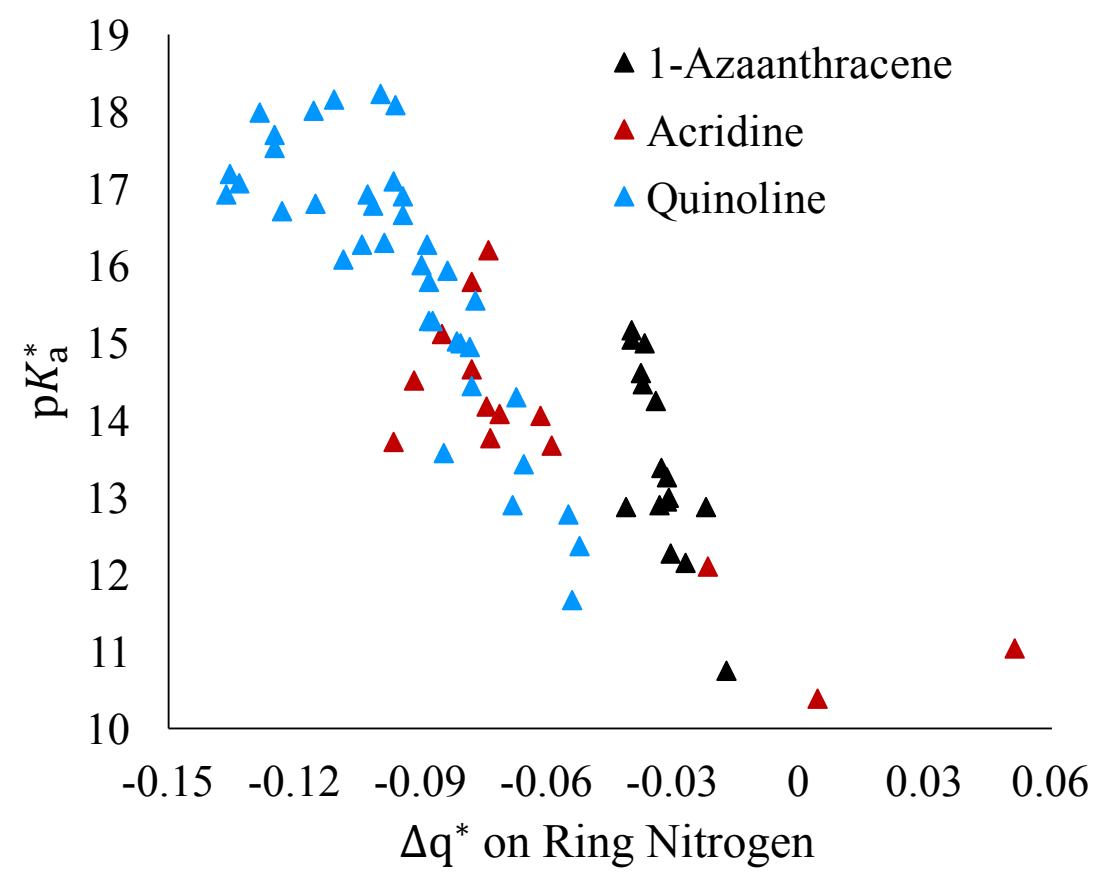

Figure 8: Plot of $\mathrm{p} K_{\mathrm{a}}^{*}$ versus change in charge $\left(\Delta \mathrm{q}^{*}\right)$ on the ring nitrogen at the excited state optimized geometry for the disubstituted 1-azaanthracene (black), acridine (red), and quinoline (blue) compounds. Linear regression analysis leads to $\mathrm{R}^{2}$ values of $0.63,0.71$, and 0.71 for the 1-azaanthracene, acridine, and quinoline data respectively.

\section{On the Validity of the Förster Mechanism for Nitrogen-Containing Aromatic Heterocycles Containing Strong Electron-Donating Groups}

The analysis presented in this paper assumes that the photobasicity of nitrogen-containing heterocycles containing strong electron-donating groups is well-described by the Förster mechanism. This relies on the $\mathrm{S}_{\mathrm{CT}}$ excited state having a long enough lifetime for the excited state protonation to occur prior to any non-radiative transitions to other states. Under such conditions, the trends in the photobasicity of these compounds will be well captured by the thermodynamic analysis presented above.

Using transient absorption spectroscopy, Dawlaty and coworkers identified evidence of $\mathrm{S}_{\mathrm{CT}}$ undergoing intersystem crossing into the triplet manifold for a series of 5-R quinolines. ${ }^{21}$ In particular, for 5-aminoquinoline, the strongest photobase that was experimentally investigated, 
the spectroscopic evidence points to excited state protonation occurring on a timescale of $41 \mathrm{ps}$ followed by relaxation into a triplet state approximately $36 \mathrm{ps}$ later. Such a process does not necessarily invalidate the applicability of the Förster mechanism to the photobasicity of 5aminoquinoline as the intersystem crossing only occurs after the excited state protonation. In contrast, for the weaker photobases quinoline, 5-chloroquinoline, 5-bromoquinoline, and 5cyanoquinoline intersystem crossing was found to be rapid, occurring on a timescale of less than $1 \mathrm{ps}$ and preceding any excited state protonation.

While a complete analysis of intersystem crossing pathways is outside the scope of the present study, we did analyze the vertical energy gap between $\mathrm{S}_{\mathrm{CT}}$ and neighboring triplet states at the optimized $\mathrm{S}_{\mathrm{CT}}$ geometries for representative compounds identified as strong photobases. This data, which was calculated using the Tamm-Dancoff approximation to minimize triplet instability problems, is summarized in Tables S13-S16 in the Supporting Information. ${ }^{43}$ For the acridine and 1-azaanthracene compounds, the average $\left|E_{\mathrm{T}_{\min }}-E_{\mathrm{S}_{\mathrm{CT}}}\right|$ is $0.52 \mathrm{eV}$ and $0.71 \mathrm{eV}$ for the basic and acidic forms respectively, where $\mathrm{T}_{\min }$ is chosen as the triplet state closest in energy to $\mathrm{S}_{\mathrm{CT}}$. $\mathrm{T}_{\min }$ is always uphill in energy from $\mathrm{S}_{\mathrm{CT}}$ for the base and often downhill in energy from $\mathrm{S}_{\mathrm{CT}}$ for the acid. Similar analysis performed on the quinoline derivatives shows that the average $\left|E_{\mathrm{T}_{\min }}-E_{\mathrm{S}_{\mathrm{CT}}}\right|$ is $0.21 \mathrm{eV}$ and $0.51 \mathrm{eV}$ for the basic and acidic forms. In particular, the $\mathrm{T}_{\min }$ of 6-aminoquinoline, 6-methylaminoquinoline, 6-dimethylaminoquinoline, 3,5-aminoquinoline, and 3,5-dimethylaminoquinoline is within $0.16 \mathrm{eV}$ of $\mathrm{S}_{\mathrm{CT}}$ and downhill in energy from it, suggesting a potential non-radiative relaxation pathway that could compete with excited state protonation for these five compounds. For the other quinoline derivatives, the closest triplet state is uphill in energy from $\mathrm{S}_{\mathrm{CT}}$ by $0.10-0.42 \mathrm{eV}$ for the basic form, suggesting that intersystem crossing may be less important for these compounds, at least prior to protonation. We stress, though, that the 
analysis presented here is only preliminary and that a more complete picture of the intersystem crossing pathways in these photobases will represent an important addition to the thermodynamic trends presented in this paper. Efforts to accomplish this are currently underway.

A recent computational study by the Furche group argues for an alternative mechanism for the photobasisicity of 5-methoxyquinoline in which the $\mathrm{S}_{\mathrm{CT}}$ state undergoes internal conversion into a dark singlet state with significant intermolecular charge-transfer character from a solvent water molecule to the photobase. ${ }^{44}$ This results in the transient photooxidation of the solvent water molecule, producing a 5-methoxyquinoline radical anion and $\mathrm{H}_{2} \mathrm{O}$ radical cation pair stabilized by the exciton binding energy. Subsequent proton transfer followed by backelectron transfer ultimately generates protonated 5-methoxyquinoline in the ground state and hydroxide. By comparing the calculated excited state electron affinity of 5-methoxyquinoline to the estimated $6.5 \pm 0.5 \mathrm{eV}$ ionization potential of $\mathrm{H}_{2} \mathrm{O}$, Furche and coworkers arrive at a lower bound to the exciton binding energy of $0.7 \pm 0.5 \mathrm{eV} .{ }^{45}$

In Table 1, we report the excited state electron affinity of representative compounds considered in this study, calculated as the difference in the electronic energy of $\mathrm{S}_{\mathrm{CT}}$ and the radical anion ( $\mathrm{E}_{\text {radical anion }}-E_{\mathrm{S}_{\mathrm{CT}}}$ ) at the $\mathrm{S}_{\mathrm{CT}}$ optimized geometry. The radical anion is described using the restricted open-shell formalism to eliminate spin contamination. As shown in Table 1, in going from 5-methoxyquinoline to 5-aminoquinoline the $\mathrm{E}_{\text {radical anion }}-E_{\mathrm{S}_{\mathrm{CT}}}$ decreases in magnitude by over $0.5 \mathrm{eV}$ from $-5.63 \mathrm{eV}$ to $-5.11 \mathrm{eV}$. The excited state electron affinity is even smaller in magnitude when a second electron-donating group is added, $\mathrm{E}_{\text {radical anion }}-E_{\mathrm{S}_{\mathrm{CT}}}=-4.53 \mathrm{eV}$ for 5,6-aminoquinoline, $-4.53 \mathrm{eV}$ for 1,2-aminoacridine, and $-4.51 \mathrm{eV}$ for 6,7-amino-1-azaanthracene. 
Table 1 also reports the energy difference between $\mathrm{S}_{\mathrm{CT}}$ and the intermolecular charge transfer state involving the solvent water molecule that is hydrogen bonding with the photobase, $\mathrm{S}_{\mathrm{CT} \mathrm{H}_{2} \mathrm{O}}$, at optimized geometries on $\mathrm{S}_{0}$ and $\mathrm{S}_{\mathrm{CT}}$. These calculations were performed with four explicit water molecules forming a hydrogen bonding network around the ring nitrogen, the same model as used by Furche and coworkers. At both the $\mathrm{S}_{0}$ and $\mathrm{S}_{\mathrm{CT}}$ geometries, $E_{\mathrm{S}_{\mathrm{CT} \mathrm{H}_{2} \mathrm{O}}}-E_{\mathrm{S}_{\mathrm{CT}}}$ increases as the substituent is made more electron-donating. The addition of a second amine group results in a further increase in the energy gap, raising $E_{\mathrm{S}_{\mathrm{CT} \mathrm{H}_{2} \mathrm{O}}}-E_{\mathrm{S}_{\mathrm{CT}}}$ to over $1.3 \mathrm{eV}$ and $2.2 \mathrm{eV}$ at the $\mathrm{S}_{0}$ and $\mathrm{S}_{\mathrm{CT}}$ optimized geometries, respectively. Finally, for all of the compounds, relaxation on $\mathrm{S}_{\mathrm{CT}}$ results in an increase in $E_{\mathrm{S}_{\mathrm{CT}_{\mathrm{H}} \mathrm{O}}}-E_{\mathrm{S}_{\mathrm{CT}}}$.

Table 1: Calculated exited state electron affinities $\left(E_{\text {radical anion }}-E_{\mathrm{S}_{\mathrm{CT}}}\right)$ and $E_{\mathrm{S}_{\mathrm{CT} \mathrm{H}_{2} \mathrm{O}}}-E_{\mathrm{S}_{\mathrm{CT}}}$ energy gaps for a range of nitrogen-containing heterocyclic compounds.

\begin{tabular}{|c|c|c|c|}
\hline Compound & $\underset{(\mathrm{eV})}{E_{\text {radical anion }}}-E_{\mathrm{S}_{\mathrm{CT}}}$ & $\begin{array}{c}E_{\mathrm{S}_{\mathrm{CT} \mathrm{H}} \mathrm{O}}-E_{\mathrm{S}_{\mathrm{CT}}} \\
\mathrm{S}_{\mathbf{0}} \text { Geometry } \\
(\mathrm{eV})^{47}\end{array}$ & $\begin{array}{c}E_{\mathrm{S}_{\mathrm{CT}} \mathrm{O}}-E_{\mathrm{S}_{\mathrm{CT}}} \\
\text { S }_{\mathrm{CT}} \text { Geometry } \\
\quad(\mathrm{eV})^{47}\end{array}$ \\
\hline 5-chloroquinoline & -6.21 & 0.25 & 0.66 \\
\hline quinoline & -6.21 & 0.08 & 0.45 \\
\hline 5-methylquinoline & -5.99 & 0.28 & 0.73 \\
\hline 5-methoxyquinoline & -5.63 & 0.68 & 1.22 \\
\hline 5-aminoquinoline & -5.11 & 1.07 & 1.72 \\
\hline 5-dimethylaminoquinoline & -5.09 & 1.02 & 1.68 \\
\hline 5,6-aminoquinoline & -4.53 & 1.37 & 2.23 \\
\hline 1,2-aminoacridine & -4.53 & 1.57 & 2.26 \\
\hline 6,7-amino-1-azaanthracene $e^{46}$ & -4.51 & 1.59 & 2.23 \\
\hline
\end{tabular}

The analysis reported in Table 1 suggests that as the strength and number of electrondonating substituents increases, the photooxidative mechanism becomes less favorable in two ways. First, the major component of the thermodynamic driving force for the solvent to solute charge-transfer, the excited state electron affinity of the photobase, is reduced by over $1 \mathrm{eV}$ from 
5-methoxyquinoline to the disubstituted compounds. Second, the two states involved in the photooxidation mechanism, $\mathrm{S}_{\mathrm{CT}}$ and $\mathrm{S}_{\mathrm{CT} \mathrm{H}_{2} \mathrm{O}}$, grow further apart in energy as the substituents are made increasingly electron-donating. This energy gap is important because the photooxidative mechanism relies on the existence of a thermally accessible conical intersection between $\mathrm{S}_{\mathrm{CT}}$ and $\mathrm{S}_{\mathrm{CT} \mathrm{H}_{2} \mathrm{O}}$, which becomes less likely as $E_{\mathrm{S}_{\mathrm{CT} \mathrm{H}_{2} \mathrm{O}}}-E_{\mathrm{S}_{\mathrm{CT}}}$ increases. Moreover, this energy gap significantly increases with vibrational relaxation on $\mathrm{S}_{\mathrm{CT}}$. It is therefore reasonable to conclude that the photooxidative mechanism becomes less likely as the electron-donating strength of the substituent(s) increases.

\section{Conclusions}

Overall, the results reported in this study demonstrate the degree to which two key properties of photobases, $\mathrm{p} K_{\mathrm{a}}^{*}$ and the excitation energy, can be tuned for quinoline and related compounds through substituents. We demonstrated that the photobasicity is affected by the identity, quantity, and position of the substituent(s). We showed that the addition of a second electron-donating substituent to quinoline can result in a significant increase in $\mathrm{p} K_{\mathrm{a}}^{*}$ relative to the monosubstituted quinoline compounds. We identified a number of disubstituted acridine and 1-azaanthracene compounds with vertical excitation energies under $3.1 \mathrm{eV}$ and $\mathrm{p} K_{\mathrm{a}}^{*}>14$. The structure-function relationships uncovered in this study therefore provide insights into the design principles needed for the development of new photocatalysts which incorporate photobasicity. Efforts to extend this analysis to more complex nitrogen-containing heterocyclic aromatics containing multiple heteroatoms as well as to more rigorously explore the impact of other photochemical pathways (e.g. intersystem crossing) on the photobasicity of the compounds considered in this study are currently underway in our lab.

\section{Supporting Information}


The complete dataset analyzed in this study, images of the HONTO and LUNTO for representative compounds, plots illustrating the correlation between $\mathrm{p} K_{\mathrm{a}}^{*}$ and $\Delta \mathrm{q}$ on the ring N, and analysis of energy differences between $\mathrm{S}_{\mathrm{CT}}$ and neighboring triplet states are provided in the Supporting Information.

\section{Acknowledgements}

This work used the Extreme Science and Engineering Discovery Environment (XSEDE), which is supported by National Science Foundation grant number ACI-1548562. This work specifically used the Comet cluster at the San Diego Supercomputer Center through allocation TG-CHE180057. Additional computational resources were provided through the Center for Computational and Applied Mathematics at California State University, Fullerton. A. F. and K. J. acknowledge funding from Project RAISE, U.S. Department of Education HSI-STEM award number P031C160152. This work benefited from a helpful conversation with Fu-Ming Tao.

\section{References}

(1) Tolbert, L. M.; Solntsev, K. M. Excited-State Proton Transfer: From Constrained Systems to "Super" Photoacids to Superfast Proton Transfer. Acc. Chem. Res. 2002, 35 (1), 19-27. https://doi.org/10.1021/ar990109f.

(2) Zhou, P.; Han, K. Unraveling the Detailed Mechanism of Excited-State Proton Transfer. Acc. Chem. Res. 2018, 51 (7), 1681-1690. https://doi.org/10.1021/acs.accounts.8b00172.

(3) Lennox, J. C.; Kurtz, D. A.; Huang, T.; Dempsey, J. L. Excited-State Proton-Coupled Electron Transfer: Different Avenues for Promoting Proton/Electron Movement with Solar Photons. ACS Energy Lett. 2017, 2 (5), 1246-1256. https://doi.org/10.1021/acsenergylett.7b00063.

(4) Spry, D. B.; Fayer, M. D. Charge Redistribution and Photoacidity: Neutral versus Cationic 
Photoacids. J. Chem. Phys. 2008, 128 (8). https://doi.org/10.1063/1.2825297.

(5) Granucci, G.; Hynes, J. T.; Millié, P.; Tran-Thi, T.-H. A Theoretical Investigation of Excited-State Acidity of Phenol and Cyanophenols. J. Am. Chem. Soc. 2000, 122 (49), 12243-12253. https://doi.org/10.1021/ja993730j.

(6) Solntsev, K. M.; Huppert, D.; Tolbert, L. M.; Agmon, N. Solvatochromic Shifts of “super” Photoacids [5]. J. Am. Chem. Soc. 1998, 120 (31), 7981-7982. https://doi.org/10.1021/ja9808604.

(7) Ditkovich, J.; Mukra, T.; Pines, D.; Huppert, D.; Pines, E. Bifunctional Photoacids: Remote Protonation Affecting Chemical Reactivity. J. Phys. Chem. B 2015, 119 (6), 2690-2701. https://doi.org/10.1021/jp509104x.

(8) Simkovitch, R.; Shomer, S.; Gepshtein, R.; Huppert, D. How Fast Can a Proton-Transfer Reaction Be beyond the Solvent-Control Limit? J. Phys. Chem. B 2015, 119 (6), $2253-$ 2262. https://doi.org/10.1021/jp506011e.

(9) Simkovitch, R.; Karton-lifshin, N.; Shomer, S.; Shabat, D.; Huppert, D. Ultrafast ExcitedState Proton Transfer to the Solvent Occurs on a Hundred-Femtosecond Time-Scale.

2013. https://doi.org/10.1021/jp4014724.

(10) Agmon, N. Elementary Steps in Excited-State Proton Transfer †. J. Phys. Chem. A 2005, 109 (1), 13-35. https://doi.org/10.1021/jp047465m.

(11) Cotter, L. F.; Brown, P. J.; Nelson, R. C.; Takematsu, K. Divergent Hammett Plots of the Ground- and Excited-State Proton Transfer Reactions of 7-Substituted-2-Naphthol Compounds. J. Phys. Chem. B 2019, 123 (19), 4301-4310. https://doi.org/10.1021/acs.jpcb.9b01295.

(12) Favaro, G.; Mazzucato, U.; Masetti, F. Excited State Reactivity of Aza Aromatics. I. 
Basicity of 3-Styrylpyridines in the First Excited Singlet State. J. Phys. Chem. 1973, 77 (5), 601-604. https://doi.org/10.1021/j100624a007.

(13) Pines, E.; Huppert, D.; Gutman, M.; Nachliel, N.; Fishman, M. The POH Jump:

Determination of Deprotonation Rates of Water by 6-Methoxyquinoline and Acridine. $J$. Phys. Chem. 1986, 90 (23), 6366-6370. https://doi.org/10.1021/j100281a061.

(14) Nachliel, E.; Ophir, Z.; Gutman, M. Kinetic Analysis of Fast Alkalinization Transient by Photoexcited Heterocyclic Compounds: POH Jump. J. Am. Chem. Soc. 1987, 109 (5), 1342-1345. https://doi.org/10.1021/ja00239a009.

(15) Solntsev, K. M.; Sullivan, E. N.; Tolbert, L. M.; Ashkenazi, S.; Leiderman, P.; Huppert, D. Excited-State Proton Transfer Reactions of 10-Hydroxycamptothecin 1. J. Am. Chem. Soc. 2004, 126 (39), 12701-12708. https://doi.org/10.1021/ja047821e.

(16) Akulov, K.; Simkovitch, R.; Erez, Y.; Gepshtein, R.; Schwartz, T.; Huppert, D. Acid Effect on Photobase Properties of Curcumin. J. Phys. Chem. A 2014, 118 (13), $2470-$ 2479. https://doi.org/10.1021/jp501061p.

(17) Poizat, O.; Bardez, E.; Buntinx, G.; Alain, V. Picosecond Dynamics of the Photoexcited 6-Methoxyquinoline and 6-Hydroxyquinoline Molecules in Solution. J. Phys. Chem. A 2004, 108 (11), 1873-1880. https://doi.org/10.1021/jp030964n.

(18) Yatsuhashi, T.; Inoue, H. Molecular Mechanism of Radiationless Deactivation of Aminoanthraquinones through Intermolecular Hydrogen-Bonding Interaction with Alcohols and Hydroperoxides. J. Phys. Chem. A 1997, 101 (44), 8166-8173. https://doi.org/10.1021/jp970581n.

(19) Sheng, W.; Nairat, M.; Pawlaczyk, P. D.; Mroczka, E.; Farris, B.; Pines, E.; Geiger, J. H.; Borhan, B.; Dantus, M. Ultrafast Dynamics of a "Super" Photobase. Angew. Chemie Int. 
Ed. 2018, 57 (45), 14742-14746. https://doi.org/10.1002/anie.201806787.

(20) Driscoll, E. W.; Hunt, J. R.; Dawlaty, J. M. Photobasicity in Quinolines: Origin and Tunability via the Substituents' Hammett Parameters. J. Phys. Chem. Lett. 2016, 7 (11), 2093-2099. https://doi.org/10.1021/acs.jpclett.6b00790.

(21) Driscoll, E. W.; Hunt, J. R.; Dawlaty, J. M. Proton Capture Dynamics in Quinoline Photobases: Substituent Effect and Involvement of Triplet States. J. Phys. Chem. A 2017, 121, 7099-7107. https://doi.org/10.1021/acs.jpca.7b04512.

(22) Hunt, J. R.; Dawlaty, J. M. Photodriven Deprotonation of Alcohols by a Quinoline Photobase. J. Phys. Chem. A 2018, 122 (40), 7931-7940. https://doi.org/10.1021/acs.jpca.8b06152.

(23) Demianets, I.; Hunt, J. R.; Dawlaty, J. M.; Williams, T. J. Optical PK ${ }_{a}$ Control in a Bifunctional Iridium Complex. Organometallics 2019, 38 (2), 200-204. https://doi.org/10.1021/acs.organomet.8b00778.

(24) Hunt, J. R.; Tseng, C.; Dawlaty, J. M. Donor-Acceptor Preassociation, Excited State Solvation Threshold, and Optical Energy Cost as Challenges in Chemical Applications of Photobases. Faraday Discuss. 2019, 00, 1-17. https://doi.org/10.1039/c8fd00215k.

(25) Hunt, J. R.; Dawlaty, J. M. Kinetic Evidence for the Necessity of Two Proton Donor Molecules for Successful Excited State Proton Transfer by a Photobase. J. Phys. Chem. A 2019, 123 (48), 10372-10380. https://doi.org/10.1021/acs.jpca.9b08970.

(26) Chai, J.-D.; Head-Gordon, M. Long-Range Corrected Hybrid Density Functionals with Damped Atom-Atom Dispersion Corrections. Phys. Chem. Chem. Phys. 2008, 10 (44), 6615. https://doi.org/10.1039/b810189b.

(27) Chai, J.-D.; Head-Gordon, M. Systematic Optimization of Long-Range Corrected Hybrid 
Density Functionals. J. Chem. Phys. 2008, 128 (8), 084106.

https://doi.org/10.1063/1.2834918.

(28) Tomasi, J.; Mennucci, B.; Cammi, R. Quantum Mechanical Continuum Solvation Models. Chem. Rev. 2005, 105 (8), 2999-3094. https://doi.org/10.1021/cr9904009.

(29) Lange, A. W.; Herbert, J. M. A Smooth, Nonsingular, and Faithful Discretization Scheme for Polarizable Continuum Models: The Switching/Gaussian Approach. J. Chem. Phys. 2010, 133 (24), 244111. https://doi.org/10.1063/1.3511297.

(30) Lange, A. W.; Herbert, J. M. Polarizable Continuum Reaction-Field Solvation Models Affording Smooth Potential Energy Surfaces. J. Phys. Chem. Lett. 2010, 1 (2), 556-561. https://doi.org/10.1021/jz900282c.

(31) Shao, Y.; Gan, Z.; Epifanovsky, E.; Gilbert, A. T. B.; Wormit, M.; Kussmann, J.; Lange, A. W.; Behn, A.; Deng, J.; Feng, X.; et al. Advances in Molecular Quantum Chemistry Contained in the Q-Chem 4 Program Package. Mol. Phys. 2015, 113 (2), 184-215. https://doi.org/10.1080/00268976.2014.952696.

(32) Cordova, F.; Doriol, L. J.; Ipatov, A.; Casida, M. E.; Filippi, C.; Vela, A. Troubleshooting Time-Dependent Density-Functional Theory for Photochemical Applications: Oxirane. $J$. Chem. Phys. 2007, 127 (16), 164111. https://doi.org/10.1063/1.2786997.

(33) Mewes, J.-M.; You, Z.-Q.; Wormit, M.; Kriesche, T.; Herbert, J. M.; Dreuw, A. Experimental Benchmark Data and Systematic Evaluation of Two a Posteriori, Polarizable-Continuum Corrections for Vertical Excitation Energies in Solution. J. Phys. Chem. A 2015, 119 (21), 5446-5464. https://doi.org/10.1021/jp511163y.

(34) You, Z.-Q.; Mewes, J.-M.; Dreuw, A.; Herbert, J. M. Comparison of the Marcus and Pekar Partitions in the Context of Non-Equilibrium, Polarizable-Continuum Solvation 
Models. J. Chem. Phys. 2015, 143 (20), 204104. https://doi.org/10.1063/1.4936357.

(35) Rohrdanz, M. A.; Martins, K. M.; Herbert, J. M. A Long-Range-Corrected Density Functional That Performs Well for Both Ground-State Properties and Time-Dependent Density Functional Theory Excitation Energies, Including Charge-Transfer Excited States. J. Chem. Phys. 2009, 130 (5), 054112. https://doi.org/10.1063/1.3073302.

(36) Prlj, A.; Sandoval-Salinas, M. E.; Casanova, D.; Jacquemin, D.; Corminboeuf, C. LowLying $\Pi \pi *$ States of Heteroaromatic Molecules: A Challenge for Excited State Methods. J. Chem. Theory Comput. 2016, 12 (6), 2652-2660. https://doi.org/10.1021/acs.jctc.6b00245.

(37) Kohn, A. W.; Lin, Z.; Van Voorhis, T. Toward Prediction of Nonradiative Decay Pathways in Organic Compounds I: The Case of Naphthalene Quantum Yields. J. Phys. Chem. C 2019, 123 (25), 15394-15402. https://doi.org/10.1021/acs.jpcc.9b01243.

(38) Martin, R. L. Natural Transition Orbitals. J. Chem. Phys. 2003, 118 (11), 4775-4777. https://doi.org/10.1063/1.1558471.

(39) Plasser, F.; Wormit, M.; Dreuw, A. New Tools for the Systematic Analysis and Visualization of Electronic Excitations. I. Formalism. J. Chem. Phys. 2014, 141 (2), 024106. https://doi.org/10.1063/1.4885819.

(40) Closser, K. D.; Gessner, O.; Head-Gordon, M. Simulations of the Dissociation of Small Helium Clusters with Ab Initio Molecular Dynamics in Electronically Excited States. $J$. Chem. Phys. 2014, 140 (13), 134306. https://doi.org/10.1063/1.4869193.

(41) Brown, H. C.; Okamoto, Y. Electrophilic Substituent Constants. J. Am. Chem. Soc. 1958, 80 (18), 4979-4987. https://doi.org/10.1021/ja01551a055.

(42) Leffler, J. E.; Grunwald, E. Rates and Equilibria of Organic Reactions: As Treated by 
Statistical, Thermodynamic and Extrathermodynamic Methods; John Wiley \& Sons, Inc.: New York, 1963.

(43) Peach, M. J. G.; Williamson, M. J.; Tozer, D. J. Influence of Triplet Instabilities in TDDFT. J. Chem. Theory Comput. 2011, 7 (11), 3578-3585. https://doi.org/10.1021/ct200651r.

(44) Roy, S.; Ardo, S.; Furche, F. 5-Methoxyquinoline Photobasicity Is Mediated by Water Oxidation. J. Phys. Chem. A 2019, 123 (31), 6645-6651. https://doi.org/10.1021/acs.jpca.9b05341.

(45) Bernas, A.; Grand, D. The So-Called Ionization Potential of Water and Associated Liquids. J. Phys. Chem. 1994, 98 (13), 3440-3443. https://doi.org/10.1021/j100064a027.

(46) The reported data is from an optimized geometry with a single imaginary vibrational frequency of $28.14 \mathrm{i} \mathrm{cm}^{-1}$. We were unable to obtain a better optimized geometry for this complex.

(47) The electronic excited states were obtained using the Tamm-Dancoff approximation because of numerical issues that arose when calculating the full TD-DFT energies for some of these complexes. 


\section{TOC Graphic}

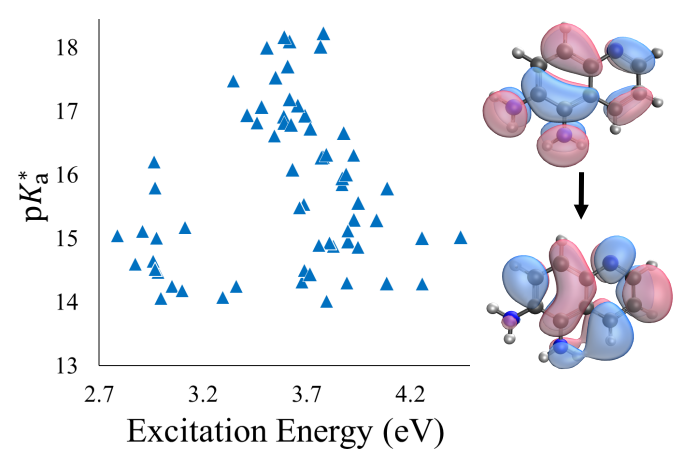


Supporting Information for "Structure-Photochemical Function Relationships in NitrogenContaining Heterocyclic Aromatic Photobases Derived from Quinoline"

Sophya F. Alamudun, Kyle Tanovitz, April Fajardo, Kaitlind Johnson, Andy Pham, Tina Jamshidi Araghi, and Andrew S. Petit*

Department of Chemistry and Biochemistry, California State University, Fullerton, California 92834-6866, United States

*Corresponding author: apetit@,fullerton.edu 


\section{Table of Contents}

\begin{tabular}{|c|c|}
\hline & Page(s) \\
\hline Figure S1: Substituent position numbering system for the quinoline compounds & S4 \\
\hline $\begin{array}{l}\text { Tables S1-S3: Vertical excitation energy, oscillator strength, change in charge on } \\
\text { the ring nitrogen, } \mathrm{p} K_{\mathrm{a}} \text {, and } \mathrm{p} K_{\mathrm{a}}^{*} \text { for the } 5-\mathrm{R}, 3-\mathrm{R} \text {, and } 4-\mathrm{R} \text { monosubstituted } \\
\text { quinoline compounds }\end{array}$ & S4-S5 \\
\hline $\begin{array}{l}\text { Figure S2: Highest occupied natural transition orbital and lowest unoccupied } \\
\text { natural transition orbital for 3-aminoquinoline, 4-aminoquinoline, and 5- } \\
\text { aminoquinoline. }\end{array}$ & S6 \\
\hline $\begin{array}{l}\text { Tables S4-S6: Vertical excitation energy, oscillator strength, change in charge on } \\
\text { the ring nitrogen, } \mathrm{p} K_{\mathrm{a}} \text {, and } \mathrm{p} K_{\mathrm{a}}^{*} \text { for the } 6-\mathrm{R}, 7-\mathrm{R} \text {, and } 8-\mathrm{R} \text { monosubstituted } \\
\text { quinoline compounds }\end{array}$ & S6-S7 \\
\hline $\begin{array}{l}\text { Figure S3: Highest occupied natural transition orbital and lowest unoccupied } \\
\text { natural transition orbital for 6-aminoquinoline, } 7 \text {-aminoquinoline, and 8- } \\
\text { aminoquinoline }\end{array}$ & S8 \\
\hline $\begin{array}{l}\text { Figure S4: Calculated } \mathrm{p} K_{\mathrm{a}}^{*} \text { versus the Hammett } \sigma_{\mathrm{para}}^{+} \text {parameter of the substituent } \\
\text { for the monosubstituted quinoline compounds considered in this study. }\end{array}$ & S9 \\
\hline $\begin{array}{l}\text { Figure S5: Plot of } \mathrm{p} K_{\mathrm{a}}^{*} \text { versus vertical excitation energy for the monosubstituted } \\
\text { quinoline compounds }\end{array}$ & $\mathrm{S} 10$ \\
\hline $\begin{array}{l}\text { Figure S6: Optimized geometries of the basic and acidic forms of } \\
\text { 8-hydroxyquinoline on } \mathrm{S}_{0}\end{array}$ & S11 \\
\hline $\begin{array}{l}\text { Figure S7-S8: Optimized } \mathrm{S}_{0} \text { and } \mathrm{S}_{\mathrm{CT}} \text { geometries of the basic and acidic forms of } \\
\text { 8-aminoquinoline, 8-dimethylaminoquinoline, and 8-methoxyquinoline }\end{array}$ & S11-S12 \\
\hline $\begin{array}{l}\text { Figure S9: Plot of } \mathrm{p} K_{\mathrm{a}}^{*} \text { versus change in charge }(\Delta \mathrm{q}) \text { on the ring nitrogen for all of } \\
\text { the monosubstituted quinoline compounds considered in this study }\end{array}$ & S13 \\
\hline $\begin{array}{l}\text { Tables S7-S8: Vertical excitation energy, oscillator strength, change in charge on } \\
\text { the ring nitrogen, } \mathrm{p} K_{\mathrm{a}} \text {, and } \mathrm{p} K_{\mathrm{a}}^{*} \text { for the disubstituted quinoline compounds }\end{array}$ & S14-S15 \\
\hline $\begin{array}{l}\text { Figures S10-S11: Highest occupied natural transition orbital and lowest } \\
\text { unoccupied natural transition orbital for 5,6-aminoquinoline, 4,5-aminoquinoline, } \\
\text { 5,7-aminoquinoline, and 3,6-aminoquinoline. }\end{array}$ & S15-S16 \\
\hline $\begin{array}{l}\text { Figure S12: Plot of } \mathrm{p} K_{\mathrm{a}}^{*} \text { versus vertical excitation energy for the disubstituted } \\
\text { quinoline compounds }\end{array}$ & S16 \\
\hline $\begin{array}{l}\text { Figure S13: Plot of } \mathrm{p} K_{\mathrm{a}}^{*} \text { versus } \Delta \mathrm{q} \text { on the ring nitrogen for the disubstituted } \\
\text { quinoline compounds }\end{array}$ & S17 \\
\hline $\begin{array}{l}\text { Figure S14: Substituent position numbering system for the isoquinoline } \\
\text { compounds }\end{array}$ & S17 \\
\hline
\end{tabular}




\begin{tabular}{|c|c|}
\hline & Page(s) \\
\hline $\begin{array}{l}\text { Table S9: Vertical excitation energy, oscillator strength, change in charge on the } \\
\text { ring nitrogen, } \mathrm{p} K_{\mathrm{a}} \text {, and } \mathrm{p} K_{\mathrm{a}}^{*} \text { for the isoquinoline compounds }\end{array}$ & S18 \\
\hline $\begin{array}{l}\text { Figures S15-S16: Highest occupied natural transition orbital and lowest } \\
\text { unoccupied natural transition orbital for 5-amino-isoquinoline, 4-amino- } \\
\text { isoquinoline, 5,6-amino-isoquinoline, and 7,8-amino-isoquinoline. }\end{array}$ & S19 \\
\hline $\begin{array}{l}\text { Figure S17: Plot of } \mathrm{p} K_{\mathrm{a}}^{*} \text { versus vertical excitation energy for the isoquinoline } \\
\text { compounds }\end{array}$ & S20 \\
\hline $\begin{array}{l}\text { Figure S18: Plot of } \mathrm{p} K_{\mathrm{a}}^{*} \text { versus } \Delta \mathrm{q} \text { on the ring nitrogen for the isoquinoline } \\
\text { compounds }\end{array}$ & $\mathrm{S} 21$ \\
\hline Figure S19: Substituent position numbering system for the acridine compounds & S22 \\
\hline $\begin{array}{l}\text { Table S10: Vertical excitation energy, oscillator strength, change in charge on the } \\
\text { ring nitrogen, } \mathrm{p} K_{\mathrm{a}} \text {, and } \mathrm{p} K_{\mathrm{a}}^{*} \text { for the acridine compounds }\end{array}$ & S22 \\
\hline $\begin{array}{l}\text { Figures S20-S21: Highest occupied natural transition orbital and lowest } \\
\text { unoccupied natural transition orbital for 1,2-amino-acridine, 1,3-amino-acridine, } \\
\text { 3,6-amino-acridine, 2,7-amino-acridine, and 1,8-amino-acridine. }\end{array}$ & S23 \\
\hline $\begin{array}{l}\text { Figure S22: Substituent position numbering system for the 1-azaanthracene } \\
\text { compounds }\end{array}$ & S24 \\
\hline $\begin{array}{l}\text { Tables S11-S12: Vertical excitation energy, oscillator strength, change in charge } \\
\text { on the ring nitrogen, } \mathrm{p} K_{\mathrm{a}} \text {, and } \mathrm{p} K_{\mathrm{a}}^{*} \text { for the } 1 \text {-azaanthracene compounds }\end{array}$ & S24-S25 \\
\hline $\begin{array}{l}\text { Figures S23-S24: Highest occupied natural transition orbital and lowest } \\
\text { unoccupied natural transition orbital for 6,7-amino-1-azaanthracene, } \\
\text { 5-amino-1-azaanthracene, 7,8-amino-1-azaanthracene, and 9-amino-1- } \\
\text { azaanthracene. }\end{array}$ & S26 \\
\hline $\begin{array}{l}\text { Figure S25: Plot of } \mathrm{p} K_{\mathrm{a}}^{*} \text { versus vertical excitation energy for the acridine and } \\
\text { 1-azaanthracene compounds }\end{array}$ & S27 \\
\hline $\begin{array}{l}\text { Figure S26: Plot of } \mathrm{p} K_{\mathrm{a}}^{*} \text { versus } \Delta \mathrm{q} \text { on the ring nitrogen for the acridine and } \\
\text { 1-azaanthracene compounds }\end{array}$ & S28 \\
\hline $\begin{array}{l}\text { Figure S27: Plot of } \mathrm{p} K_{\mathrm{a}}^{*} \text { versus } \Delta \mathrm{q} \text { on the ring nitrogen for the disubstituted } \\
\text { 1-azaanthracene, acridine, and quinoline compounds }\end{array}$ & S29 \\
\hline $\begin{array}{l}\text { Tables S13-S16: Calculated } E_{\mathrm{SCT}} \text { and } E_{\mathrm{T}}-E_{\mathrm{SCT}} \text { between } \mathrm{S}_{\mathrm{CT}} \text { and the two closest } \\
\text { triplet states for the quinoline, acridine, and } 1 \text {-azaanthracene compounds identified } \\
\text { as strong photobases. }\end{array}$ & $\mathrm{S} 30-\mathrm{S} 33$ \\
\hline $\begin{array}{l}\text { Table S13: Calculated excited state energy }\left(E_{\mathrm{SCT}}\right) \text {, radical anion energy } \\
\left(E_{\text {radical anion }}\right) \text {, and exited state electron affinity }\left(E_{\text {radical anion }}-E_{\mathrm{SCT}}\right) \text { for a range of } \\
\text { nitrogen-containing heterocyclic compounds }\end{array}$ & S34 \\
\hline
\end{tabular}




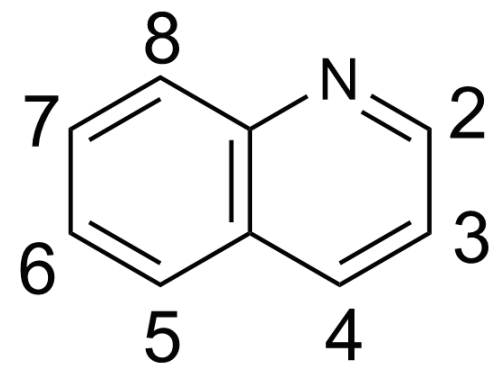

Figure S1: Substituent position numbering system for the substituted quinoline compounds.

Table S1: Calculated ground state $\mathrm{p} K_{\mathrm{a}}$, excited state $\mathrm{p} K_{\mathrm{a}}^{*}$, vertical excitation energy, oscillator strength, and change in charge on the ring nitrogen at the ground-state $(\Delta q)$ and excited-state $\left(\Delta q^{*}\right)$ optimized geometries for the 5-R substituted quinoline compounds. The reported data is for the lowest energy $\pi \rightarrow \pi^{*}$ bright state with significant charge-transfer character, $\mathrm{S}_{\mathrm{CT}}$. The molecules are arranged from most electron-withdrawing substituent to most electron-donating substituent in terms of the Hammett $\sigma_{\text {para }}^{+}$. Where available, the experimental $\mathrm{p} K_{\mathrm{a}}^{*}$ determined by Dawlaty and coworkers are provided in the right-most column. ${ }^{1}$

\begin{tabular}{|cccccccc|}
\hline Substituent & $\begin{array}{c}\text { Excitation } \\
\text { Energy } \\
(\mathbf{e V})\end{array}$ & $\begin{array}{c}\text { Oscillator } \\
\text { Strength }\end{array}$ & $\begin{array}{c}\Delta \mathbf{q} \text { on } \\
\text { Ring N }\end{array}$ & $\begin{array}{c}\Delta \mathbf{q}^{*} \text { on } \\
\text { Ring N }\end{array}$ & $\mathbf{p} \boldsymbol{K}_{\mathbf{a}}$ & $\mathbf{p} \boldsymbol{K}_{\mathbf{a}}^{*}$ & $\begin{array}{c}\text { Experimental } \\
\mathbf{p} \boldsymbol{K}_{\mathbf{a}}^{*}\end{array}$ \\
\hline $\mathrm{CN}$ & 4.51 & 0.19 & -0.021 & 0.010 & 3.22 & 6.43 & 5.4 \\
$\mathrm{Br}$ & 4.51 & 0.15 & -0.054 & -0.039 & 3.79 & 11.42 & 11.2 \\
$\mathrm{Cl}$ & 4.52 & 0.13 & -0.054 & -0.039 & 3.83 & 11.18 & 9.7 \\
$\mathrm{~F}$ & 4.57 & 0.080 & -0.066 & -0.049 & 3.98 & 11.35 & - \\
$\mathrm{H}$ & 4.70 & 0.077 & -0.039 & -0.025 & 4.69 & 10.70 & 11.5 \\
$\mathrm{CH}$ & 4.52 & 0.11 & -0.064 & -0.051 & 4.85 & 12.29 & - \\
$\mathrm{OCH}_{3}$ & 4.26 & 0.12 & -0.093 & -0.080 & 4.86 & 14.29 & 15.1 \\
$\mathrm{OH}$ & 4.26 & 0.097 & -0.089 & -0.076 & 4.78 & 13.76 & - \\
$\mathrm{NH}_{2}$ & 3.87 & 0.12 & -0.102 & -0.096 & 5.39 & 15.85 & 15.9 \\
$\mathrm{~N}_{(}\left(\mathrm{CH}_{3}\right)_{2}$ & 3.93 & 0.14 & -0.089 & -0.086 & 4.94 & 16.31 & - \\
$\mathrm{NHCH}_{3}$ & 3.69 & 0.15 & -0.110 & -0.101 & 5.33 & 15.54 & - \\
\hline
\end{tabular}


Table S2: Calculated ground state $\mathrm{p} K_{\mathrm{a}}$, excited state $\mathrm{p} K_{\mathrm{a}}^{*}$, vertical excitation energy, oscillator strength, and change in charge $(\Delta q)$ on the ring nitrogen for the 3-R substituted quinoline compounds. The reported data is for the lowest energy $\pi \rightarrow \pi^{*}$ bright state with significant charge-transfer character, $\mathrm{S}_{\mathrm{CT}}$.

\begin{tabular}{|cccccc|}
\hline Substituent & $\begin{array}{c}\text { Excitation } \\
\text { Energy (eV) }\end{array}$ & $\begin{array}{c}\text { Oscillator } \\
\text { Strength }\end{array}$ & $\begin{array}{c}\Delta \mathbf{q} \text { on } \\
\text { Ring } \mathbf{~}\end{array}$ & $\mathbf{p} \boldsymbol{K}_{\mathbf{a}}$ & $\mathbf{p} \boldsymbol{K}_{\mathbf{a}}^{*}$ \\
\hline $\mathrm{CN}$ & 4.54 & 0.12 & -0.052 & 2.36 & 7.61 \\
$\mathrm{Br}$ & 4.48 & 0.093 & -0.073 & 3.11 & 10.71 \\
$\mathrm{Cl}$ & 4.50 & 0.086 & -0.071 & 3.08 & 10.51 \\
$\mathrm{~F}$ & 4.53 & 0.081 & -0.071 & 3.12 & 10.68 \\
$\mathrm{CH}_{3}$ & 4.57 & 0.076 & -0.053 & 4.83 & 9.94 \\
$\mathrm{OCH}_{3}$ & 4.32 & 0.11 & -0.089 & 3.98 & 11.86 \\
$\mathrm{OH}$ & 4.31 & 0.11 & -0.084 & 4.04 & 11.25 \\
$\mathrm{NH}_{2}$ & 3.98 & 0.13 & -0.103 & 4.69 & 12.96 \\
$\mathrm{~N}\left(\mathrm{CH}_{3}\right)_{2}$ & 3.69 & 0.15 & -0.119 & 4.71 & 14.50 \\
$\mathrm{NHCH}_{3}$ & 3.73 & 0.15 & -0.108 & 5.01 & 13.40 \\
\hline
\end{tabular}

Table S3: Calculated ground state $\mathrm{p} K_{\mathrm{a}}$, excited state $\mathrm{p} K_{\mathrm{a}}^{*}$, vertical excitation energy, oscillator strength, and change in charge on the ring nitrogen at the ground-state $(\Delta q)$ and excited-state $\left(\Delta q^{*}\right)$ optimized geometries for the 4-R substituted quinoline compounds. The reported data is for the lowest energy $\pi \rightarrow \pi^{*}$ bright state with significant charge-transfer character, $\mathrm{S}_{\mathrm{CT}}$. For the 4- $-\mathrm{OCH}_{3}, 4-\mathrm{OH}, 4-\mathrm{NH}_{2}$, and 4- $\mathrm{NHCH}_{3}$ compounds, the chosen state has the least positive $\Delta \mathrm{q}$ on the ring $\mathrm{N}$ of the low-lying $\pi \rightarrow \pi^{*}$ states.

\begin{tabular}{|ccccccc|}
\hline Substituent & $\begin{array}{c}\text { Excitation } \\
\text { Energy (eV) }\end{array}$ & $\begin{array}{c}\text { Oscillator } \\
\text { Strength }\end{array}$ & $\begin{array}{c}\Delta \mathbf{q} \text { on } \\
\text { Ring N }\end{array}$ & $\begin{array}{c}\Delta \mathbf{q}^{*} \text { on } \\
\text { Ring N }\end{array}$ & $\mathbf{p} \boldsymbol{K}_{\mathbf{a}}$ & $\mathbf{p} \boldsymbol{K}_{\mathbf{a}}^{*}$ \\
\hline $\mathrm{CN}$ & 4.25 & 0.12 & -0.071 & -0.069 & 2.45 & 8.99 \\
$\mathrm{Br}$ & 4.55 & 0.13 & -0.025 & -0.016 & 3.78 & 9.20 \\
$\mathrm{Cl}$ & 4.57 & 0.11 & -0.021 & -0.012 & 3.86 & 8.85 \\
$\mathrm{~F}$ & 4.73 & 0.076 & -0.021 & 0.008 & 4.26 & 9.02 \\
$\mathrm{CH}_{3}$ & 4.67 & 0.11 & -0.012 & 0.003 & 5.22 & 9.45 \\
$\mathrm{OCH}_{3}$ & 4.65 & 0.14 & 0.037 & 0.057 & 5.89 & 7.78 \\
$\mathrm{OH}$ & 4.64 & 0.10 & 0.039 & 0.058 & 5.82 & 7.84 \\
$\mathrm{NH}_{2}$ & 4.33 & 0.19 & 0.080 & 0.106 & 7.28 & 5.69 \\
$\mathrm{NHCH}_{3}$ & 4.28 & 0.24 & 0.072 & 0.098 & 7.55 & 6.22 \\
\hline
\end{tabular}




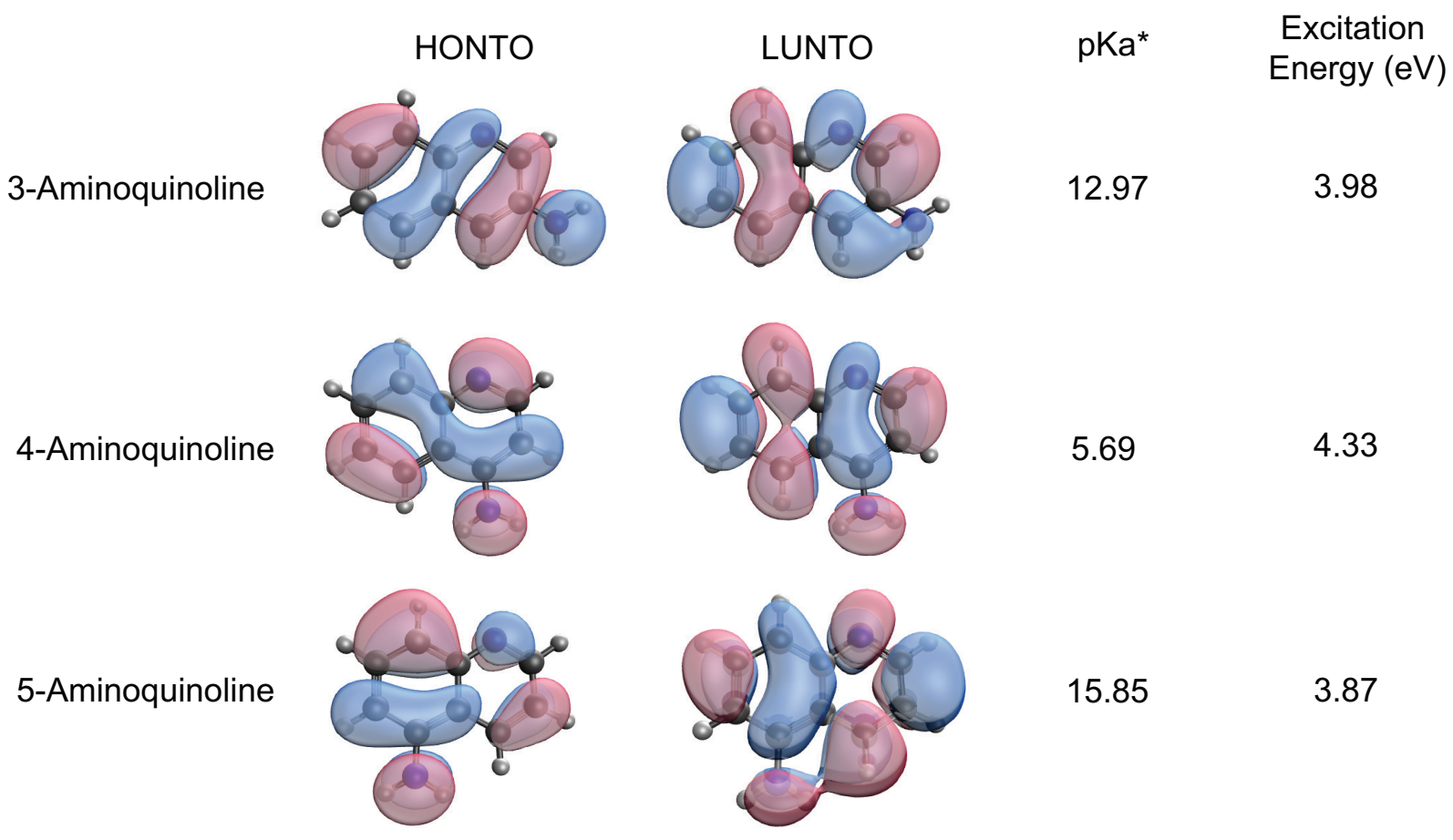

Figure S2: The highest occupied natural transition orbital (HONTO) and lowest unoccupied natural transition orbital (LUNTO) at the excited state optimized geometry, along with the $\mathrm{p} K_{\mathrm{a}}^{*}$ and vertical excitation energy, for 3-aminoquinoline, 4-aminoquinoline, and 5-aminoquinoline. The HONTOs and LUNTOs are plotted with an isovalue of 0.06 .

Table S4: Calculated ground state $\mathrm{p} K_{\mathrm{a}}$, excited state $\mathrm{p} K_{\mathrm{a}}^{*}$, vertical excitation energy, oscillator strength, and change in charge on the ring nitrogen at the ground-state $(\Delta q)$ and excited-state $\left(\Delta q^{*}\right)$ optimized geometries for the 6-R substituted quinoline compounds. The reported data is for the lowest energy $\pi \rightarrow \pi^{*}$ bright state with significant charge-transfer character, $\mathrm{S}_{\mathrm{CT}}$.

\begin{tabular}{|ccccccc|}
\hline Substituent & $\begin{array}{c}\text { Excitation } \\
\text { Energy (eV) }\end{array}$ & $\begin{array}{c}\text { Oscillator } \\
\text { Strength }\end{array}$ & $\begin{array}{c}\Delta \mathbf{q} \text { on } \\
\text { Ring N }\end{array}$ & $\begin{array}{c}\Delta \mathbf{q}^{*} \text { on } \\
\text { Ring N }\end{array}$ & $\mathbf{p} \boldsymbol{K}_{\mathbf{a}}$ & $\mathbf{p} \boldsymbol{K}_{\mathbf{a}}^{*}$ \\
\hline $\mathrm{CN}$ & 4.48 & 0.034 & -0.0048 & 0.029 & 3.47 & 6.44 \\
$\mathrm{Br}$ & 4.54 & 0.075 & -0.019 & -0.021 & 4.00 & 10.07 \\
$\mathrm{Cl}$ & 4.55 & 0.071 & -0.018 & -0.022 & 4.03 & 9.98 \\
$\mathrm{~F}$ & 4.56 & 0.075 & -0.019 & -0.029 & 4.20 & 10.18 \\
$\mathrm{CH}_{3}$ & 4.55 & 0.065 & -0.026 & -0.038 & 4.88 & 11.46 \\
$\mathrm{OCH}_{3}$ & 4.18 & 0.12 & -0.040 & -0.052 & 4.77 & 12.03 \\
$\mathrm{OH}$ & 4.29 & 0.10 & -0.038 & -0.051 & 4.78 & 11.76 \\
$\mathrm{NH}_{2}$ & 3.94 & 0.12 & -0.052 & -0.068 & 5.36 & 13.96 \\
$\mathrm{~N}_{(}$ & 3.68 & 0.13 & -0.061 & -0.071 & 5.31 & 14.32 \\
$\mathrm{NHCH}_{3}$ & 3.80 & 0.12 & -0.060 & -0.072 & 5.17 & 14.01 \\
\hline
\end{tabular}


Table S5: Calculated ground state $\mathrm{pK}_{\mathrm{a}}$, excited state $\mathrm{p} K_{\mathrm{a}}^{*}$, vertical excitation energy, oscillator strength, and change in charge $(\Delta q)$ on the ring nitrogen for the 7-R substituted quinoline compounds. The reported data is for the lowest energy $\pi \rightarrow \pi^{*}$ bright state with significant charge-transfer character, $\mathrm{S}_{\mathrm{CT}}$.

\begin{tabular}{|cccccc|}
\hline Substituent & $\begin{array}{c}\text { Excitation } \\
\text { Energy (eV) }\end{array}$ & $\begin{array}{c}\text { Oscillator } \\
\text { Strength }\end{array}$ & $\begin{array}{c}\Delta \mathbf{q} \text { on } \\
\text { Ring N }\end{array}$ & $\mathbf{p} \boldsymbol{K}_{\mathbf{a}}$ & $\mathbf{p} \boldsymbol{K}_{\mathbf{a}}^{*}$ \\
\hline $\mathrm{CN}$ & 4.66 & 0.16 & -0.034 & 3.25 & 7.50 \\
$\mathrm{Br}$ & 4.55 & 0.098 & -0.040 & 4.00 & 10.28 \\
$\mathrm{Cl}$ & 4.56 & 0.089 & -0.039 & 4.05 & 9.76 \\
$\mathrm{~F}$ & 4.58 & 0.089 & -0.042 & 4.30 & 9.83 \\
$\mathrm{CH}_{3}$ & 4.56 & 0.082 & -0.050 & 5.01 & 11.05 \\
$\mathrm{OCH}_{3}$ & 4.22 & 0.14 & -0.057 & 5.25 & 10.98 \\
$\mathrm{OH}$ & 4.31 & 0.12 & -0.053 & 5.19 & 10.72 \\
$\mathrm{NH}_{2}$ & 3.99 & 0.15 & -0.059 & 6.21 & 11.81 \\
$\mathrm{~N}\left(\mathrm{CH}_{3}\right)_{2}$ & 3.75 & 0.18 & -0.064 & 6.30 & 12.13 \\
$\mathrm{NHCH}_{3}$ & 3.73 & 0.18 & -0.060 & 6.11 & 11.42 \\
\hline
\end{tabular}

Table S6: Calculated ground state $\mathrm{pK}$, excited state $\mathrm{p} K_{\mathrm{a}}^{*}$, vertical excitation energy, oscillator strength, and change in charge $(\Delta q)$ on the ring nitrogen for the 8-R substituted quinoline compounds. The reported data is for the lowest energy $\pi \rightarrow \pi^{*}$ bright state with significant charge-transfer character, $\mathrm{S}_{\mathrm{CT}}$.

\begin{tabular}{|cccccc|}
\hline Substituent & $\begin{array}{c}\text { Excitation } \\
\text { Energy (eV) }\end{array}$ & $\begin{array}{c}\text { Oscillator } \\
\text { Strength }\end{array}$ & $\begin{array}{c}\Delta \mathbf{q} \text { on } \\
\text { Ring N }\end{array}$ & $\mathbf{p} \boldsymbol{K}_{\mathbf{a}}$ & $\mathbf{p} \boldsymbol{K}_{\mathbf{a}}^{*}$ \\
\hline $\mathrm{CN}$ & 4.59 & 0.12 & -0.014 & 2.46 & 4.51 \\
$\mathrm{Br}$ & 4.50 & 0.14 & -0.043 & 3.56 & 9.81 \\
$\mathrm{Cl}$ & 4.52 & 0.12 & -0.042 & 3.62 & 9.90 \\
$\mathrm{~F}$ & 4.57 & 0.074 & -0.058 & 3.60 & 10.73 \\
$\mathrm{CH}_{3}$ & 4.54 & 0.10 & -0.059 & 4.73 & 11.49 \\
$\mathrm{OCH}_{3}$ & 4.28 & 0.11 & -0.093 & 5.05 & 13.84 \\
$\mathrm{OH}$ & 4.20 & 0.080 & -0.100 & 3.62 & 10.80 \\
$\mathrm{NH}_{2}$ & 3.85 & 0.10 & -0.117 & 3.83 & 12.57 \\
$\mathrm{~N}_{2}\left(\mathrm{CH}_{3}\right)_{2}$ & 3.89 & 0.14 & -0.099 & 5.26 & 14.31 \\
$\mathrm{NHCH}_{3}$ & 3.70 & 0.12 & -0.126 & 3.46 & 12.26 \\
\hline
\end{tabular}




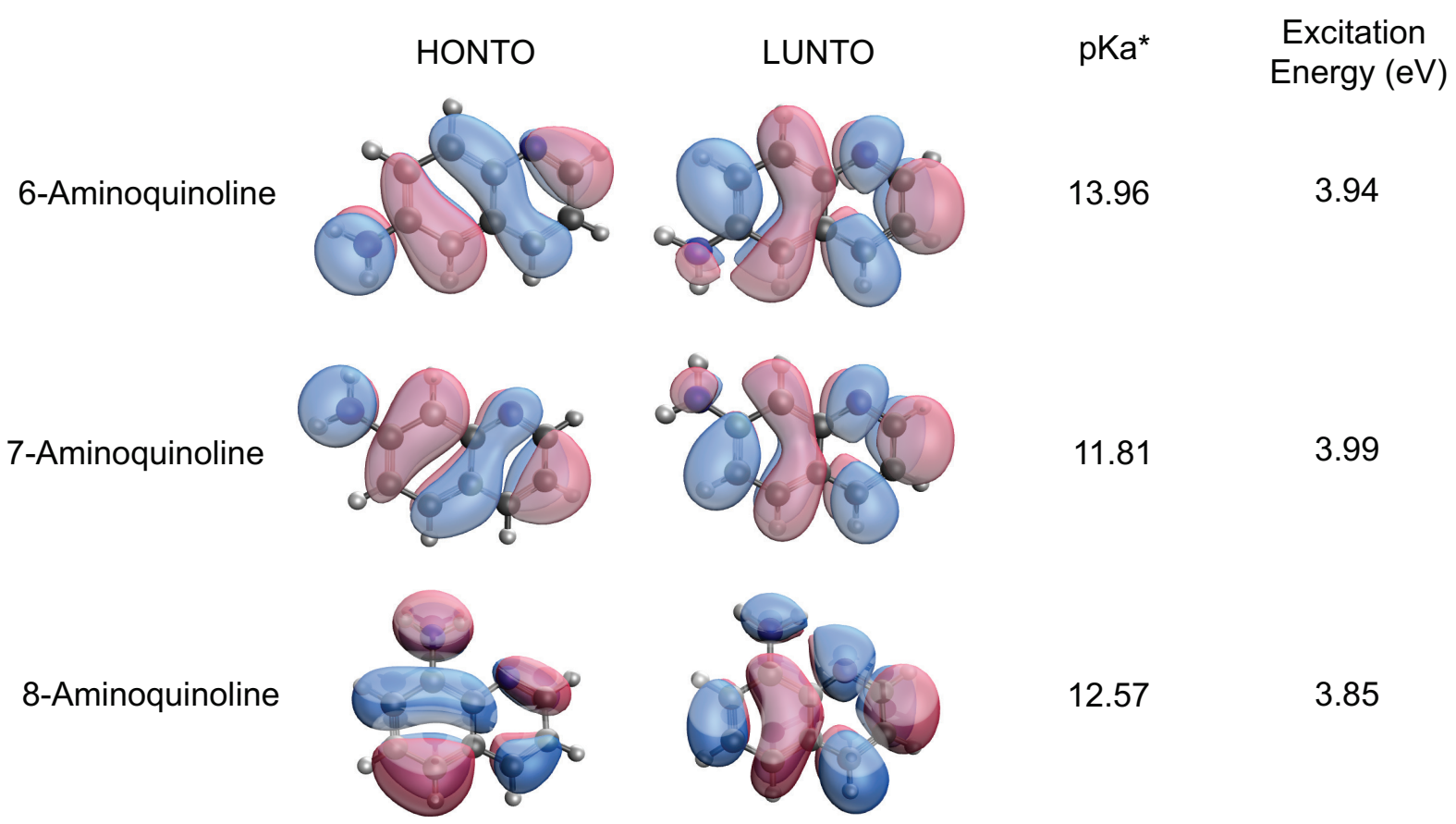

Figure S3: The highest occupied natural transition orbital (HONTO) and lowest unoccupied natural transition orbital (LUNTO) at the excited state optimized geometry, along with the $\mathrm{p} K_{\mathrm{a}}^{*}$ and vertical excitation energy, for 6-aminoquinoline, 7-aminoquinoline, and 8-aminoquinoline. The HONTOs and LUNTOs are plotted using an isolvalue of 0.06 . 


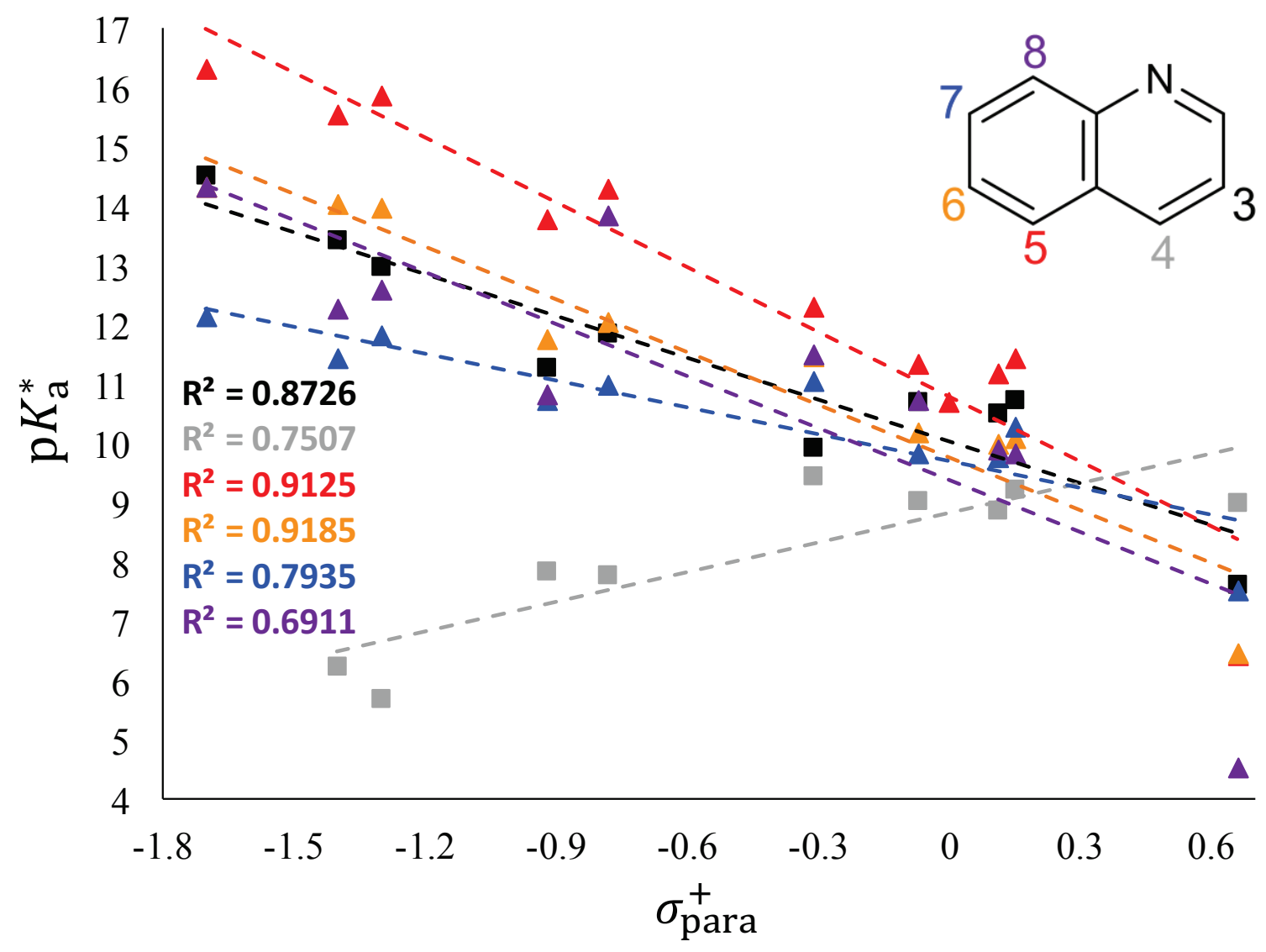

Figure S4: Calculated $\mathrm{p} K_{\mathrm{a}}^{*}$ versus the Hammett $\sigma_{\mathrm{para}}^{+}$parameter of the substituent for the monosubstituted quinoline compounds considered in this study. 


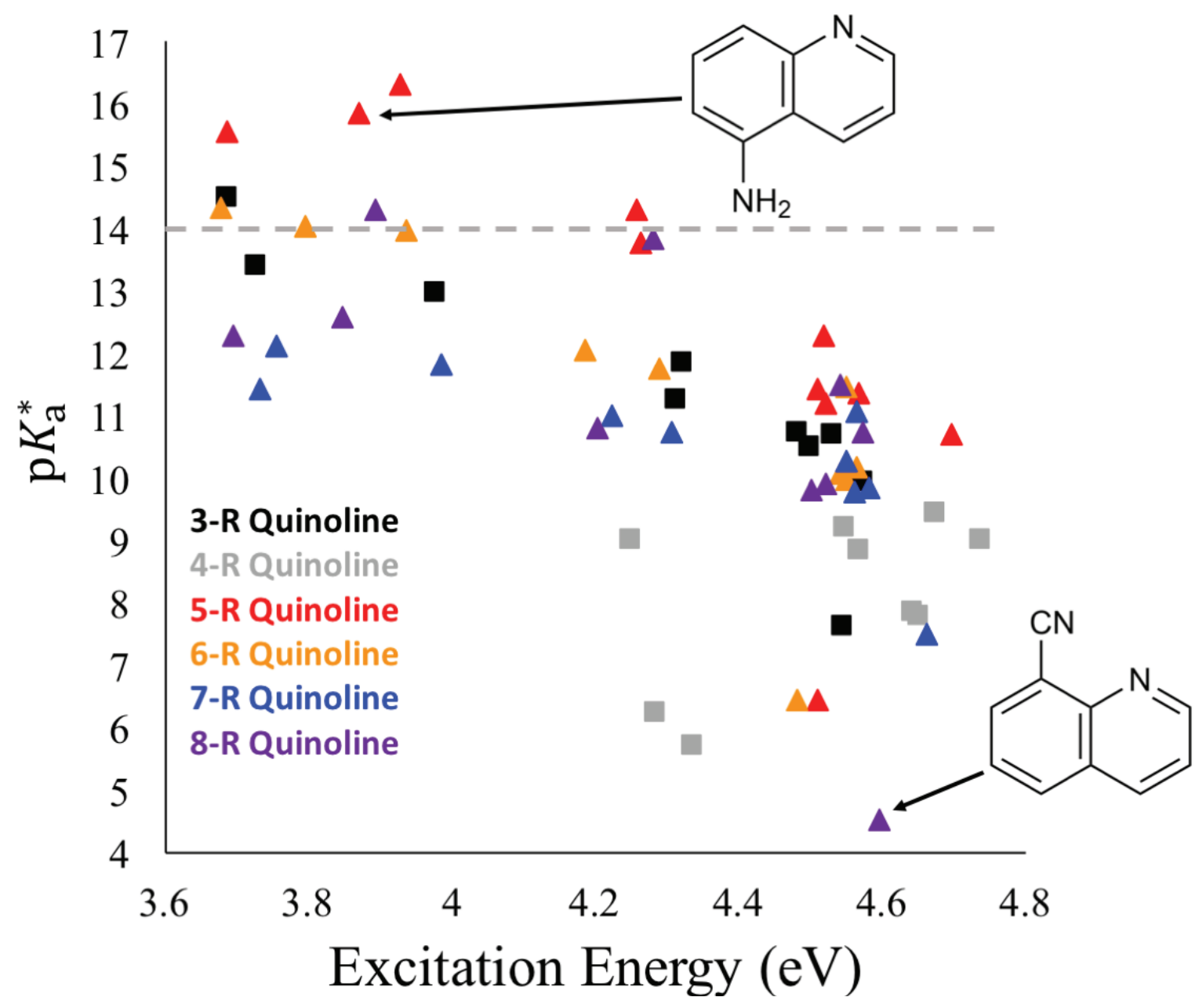

Figure S5: Plot of $\mathrm{p} K_{\mathrm{a}}^{*}$ versus vertical excitation energy for all monosubstituted quinoline compounds. The squares represent compounds where the substituent is on the nitrogencontaining ring whereas the triangles represent compounds with the substituent on the fused benzene ring. Recall that all compounds with $\mathrm{p} K_{\mathrm{a}}^{*}>14$ are strong bases in the excited state. 


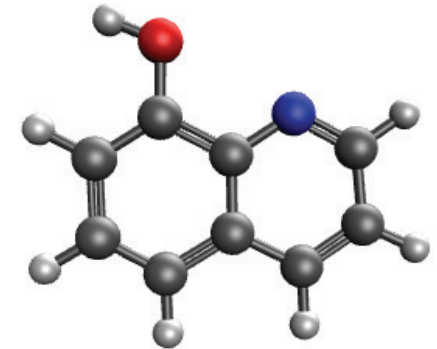

anti conformer of base

$G=3.25 \mathrm{kcal} / \mathrm{mol}$

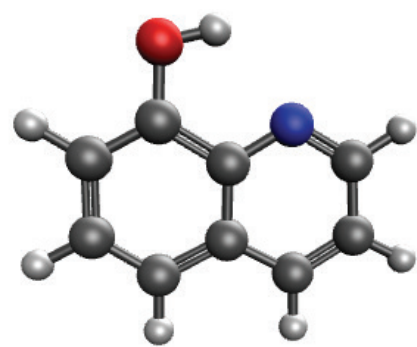

syn conformer of base $G=0.0 \mathrm{kcal} / \mathrm{mol}$

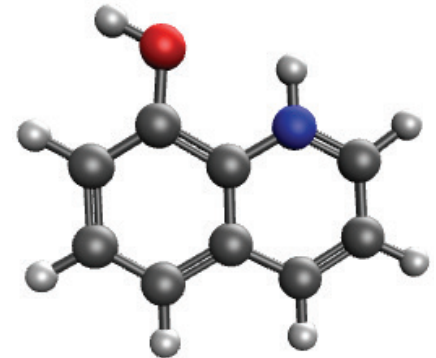

syn conformer of acid trans conformer not a stable minimum

Figure S6: Optimized geometries on $\mathrm{S}_{0}$ of the base and conjugate acid forms of 8-hydroxyquinoline. While both syn and anti conformers exist for the base, only the trans conformer is a stable minimum for the conjugate acid. The syn conformer of the base is 3.25 $\mathrm{kcal} / \mathrm{mol}$ lower in free energy than the trans conformer.

$\mathrm{S}_{0}$ Optimized Geometry
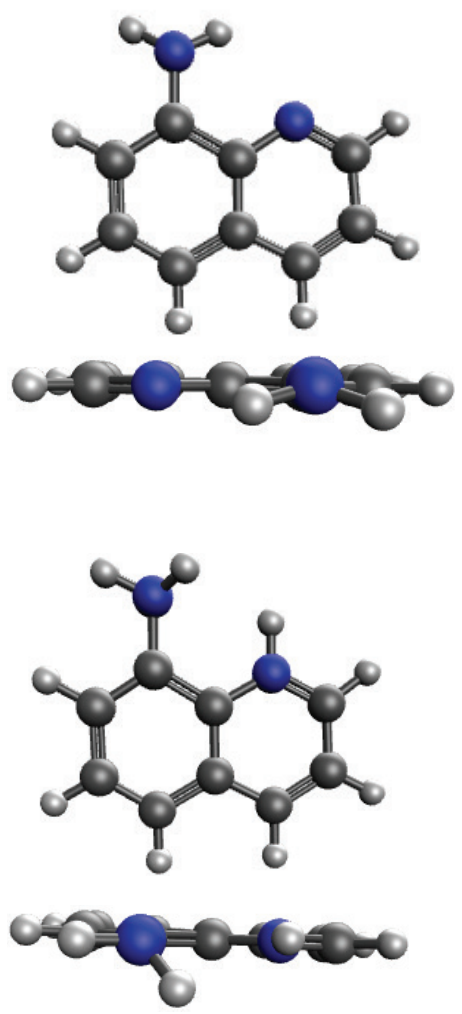

$\mathrm{S}_{\mathrm{CT}}$ Optimized Geometry
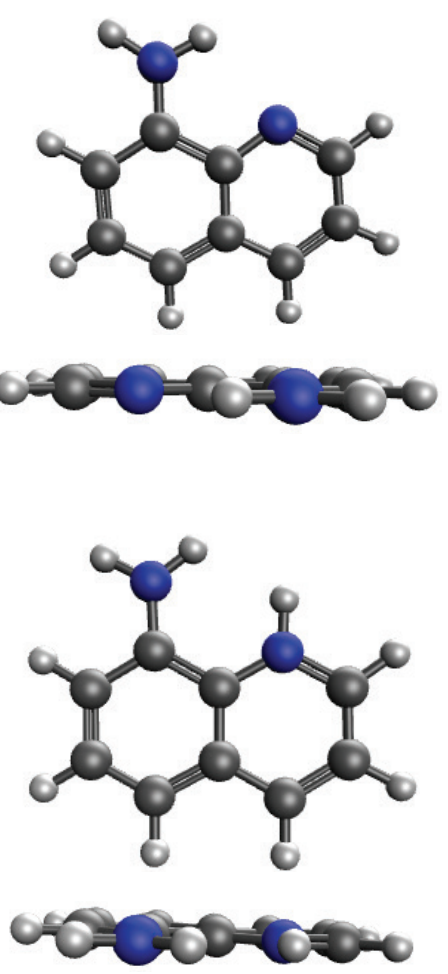

Figure S7: Optimized geometries on $\mathrm{S}_{0}$ and $\mathrm{S}_{\mathrm{CT}}$ for the acidic and basic forms of 8 -aminoquinoline. Note that the major consequence of the excited state geometry optimization is the planarization of the amine group. 


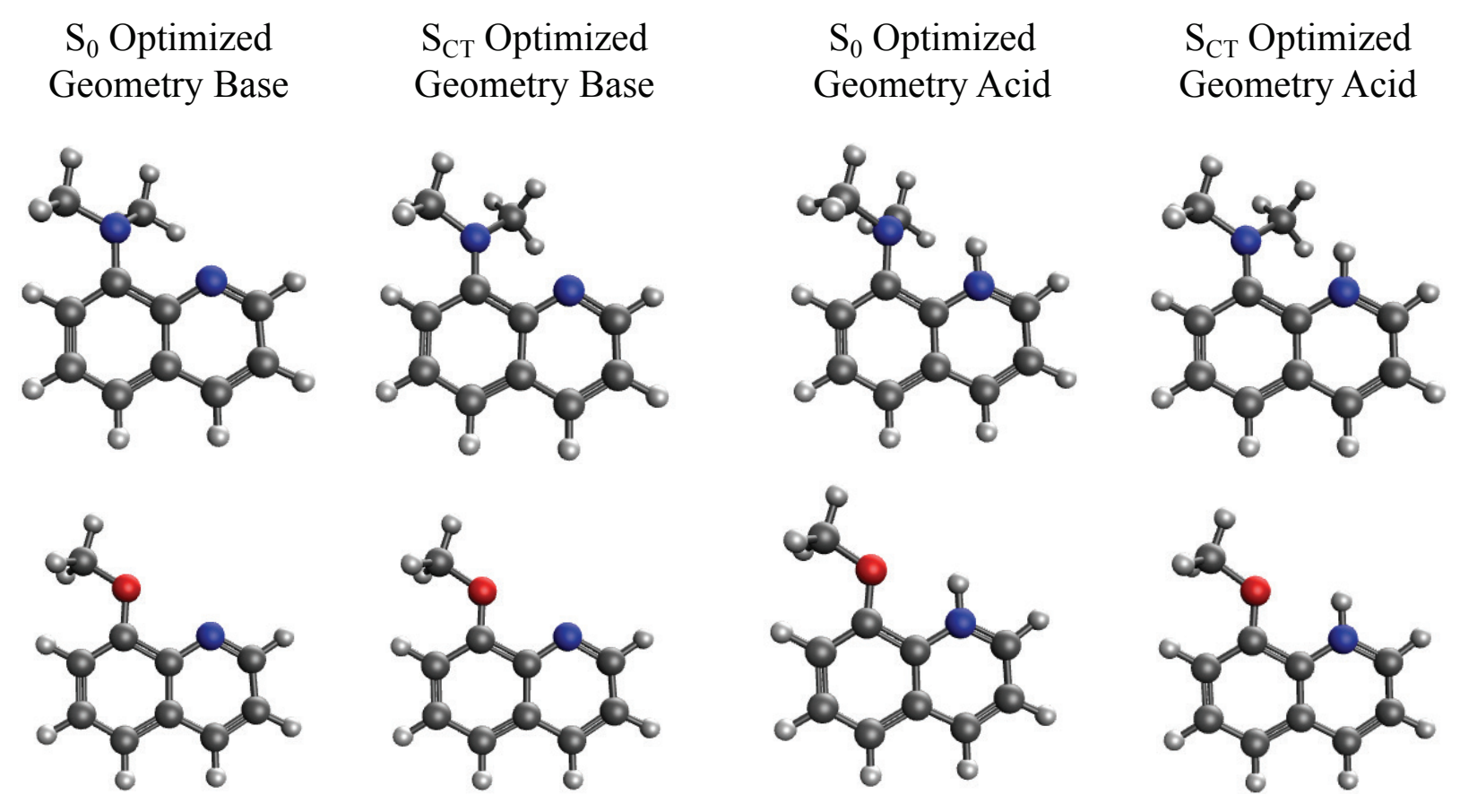

Figure S8: Optimized geometries on $\mathrm{S}_{0}$ and $\mathrm{S}_{\mathrm{CT}}$ for the acidic and basic forms of 8-dimethylaminoquinoline and 8-methoxyquinoline. For 8-dimethylaminoquinoline, the major consequence of the excited state geometry optimization is the dimethylamine group becoming more planar. In the acidic forms, the $-\mathrm{NC}_{2} \mathrm{H}_{6}$ group is more affected by the neighboring $\mathrm{N}-\mathrm{H}$ than the $-\mathrm{OCH}_{3}$ group. 


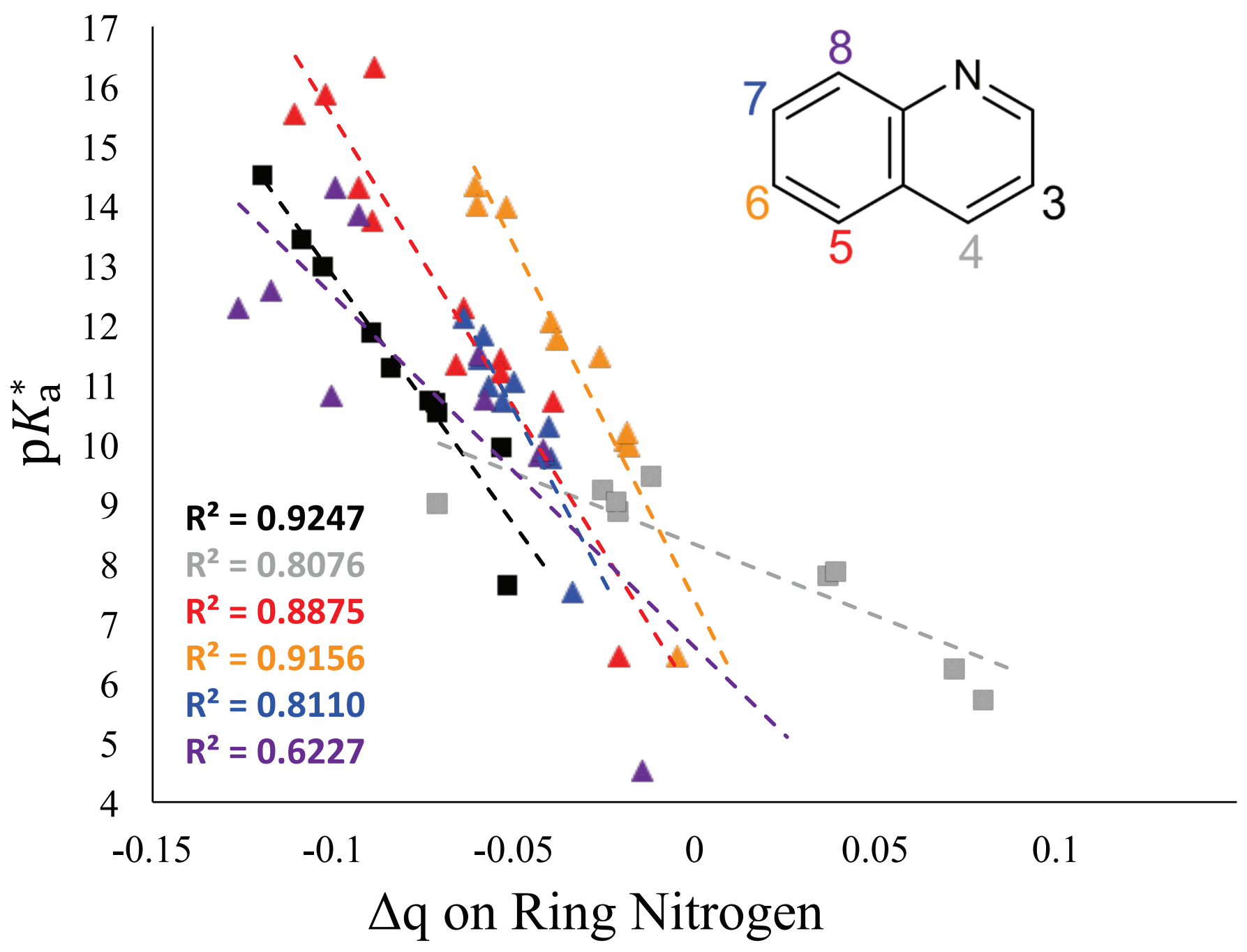

Figure S9: Plot of $\mathrm{p} K_{\mathrm{a}}^{*}$ versus change in charge $(\Delta \mathrm{q})$ on the ring nitrogen for all of the monosubstituted quinoline compounds considered in this study. Note that the $\mathrm{p} K_{\mathrm{a}}^{*}$ are calculated using adiabatic energy gaps whereas the $\Delta \mathrm{q}$ on the ring nitrogen are calculated at the ground state geometry. 
Table S7: Calculated ground state $\mathrm{p} K_{\mathrm{a}}$, excited state $\mathrm{p} K_{\mathrm{a}}^{*}$, vertical excitation energy, oscillator strength, and change in charge on the ring nitrogen at the ground-state $(\Delta q)$ and excited-state $\left(\Delta q^{*}\right)$ optimized geometries for the disubstituted quinoline compounds. The reported data is for the lowest energy $\pi \rightarrow \pi^{*}$ bright state and presented in order of increasing $\mathrm{p} K_{\mathrm{a}}^{*}$.

\begin{tabular}{|c|c|c|c|c|c|c|}
\hline Substituents & $\begin{array}{c}\text { Excitation } \\
\text { Energy } \\
\text { (eV) }\end{array}$ & $\begin{array}{l}\text { Oscillator } \\
\text { Strength }\end{array}$ & $\begin{array}{l}\Delta q \text { on } \\
\text { Ring } N\end{array}$ & $\begin{array}{l}\Delta \mathbf{q}^{*} \text { on } \\
\text { Ring } N\end{array}$ & $\mathrm{p} K_{\mathrm{a}}$ & $\mathbf{p} K_{\mathrm{a}}^{*}$ \\
\hline $5-\mathrm{CH}_{3}, 7-\mathrm{OCH}_{3}$ & 4.15 & 0.15 & -0.067 & -0.054 & 5.41 & 11.66 \\
\hline $5-\mathrm{CH}_{3}, 7-\mathrm{CH}_{3}$ & 4.47 & 0.10 & -0.071 & -0.052 & 5.18 & 12.36 \\
\hline $5-\mathrm{CH}_{3}, 6-\mathrm{CH}_{3}$ & 4.40 & 0.089 & -0.051 & -0.055 & 5.07 & 12.77 \\
\hline $5-\mathrm{OCH}_{3}, 7-\mathrm{OCH}_{3}$ & 4.02 & 0.14 & -0.086 & -0.068 & 5.44 & 12.91 \\
\hline $5-\mathrm{CH}_{3}, 6-\mathrm{OCH}_{3}$ & 4.07 & 0.11 & -0.052 & -0.066 & 4.95 & 13.42 \\
\hline $4-\mathrm{NH}_{2}, 5-\mathrm{NH}_{2}$ & 4.16 & 0.21 & 0.011 & -0.084 & 7.88 & 13.58 \\
\hline 6-NH,$~ 7-\mathrm{NH}_{2}$ & 4.09 & 0.28 & -0.060 & -0.067 & 6.43 & 14.29 \\
\hline $5-\mathrm{NH}_{2}, 7-\mathrm{NH}_{2}$ & 3.71 & 0.11 & -0.091 & -0.078 & 6.80 & 14.44 \\
\hline $5-\mathrm{CH}_{3}, 6-\mathrm{NH}_{2}$ & 3.90 & 0.10 & -0.060 & -0.079 & 5.51 & 14.95 \\
\hline $5-\mathrm{OCH}_{3}, 7-\mathrm{CH}_{3}$ & 4.26 & 0.12 & -0.096 & -0.081 & 5.15 & 15.00 \\
\hline $5-\mathrm{OCH}_{3}, 6-\mathrm{CH}_{3}$ & 4.44 & 0.078 & -0.050 & -0.082 & 4.54 & 15.02 \\
\hline $3-\mathrm{NH}_{2}, 6-\mathrm{NH}_{2}$ & 4.04 & 0.20 & -0.076 & -0.087 & 5.30 & 15.28 \\
\hline $5-\mathrm{NH}_{2}, 7-\mathrm{OCH}_{3}$ & 3.93 & 0.10 & -0.099 & -0.088 & 5.97 & 15.29 \\
\hline $4-\mathrm{CH}_{3}, 5-\mathrm{NH}_{2}$ & 3.95 & 0.14 & -0.086 & -0.077 & 5.99 & 15.56 \\
\hline $5-\mathrm{OCH}_{3}, 6-\mathrm{OCH}_{3}$ & 4.09 & 0.10 & -0.053 & -0.088 & 4.55 & 15.78 \\
\hline $5-\mathrm{OCH}_{3}, 6-\mathrm{NH}_{2}$ & 3.87 & 0.10 & -0.062 & -0.084 & 5.12 & 15.94 \\
\hline $5-\mathrm{NH}_{2}, 7-\mathrm{CH}_{3}$ & 3.89 & 0.11 & -0.104 & -0.090 & 5.76 & 16.01 \\
\hline $5-\mathrm{NHCH}_{3}, 8-\mathrm{CH}_{3}$ & 3.63 & 0.14 & -0.114 & -0.108 & 5.35 & 16.08 \\
\hline $5-\mathrm{NH}_{2}, 8-\mathrm{CH}_{3}$ & 3.77 & 0.12 & -0.108 & -0.104 & 5.48 & 16.27 \\
\hline $5-\mathrm{NHCH}_{3}, 6-\mathrm{CH}_{3}$ & 3.78 & 0.12 & -0.094 & -0.089 & 5.46 & 16.28 \\
\hline $5-\mathrm{NH}_{2}, 6-\mathrm{CH}_{3}$ & 3.79 & 0.099 & -0.102 & -0.099 & 5.55 & 16.31 \\
\hline $5-\mathrm{N}\left(\mathrm{CH}_{3}\right)_{2}, 8-\mathrm{CH}_{3}$ & 3.88 & 0.15 & -0.094 & -0.095 & 5.06 & 16.66 \\
\hline $3-\mathrm{NH}_{2}, 5-\mathrm{NH}_{2}$ & 3.72 & 0.12 & -0.124 & -0.123 & 5.23 & 16.72 \\
\hline $5-\mathrm{NH}_{2}, 6-\mathrm{OCH}_{3}$ & 3.62 & 0.097 & -0.093 & -0.101 & 5.41 & 16.79 \\
\hline $3-\mathrm{N}\left(\mathrm{CH}_{3}\right)_{2}, 5-\mathrm{N}\left(\mathrm{CH}_{3}\right)_{2}$ & 3.59 & 0.17 & -0.120 & -0.115 & 4.96 & 16.82 \\
\hline $5-\mathrm{NHCH}_{3}, 6-\mathrm{OCH}_{3}$ & 3.59 & 0.11 & -0.089 & -0.094 & 5.42 & 16.91 \\
\hline $5-\mathrm{NH}_{2}, 6-\mathrm{OH}$ & 3.69 & 0.098 & -0.093 & -0.103 & 5.39 & 16.93 \\
\hline
\end{tabular}


Table S8: Calculated ground state $\mathrm{p} K_{\mathrm{a}}$, excited state $\mathrm{p} K_{\mathrm{a}}^{*}$, vertical excitation energy, oscillator strength, and change in charge on the ring nitrogen at the ground-state $(\Delta q)$ and excited-state $\left(\Delta q^{*}\right)$ optimized geometries for the disubstituted quinoline compounds, continued. The reported data is for the lowest energy $\pi \rightarrow \pi^{*}$ bright state and presented in order of increasing $\mathrm{p} K_{\mathrm{a}}^{*}$.

\begin{tabular}{|c|c|c|c|c|c|c|}
\hline Substituents & $\begin{array}{c}\text { Excitation } \\
\text { Energy } \\
(\mathrm{eV})\end{array}$ & $\begin{array}{l}\text { Oscillator } \\
\text { Strength }\end{array}$ & $\begin{array}{l}\Delta q \text { on } \\
\text { Ring } N\end{array}$ & $\begin{array}{l}\Delta \mathbf{q}^{*} \text { on } \\
\text { Ring } \mathbf{N}\end{array}$ & $\mathbf{p} K_{\mathrm{a}}$ & $\mathbf{p} K_{\mathrm{a}}^{*}$ \\
\hline $5-\mathrm{NHCH}_{3}, 8-\mathrm{N}\left(\mathrm{CH}_{3}\right)_{2}$ & 3.41 & 0.14 & -0.121 & -0.136 & 6.58 & 16.93 \\
\hline $5-\mathrm{NH}_{2}, 8-\mathrm{NC}_{2} \mathrm{H}_{6}$ & 3.48 & 0.13 & -0.118 & -0.133 & 6.48 & 17.07 \\
\hline $5-\mathrm{NHCH}_{3}, 6-\mathrm{OH}$ & 3.66 & 0.11 & -0.088 & -0.097 & 5.38 & 17.09 \\
\hline $3-\mathrm{NHCH}_{3}, 5-\mathrm{NHCH}_{3}$ & 3.62 & 0.13 & -0.138 & -0.135 & 5.19 & 17.19 \\
\hline $5-\mathrm{N}\left(\mathrm{CH}_{3}\right)_{2}, 8-\mathrm{N}\left(\mathrm{CH}_{3}\right)_{2}$ & 3.55 & 0.16 & -0.105 & -0.125 & 5.89 & 17.53 \\
\hline $5-\mathrm{NH}_{2}, 8-\mathrm{OCH}_{3}$ & 3.61 & 0.10 & -0.122 & -0.125 & 5.54 & 17.70 \\
\hline $5-\mathrm{NHCH}_{3}, 8-\mathrm{OCH}_{3}$ & 3.51 & 0.11 & -0.126 & -0.128 & 5.65 & 18.00 \\
\hline $5-\mathrm{N}\left(\mathrm{CH}_{3}\right)_{2}, 8-\mathrm{OCH}_{3}$ & 3.77 & 0.12 & -0.110 & -0.116 & 5.18 & 18.01 \\
\hline $5-\mathrm{NHCH}_{3}, 6-\mathrm{NHCH}_{3}$ & 3.62 & 0.11 & -0.069 & -0.096 & 5.51 & 18.10 \\
\hline $5-\mathrm{NH}_{2}, 6-\mathrm{NH}_{2}$ & 3.59 & 0.079 & -0.092 & -0.111 & 5.57 & 18.16 \\
\hline $5-\mathrm{NHCH}_{3}, 6-\mathrm{NH}_{2}$ & 3.78 & 0.094 & -0.0700 & -0.100 & 5.36 & 18.22 \\
\hline
\end{tabular}

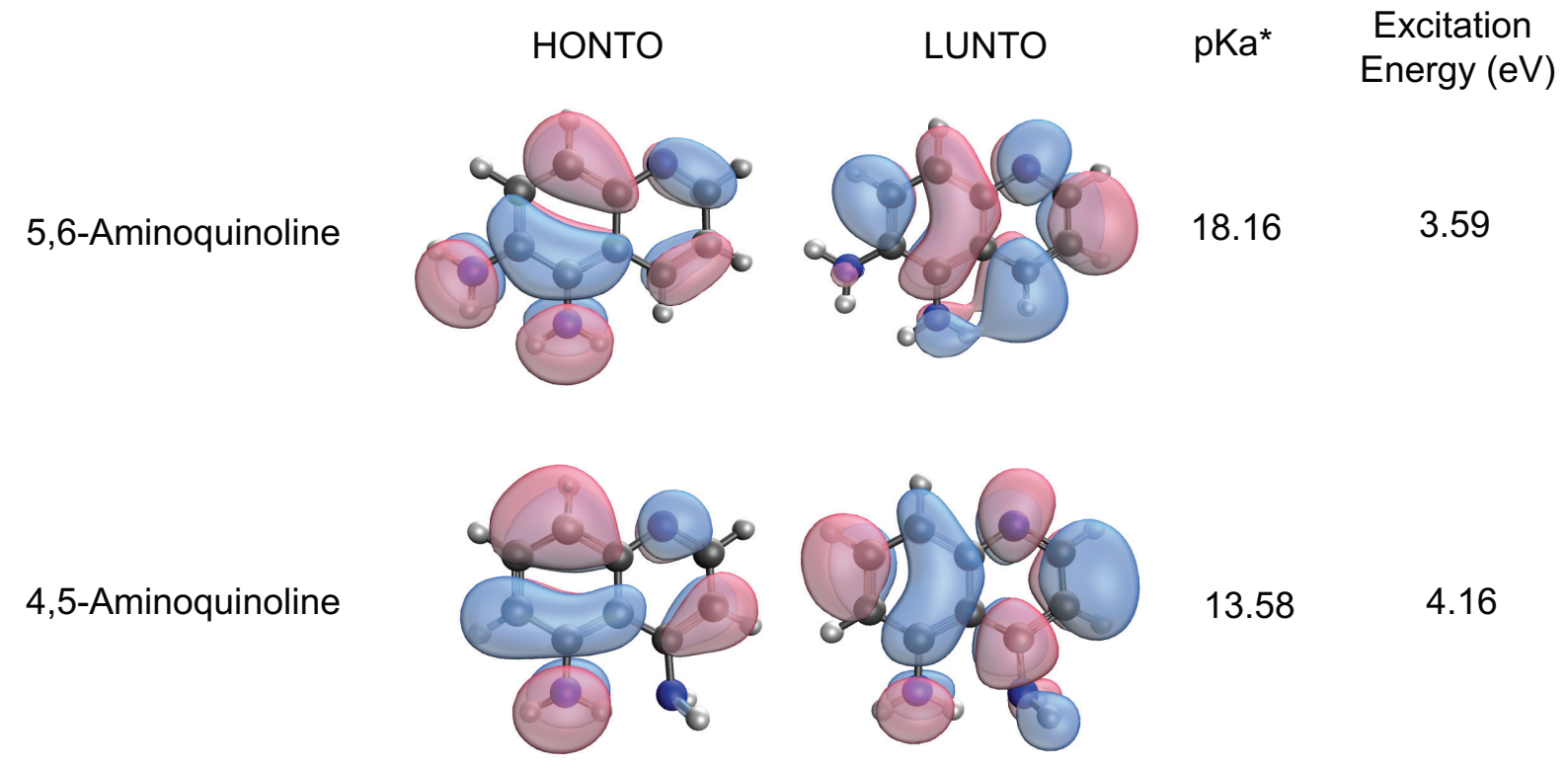

Figure S10: The highest occupied natural transition orbital (HONTO) and lowest unoccupied natural transition orbital (LUNTO) at the excited state optimized geometry, along with the $\mathrm{p} K_{\mathrm{a}}^{*}$ and vertical excitation energy, for 5,6-aminoquinoline and 4,5-aminoquinoline. 


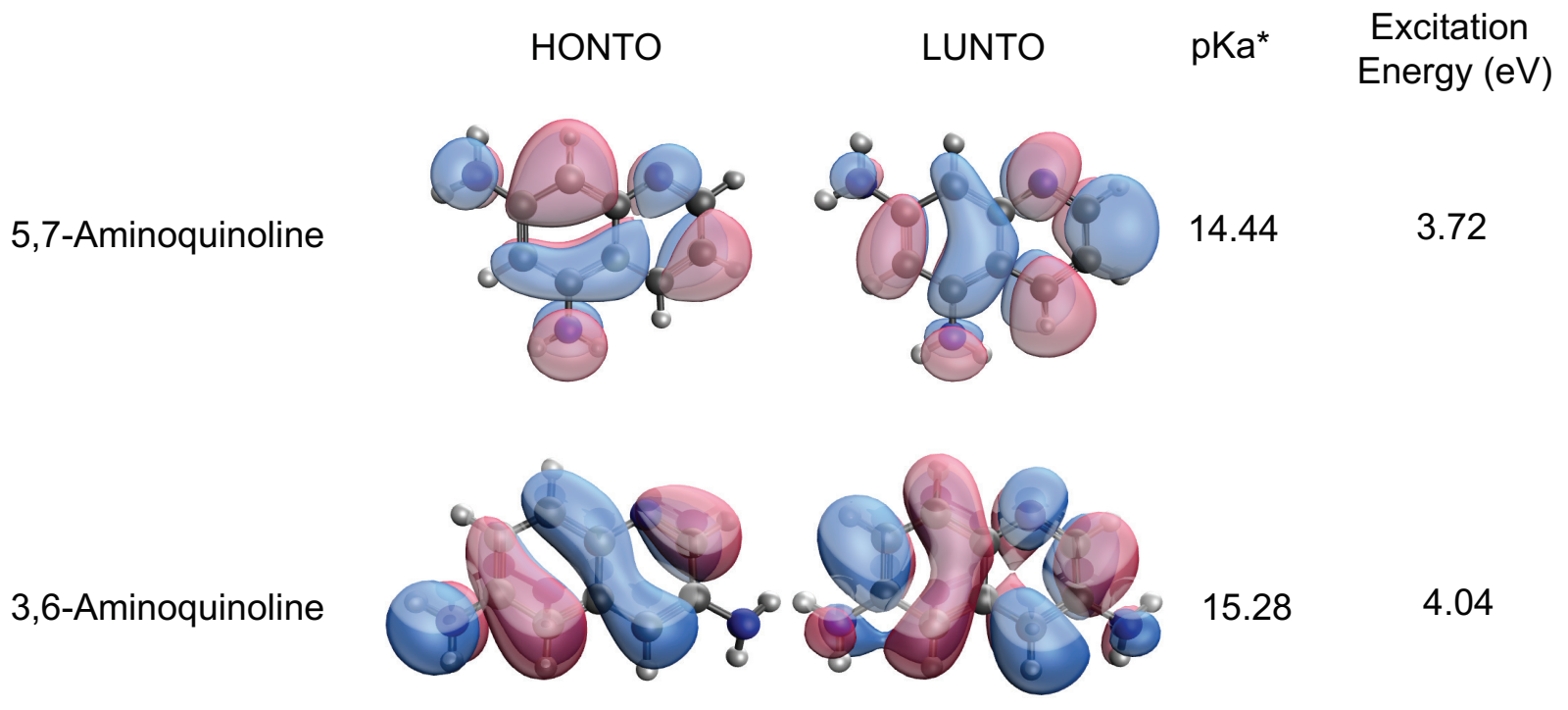

Figure S11: The highest occupied natural transition orbital (HONTO) and lowest unoccupied natural transition orbital (LUNTO) at the excited state optimized geometry, along with the $\mathrm{p} K_{\mathrm{a}}^{*}$ and vertical excitation energy, for 5,7-aminoquinoline and 3,6-aminoquinoline.

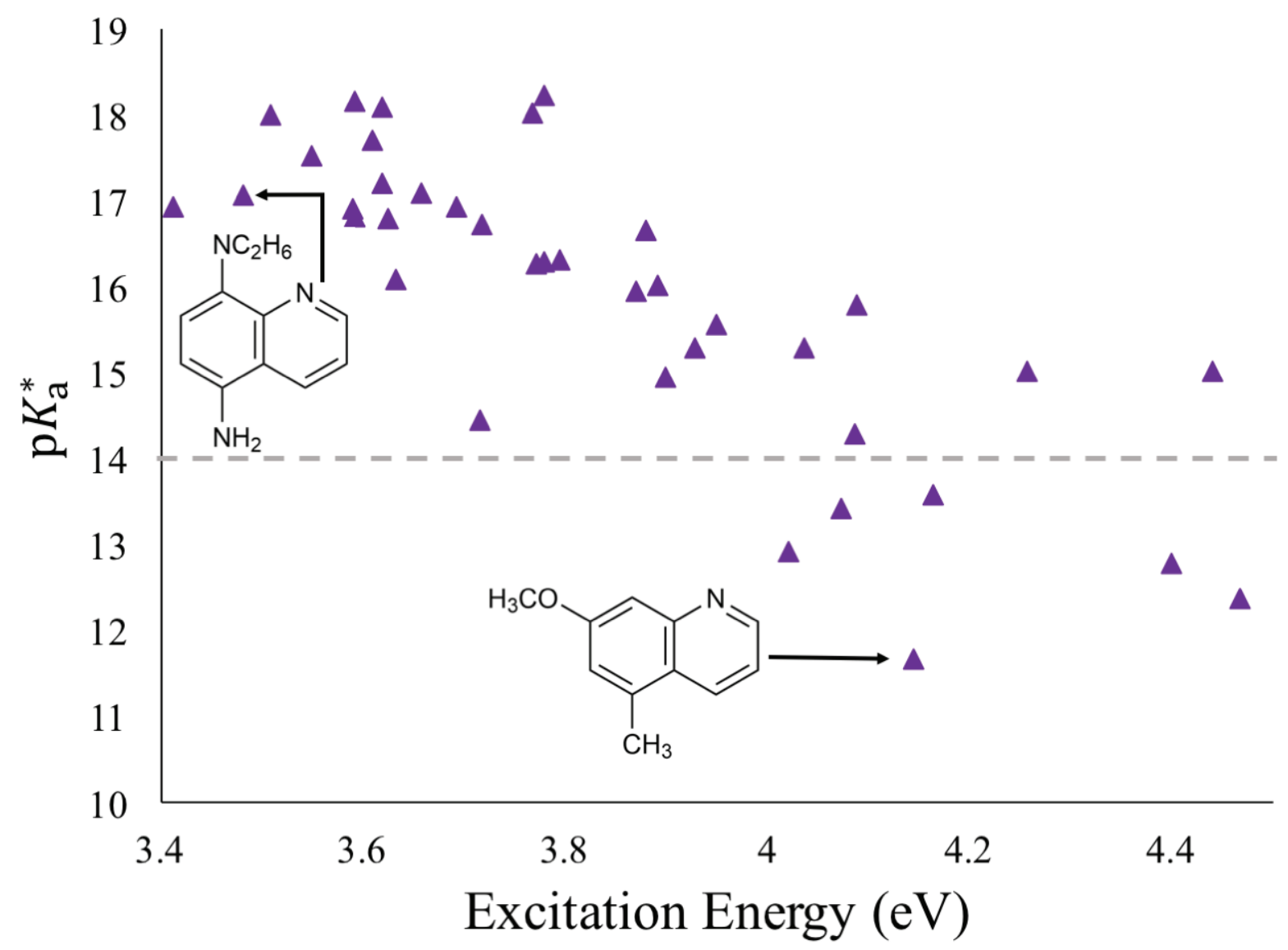

Figure S12: Plot of $\mathrm{p} K_{\mathrm{a}}^{*}$ versus vertical excitation energy for the disubstituted quinoline compounds. Recall that all compounds with $\mathrm{p} K_{\mathrm{a}}^{*}>14$ are strong bases in the excited state. 


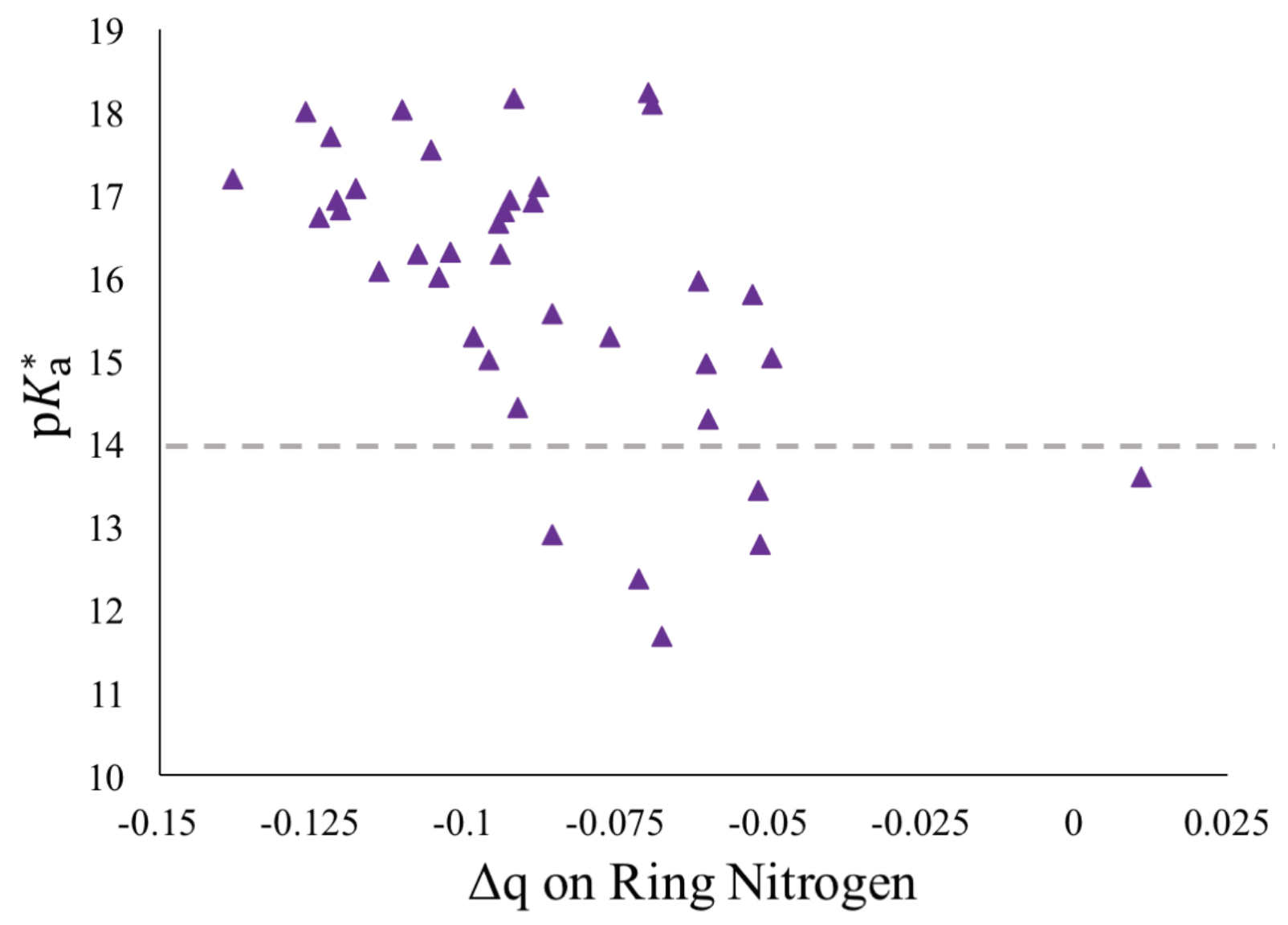

Figure S13: Plot of $\mathrm{p} K_{\mathrm{a}}^{*}$ versus change in charge $(\Delta \mathrm{q})$ on the ring nitrogen for the disubstituted quinoline compounds. Note that the $\mathrm{p} K_{\mathrm{a}}^{*}$ are calculated using adiabatic energy gaps whereas the $\Delta \mathrm{q}$ on the ring $\mathrm{N}$ are calculated at the ground state geometry. While there is some correlation between $\mathrm{p} K_{\mathrm{a}}^{*}$ and $\Delta \mathrm{q}$ on the ring $\mathrm{N}$, the trend is too noisy to allow a calculated $\Delta \mathrm{q}$ on the ring $\mathrm{N}$ to accurately predict $\mathrm{p} K_{\mathrm{a}}^{*}$.

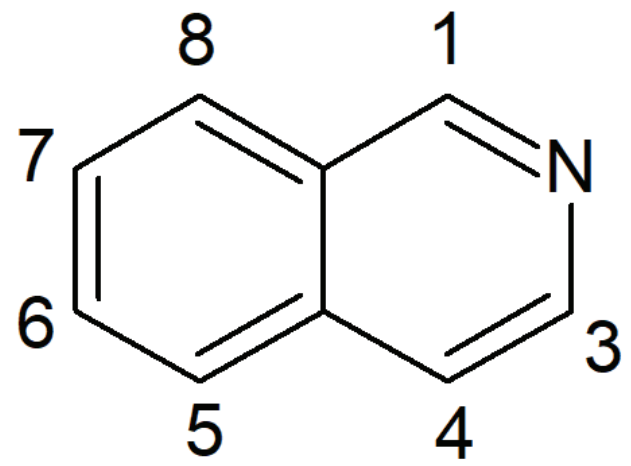

Figure S14: Substituent position numbering system for the isoquinoline compounds. 
Table S9: Calculated ground state $\mathrm{p} K_{\mathrm{a}}$, excited state $\mathrm{p} K_{\mathrm{a}}^{*}$, vertical excitation energy, oscillator strength, and change in charge $(\Delta q)$ on the ring nitrogen for the isoquinoline compounds. The reported data is for the lowest energy $\pi \rightarrow \pi^{*}$ bright state. The monosubstituted and disubstituted compounds are each reported in order of increasing $\mathrm{p} K_{\mathrm{a}}^{*}$.

\begin{tabular}{|c|c|c|c|c|c|}
\hline Substituent & $\begin{array}{c}\text { Excitation } \\
\text { Energy } \\
(\mathrm{eV})\end{array}$ & $\begin{array}{l}\text { Oscillator } \\
\text { Strength }\end{array}$ & $\begin{array}{c}\Delta q \text { on } \\
\text { Ring } N\end{array}$ & $\mathrm{p} K_{\mathrm{a}}$ & $\mathbf{p} K_{\mathbf{a}}^{*}$ \\
\hline 4-NH2 & 4.07 & 0.18 & -0.065 & 5.49 & 8.06 \\
\hline 4-OCH3 & 4.43 & 0.12 & -0.084 & 4.44 & 8.72 \\
\hline $4-\mathrm{CH} 3$ & 4.44 & 0.12 & -0.083 & 5.03 & 9.23 \\
\hline $6-\mathrm{OCH}_{3}$ & 4.43 & 0.081 & 0.002 & 5.46 & 9.87 \\
\hline $6-\mathrm{CH}_{3}$ & 4.55 & 0.066 & -0.085 & 5.13 & 10.18 \\
\hline $6-\mathrm{NH}_{2}$ & 4.18 & 0.079 & 0.012 & 6.32 & 10.30 \\
\hline $6-\mathrm{NHCH}_{3}$ & 4.11 & 0.076 & 0.013 & 6.35 & 10.40 \\
\hline 7- $\mathrm{CH}_{3}$ & 4.41 & 0.076 & -0.089 & 4.99 & 10.81 \\
\hline $5-\mathrm{CH}_{3}$ & 4.43 & 0.11 & -0.093 & 4.83 & 10.95 \\
\hline $7-\mathrm{OCH}_{3}$ & 4.08 & 0.094 & -0.092 & 4.95 & 11.48 \\
\hline $8-\mathrm{CH}_{3}$ & 4.40 & 0.12 & -0.093 & 5.02 & 11.70 \\
\hline 7- $\mathrm{NHCH}_{3}$ & 3.63 & 0.091 & -0.093 & 5.39 & 13.12 \\
\hline $5-\mathrm{OCH}_{3}$ & 4.25 & 0.12 & -0.110 & 4.71 & 13.38 \\
\hline 7-NH & 3.87 & 0.080 & -0.093 & 5.55 & 13.43 \\
\hline $8-\mathrm{OCH}_{3}$ & 4.25 & 0.16 & -0.102 & 5.06 & 13.75 \\
\hline $5-\mathrm{NH}_{2}$ & 3.95 & 0.14 & -0.110 & 4.90 & 14.86 \\
\hline $8-\mathrm{NHCH}_{3}$ & 3.76 & 0.19 & -0.110 & 5.40 & 14.90 \\
\hline $5-\mathrm{NHCH}_{3}$ & 3.81 & 0.14 & -0.114 & 4.72 & 14.93 \\
\hline $8-\mathrm{NH}_{2}$ & 3.90 & 0.15 & -0.108 & 5.52 & 15.12 \\
\hline 6- $\mathrm{NH}_{2}, 7-\mathrm{NH}_{2}$ & 4.15 & 0.099 & -0.065 & 6.61 & 13.29 \\
\hline $5-\mathrm{NH}_{2}, 6-\mathrm{NH}_{2}$ & 3.83 & 0.092 & -0.053 & 5.96 & 14.88 \\
\hline $5-\mathrm{NH}_{2}, 7-\mathrm{NH}_{2}$ & 3.67 & 0.093 & -0.114 & 5.61 & 15.49 \\
\hline 7-NH, $8-\mathrm{NH}_{2}$ & 3.54 & 0.11 & -0.115 & 5.83 & 16.61 \\
\hline $5-\mathrm{NH}_{2}, 8-\mathrm{NH}_{2}$ & 3.46 & 0.14 & -0.118 & 5.32 & 16.82 \\
\hline $5-\mathrm{NHCH}_{3}, 8-\mathrm{NHCH}_{3}$ & 3.35 & 0.15 & -0.122 & 5.40 & 17.48 \\
\hline
\end{tabular}




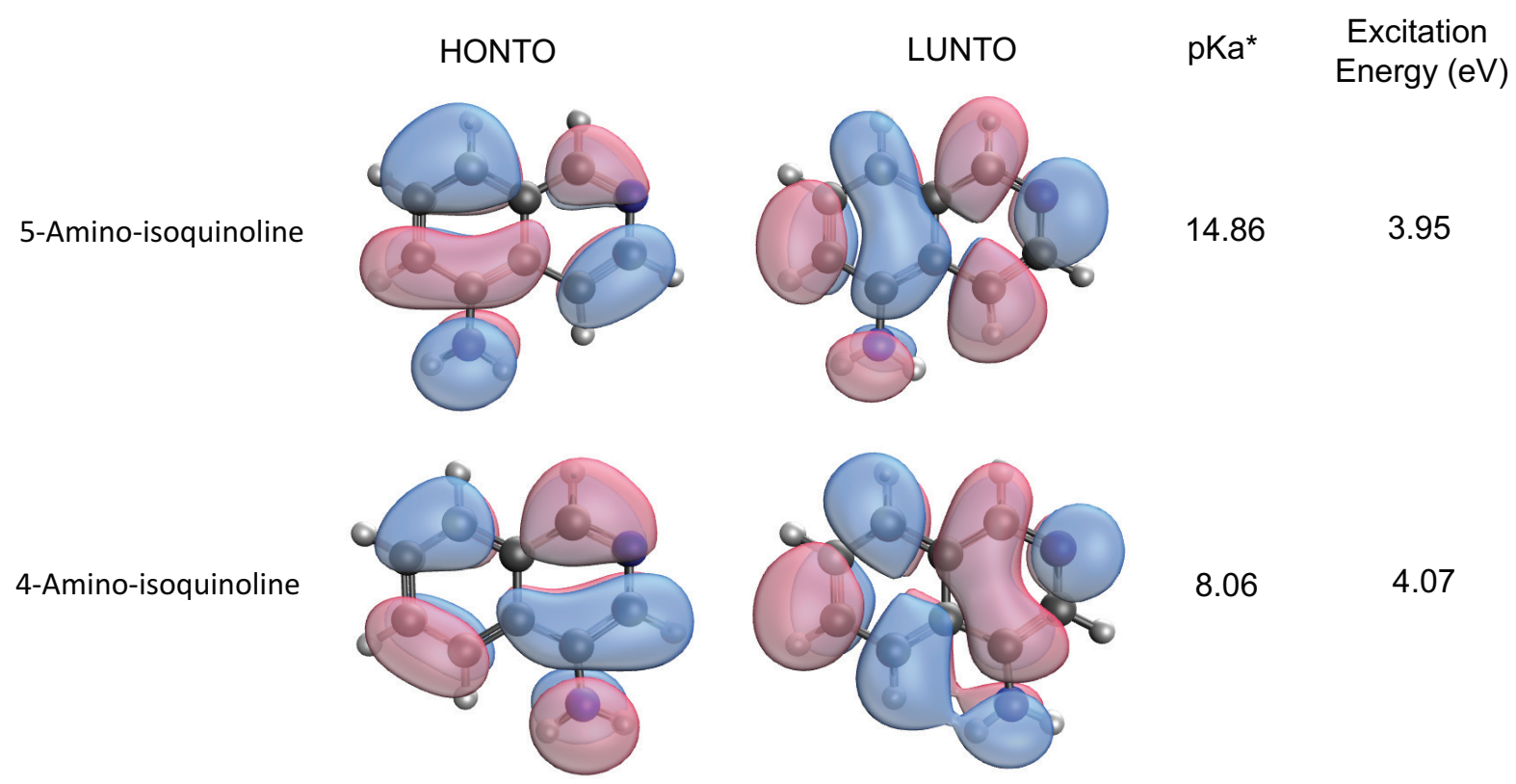

Figure S15: The highest occupied natural transition orbital (HONTO) and lowest unoccupied natural transition orbital (LUNTO) at the excited state optimized geometry, along with the $\mathrm{p} K_{\mathrm{a}}^{*}$ and vertical excitation energy, for 5-amino-isoquinoline and 4-amino-isoquinoline.

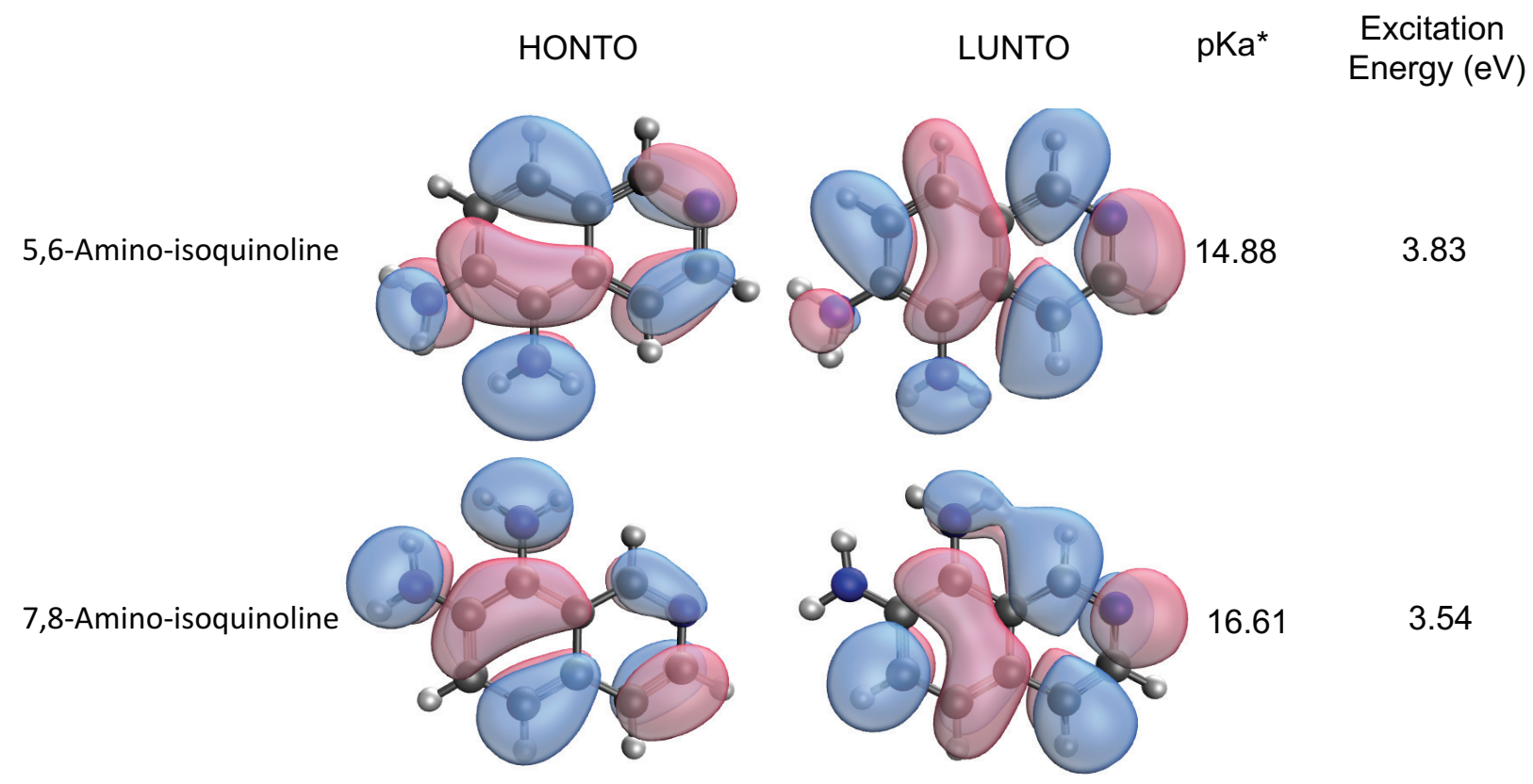

Figure S16: The highest occupied natural transition orbital (HONTO) and lowest unoccupied natural transition orbital (LUNTO) at the excited state optimized geometry, along with the $\mathrm{p} K_{\mathrm{a}}^{*}$ and vertical excitation energy, for 5,6-amino-isoquinoline and 7,8-amino-isoquinoline. 


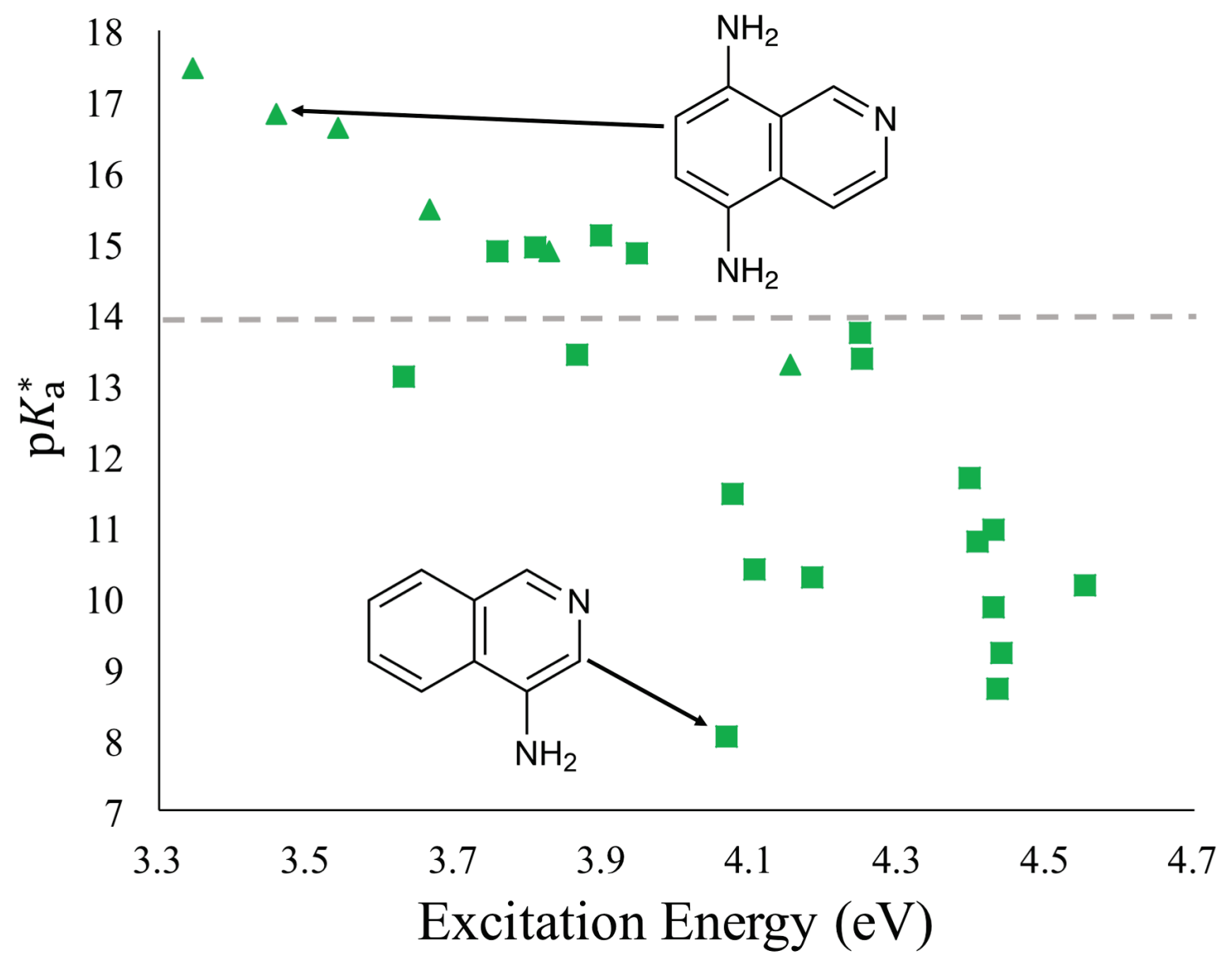

Figure S17: Plot of $\mathrm{p} K_{\mathrm{a}}^{*}$ versus vertical excitation energy for the isoquinoline compounds. The square data points represent monosubstituted isoquinoline compounds whereas the triangles are disubstituted isoquinoline compounds. Recall that all compounds with $\mathrm{p} K_{\mathrm{a}}^{*}>14$ are strong bases in the excited state. 


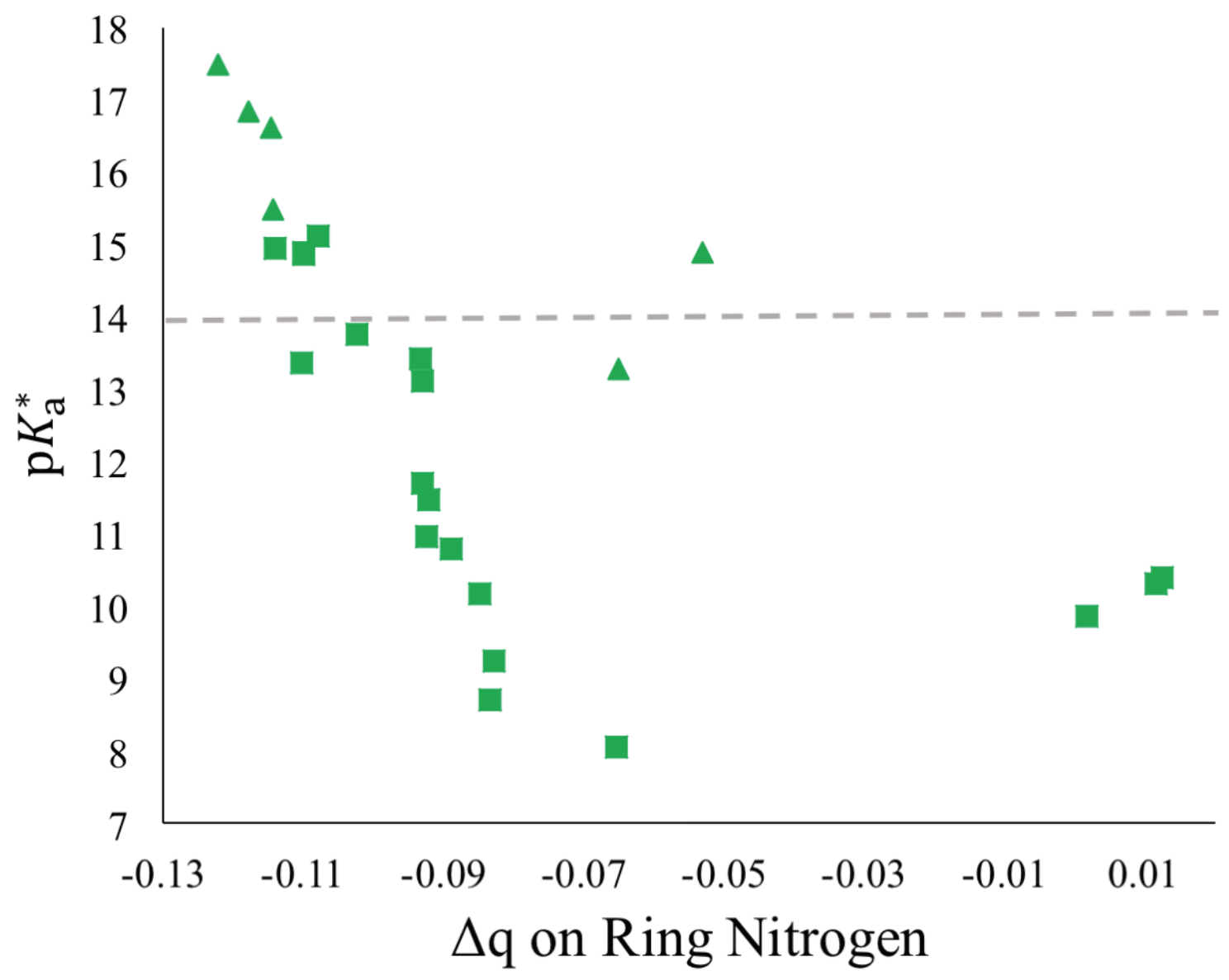

Figure S18: Plot of $\mathrm{p} K_{\mathrm{a}}^{*}$ versus change in charge $(\Delta \mathrm{q})$ on the ring nitrogen for the isoquinoline compounds. The square data points represent monosubstituted isoquinoline compounds whereas the triangles are disubstituted isoquinoline compounds. Note that the $\mathrm{p} K_{\mathrm{a}}^{*}$ are calculated using adiabatic energy gaps whereas the $\Delta \mathrm{q}$ on the ring $\mathrm{N}$ are calculated at the ground state geometry. While there is some correlation between $\mathrm{p} K_{\mathrm{a}}^{*}$ and $\Delta \mathrm{q}$ on the ring $\mathrm{N}$, the trend is too noisy to allow a calculated $\Delta \mathrm{q}$ on the ring $\mathrm{N}$ to accurately predict $\mathrm{p} K_{\mathrm{a}}^{*}$. 


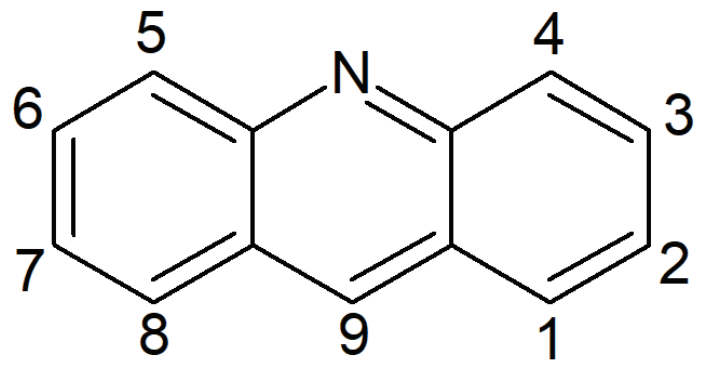

Figure S19: Substituent position numbering system for the acridine compounds.

Table S10: Calculated ground state $\mathrm{p} K_{\mathrm{a}}$, excited state $\mathrm{p} K_{\mathrm{a}}^{*}$, vertical excitation energy, oscillator strength, and change in charge on the ring nitrogen at the ground-state $(\Delta q)$ and excited-state $\left(\Delta q^{*}\right)$ optimized geometries for the acridine compounds. The reported data is for the lowest energy $\pi \rightarrow \pi^{*}$ bright state. The monosubstituted and disubstituted compounds are each reported in order of increasing $\mathrm{p} K_{\mathrm{a}}^{*}$.

\begin{tabular}{|c|c|c|c|c|c|c|}
\hline Substituents & $\begin{array}{c}\text { Excitation } \\
\text { Energy }(e V)\end{array}$ & $\begin{array}{l}\text { Oscillator } \\
\text { Strength }\end{array}$ & $\begin{array}{c}\Delta \text { q on } \\
\text { Ring } \mathbf{N}\end{array}$ & $\begin{array}{l}\Delta \mathbf{q}^{*} \text { on } \\
\operatorname{Ring} \mathbf{N}\end{array}$ & $\mathbf{p} K_{\mathrm{a}}$ & $\mathbf{p} K_{\mathbf{a}}^{*}$ \\
\hline $1-\mathrm{H}$ & 3.64 & 0.093 & 0.001 & 0.018 & 5.40 & 7.84 \\
\hline $1-\mathrm{NHCH}_{3}$ & 3.15 & 0.13 & -0.048 & -0.024 & 6.24 & 12.30 \\
\hline $1-\mathrm{NH}_{2}$ & 3.17 & 0.12 & -0.051 & -0.036 & 6.19 & 12.32 \\
\hline $1-\mathrm{NH}_{2}, 3-\mathrm{NH}_{2}$ & 3.08 & 0.15 & -0.015 & 0.004 & 7.95 & 10.38 \\
\hline $3-\mathrm{NH}_{2}, 6-\mathrm{NH}_{2}$ & 3.59 & 0.49 & -0.049 & 0.051 & 8.48 & 11.04 \\
\hline $1-\mathrm{NH}_{2}, 8-\mathrm{NH}_{2}$ & 3.07 & 0.13 & -0.046 & -0.022 & 6.90 & 12.11 \\
\hline $1-\mathrm{NH}_{2}, 2-\mathrm{OCH}_{3}$ & 2.92 & 0.090 & -0.066 & -0.059 & 5.90 & 13.66 \\
\hline $1-\mathrm{NH}_{2}, 4-\mathrm{NC}_{2} \mathrm{H}_{6}$ & 2.87 & 0.11 & -0.084 & -0.097 & 7.09 & 13.72 \\
\hline 2- $\mathrm{NHCH}_{3}, 7-\mathrm{NHCH}_{3}$ & 3.04 & 0.050 & -0.079 & -0.073 & 5.91 & 13.76 \\
\hline $1-\mathrm{NH}_{2}, 2-\mathrm{OH}$ & 3.00 & 0.090 & -0.068 & -0.061 & 5.87 & 14.06 \\
\hline 2-NH $\mathrm{NH}_{2}, 7-\mathrm{NH}_{2}$ & 3.29 & 0.053 & -0.071 & -0.071 & 6.02 & 14.07 \\
\hline $2-\mathrm{N}\left(\mathrm{CH}_{3}\right)_{2}, 7-\mathrm{N}\left(\mathrm{CH}_{3}\right)_{2}$ & 3.10 & 0.034 & -0.083 & -0.075 & 5.98 & 14.18 \\
\hline $1-\mathrm{N}\left(\mathrm{CH}_{3}\right)_{2}, 4-\mathrm{N}\left(\mathrm{CH}_{3}\right)_{2}$ & 2.97 & 0.13 & -0.082 & -0.092 & 6.46 & 14.52 \\
\hline $1-\mathrm{NH}_{2}, 4-\mathrm{OCH}_{3}$ & 2.96 & 0.094 & -0.083 & -0.078 & 6.15 & 14.65 \\
\hline $1-\mathrm{NH}_{2}, 2-\mathrm{NH}_{2}$ & 2.91 & 0.077 & -0.074 & -0.085 & 6.27 & 15.11 \\
\hline $1-\mathrm{N}\left(\mathrm{CH}_{3}\right)_{2}, 2-\mathrm{N}\left(\mathrm{CH}_{3}\right)_{2}$ & 2.97 & 0.088 & -0.067 & -0.078 & 5.83 & 15.80 \\
\hline $1-\mathrm{NHCH}_{3}, 2-\mathrm{NHCH}_{3}$ & 2.97 & 0.11 & -0.067 & -0.074 & 5.56 & 16.21 \\
\hline
\end{tabular}


$\begin{array}{lll}\text { HONTO LUNTO } & \text { pKa* } & \text { Excitation } \\ \text { Energy (eV) }\end{array}$

1,2-Amino-acridine
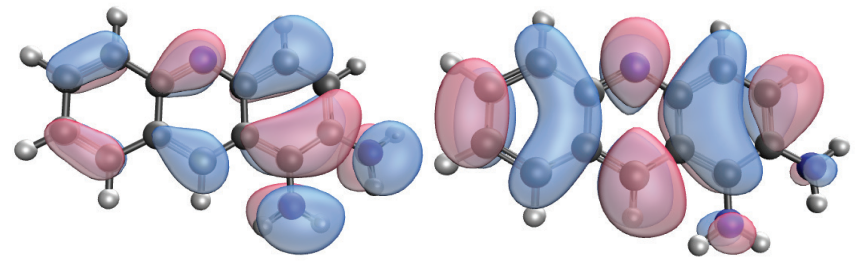

15.11

2.91

1,3-Amino-acridine
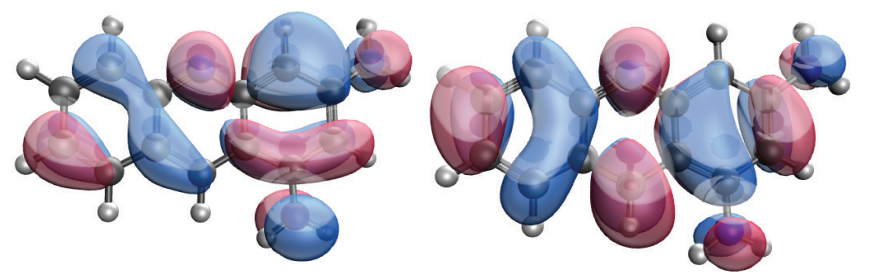

10.38

3.08

Figure S20: The highest occupied natural transition orbital (HONTO) and lowest unoccupied natural transition orbital (LUNTO) at the excited state optimized geometry, along with the $\mathrm{p} K_{\mathrm{a}}^{*}$ and vertical excitation energy, for 1,2-amino-acridine and 1,3-amino-acridine.

3,6-Amino-acridine

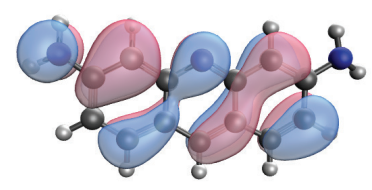

2,7-Amino-acridine
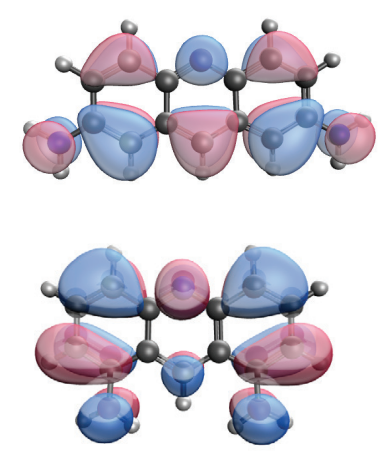

LUNTO
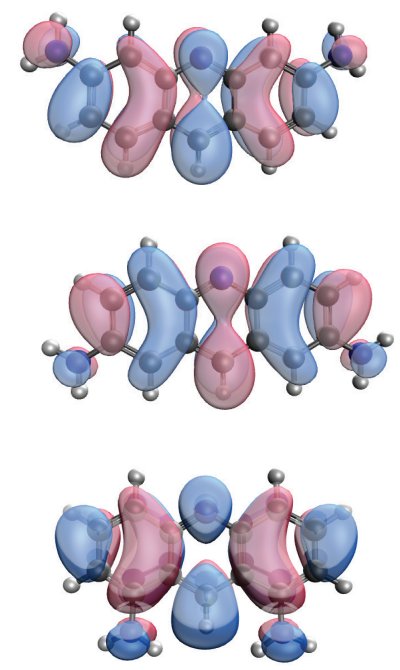

$\begin{array}{cc}\text { EKa* } & \text { Excitation } \\ \text { Energy }(\mathrm{eV})\end{array}$

11.04

3.59

14.07

3.30

12.11

3.07

Figure S21: The highest occupied natural transition orbital (HONTO) and lowest unoccupied natural transition orbital (LUNTO) at the excited state optimized geometry, along with the $\mathrm{p} K_{\mathrm{a}}^{*}$ and vertical excitation energy, for 3,6-amino-acridine, 2,7-amino-acridine, and 1,8-amino-acridine. 


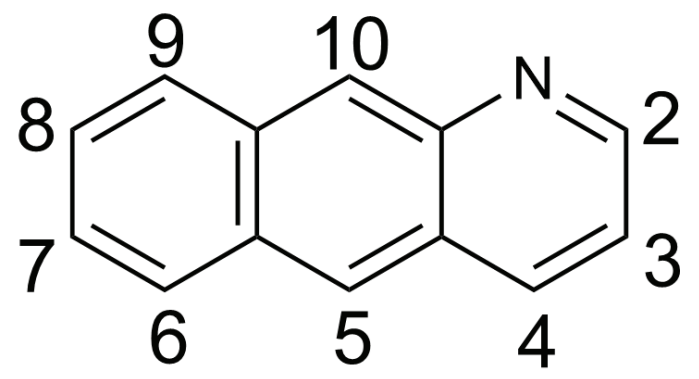

Figure S22: Substituent position numbering system for the 1-azaanthracene compounds.

Table S11: Calculated ground state $\mathrm{p} K_{\mathrm{a}}$, excited state $\mathrm{p} K_{\mathrm{a}}^{*}$, vertical excitation energy, oscillator strength, and change in charge on the ring nitrogen $(\Delta q)$ for the monosubstituted 1-azaanthracene compounds. The reported data is for the lowest energy $\pi \rightarrow \pi^{*}$ bright state and the compounds are reported in order of increasing $\mathrm{p} K_{\mathrm{a}}^{*}$.

\begin{tabular}{|c|c|c|c|c|c|}
\hline Substituents & $\begin{array}{c}\text { Excitation } \\
\text { Energy }(e V)\end{array}$ & $\begin{array}{l}\text { Oscillator } \\
\text { Strength }\end{array}$ & $\begin{array}{c}\Delta \text { q on } \\
\text { Ring } \mathbf{N}\end{array}$ & $\mathbf{p} K_{\mathrm{a}}$ & $\mathbf{p} K_{\mathbf{a}}^{*}$ \\
\hline $5-\mathrm{H}$ & 3.55 & 0.093 & -0.022 & 4.73 & 10.04 \\
\hline $5-\mathrm{NH}_{2}$ & 2.97 & 0.12 & -0.052 & 5.47 & 11.51 \\
\hline $8-\mathrm{NHCH}_{3}$ & 3.23 & 0.14 & -0.037 & 5.49 & 11.80 \\
\hline $5-\mathrm{NHCH}_{3}$ & 3.01 & 0.14 & -0.045 & 5.99 & 11.84 \\
\hline $8-\mathrm{N}\left(\mathrm{CH}_{3}\right)_{2}$ & 3.12 & 0.16 & -0.036 & 5.54 & 11.91 \\
\hline $5-\mathrm{N}\left(\mathrm{CH}_{3}\right)_{2}$ & 2.99 & 0.14 & -0.041 & 5.03 & 11.95 \\
\hline $8-\mathrm{NH}_{2}$ & 3.28 & 0.13 & -0.034 & 5.69 & 12.15 \\
\hline 7-NHCH 3 & 3.19 & 0.11 & -0.030 & 5.04 & 12.37 \\
\hline $7-\mathrm{N}\left(\mathrm{CH}_{3}\right)_{2}$ & 3.09 & 0.13 & -0.029 & 5.13 & 12.52 \\
\hline 9- $\mathrm{NHCH}_{3}$ & 3.10 & 0.12 & -0.038 & 4.53 & 12.53 \\
\hline $7-\mathrm{NH}_{2}$ & 3.26 & 0.10 & -0.027 & 5.15 & 12.57 \\
\hline 9- $\mathrm{NH}_{2}$ & 3.21 & 0.11 & -0.034 & 4.72 & 12.64 \\
\hline 9-N $\left(\mathrm{CH}_{3}\right)_{2}$ & 3.33 & 0.13 & -0.029 & 4.77 & 12.91 \\
\hline $6-\mathrm{NH}_{2}$ & 3.20 & 0.12 & -0.034 & 4.97 & 13.55 \\
\hline $6-\mathrm{N}\left(\mathrm{CH}_{3}\right)_{2}$ & 3.33 & 0.14 & -0.031 & 4.81 & 13.89 \\
\hline $6-\mathrm{NHCH}_{3}$ & 3.36 & 0.12 & -0.030 & 4.72 & 14.25 \\
\hline
\end{tabular}


Table S12: Calculated ground state $\mathrm{p} K_{\mathrm{a}}$, excited state $\mathrm{p} K_{\mathrm{a}}^{*}$, vertical excitation energy, oscillator strength, and change in charge on the ring nitrogen at the ground-state $(\Delta q)$ and excited-state $\left(\Delta q^{*}\right)$ optimized geometries for the disubstituted 1-azaanthracene compounds, continued. The reported data is for the lowest energy $\pi \rightarrow \pi^{*}$ bright state and the compounds are reported in order of increasing $\mathrm{p} K_{\mathrm{a}}^{*}$.

\begin{tabular}{|c|c|c|c|c|c|c|}
\hline Substituents & $\begin{array}{c}\text { Excitation } \\
\text { Energy } \\
\text { (eV) }\end{array}$ & $\begin{array}{l}\text { Oscillator } \\
\text { Strength }\end{array}$ & $\begin{array}{c}\Delta q \text { on } \\
\operatorname{Ring} \mathbf{N}\end{array}$ & $\begin{array}{l}\Delta \mathbf{q}^{*} \text { on } \\
\operatorname{Ring} \mathbf{N}\end{array}$ & $\mathbf{p} K_{\mathrm{a}}$ & $\mathbf{p} K_{\mathrm{a}}^{*}$ \\
\hline $7-\mathrm{OCH}_{3}, 8-\mathrm{OCH}_{3}$ & 3.55 & 0.078 & -0.032 & -0.018 & 4.97 & 10.76 \\
\hline $5-\mathrm{OCH}_{3}, 6-\mathrm{OCH}_{3}$ & 3.31 & 0.13 & -0.039 & -0.027 & 4.77 & 12.14 \\
\hline $7-\mathrm{N}\left(\mathrm{CH}_{3}\right)_{2}, 8-\mathrm{N}\left(\mathrm{CH}_{3}\right)_{2}$ & 3.32 & 0.033 & -0.035 & -0.031 & 5.31 & 12.28 \\
\hline $5-\mathrm{NH}_{2}, 6-\mathrm{NH}_{2}$ & 2.91 & 0.13 & -0.059 & -0.041 & 6.04 & 12.87 \\
\hline $6-\mathrm{OCH}_{3}, 7-\mathrm{OCH}_{3}$ & 3.29 & 0.098 & -0.024 & -0.022 & 4.71 & 12.87 \\
\hline 7- $\mathrm{NHCH}_{3}, 8-\mathrm{NHCH}_{3}$ & 3.28 & 0.092 & -0.032 & -0.033 & 5.46 & 12.89 \\
\hline $7-\mathrm{NH}_{2}, 8-\mathrm{NH}_{2}$ & 3.35 & 0.050 & -0.038 & -0.031 & 5.74 & 12.95 \\
\hline $5-\mathrm{NHCH}_{3}, 6-\mathrm{NHCH}_{3}$ & 2.96 & 0.15 & -0.049 & -0.031 & 6.74 & 13.00 \\
\hline $6-\mathrm{OCH}_{3}, 9-\mathrm{OCH}_{3}$ & 3.25 & 0.10 & -0.036 & -0.031 & 4.67 & 13.25 \\
\hline $5-\mathrm{N}\left(\mathrm{CH}_{3}\right)_{2}, 6-\mathrm{N}\left(\mathrm{CH}_{3}\right)_{2}$ & 2.91 & 0.17 & -0.045 & -0.033 & 5.41 & 13.37 \\
\hline $6-\mathrm{N}\left(\mathrm{CH}_{3}\right)_{2}, 7-\mathrm{N}\left(\mathrm{CH}_{3}\right)_{2}$ & 3.05 & 0.092 & -0.032 & -0.034 & 4.77 & 14.25 \\
\hline $6-\mathrm{NH}_{2}, 7-\mathrm{NH}_{2}$ & 2.98 & 0.078 & -0.035 & -0.037 & 5.21 & 14.47 \\
\hline $6-\mathrm{NH}_{2}, 9-\mathrm{NH}_{2}$ & 2.87 & 0.10 & -0.038 & -0.038 & 4.80 & 14.60 \\
\hline $6-\mathrm{NHCH}_{3}, 7-\mathrm{NHCH}_{3}$ & 2.98 & 0.11 & -0.030 & -0.037 & 5.12 & 15.01 \\
\hline $6-\mathrm{NHCH}_{3}, 9-\mathrm{NHCH}_{3}$ & 2.79 & 0.11 & -0.040 & -0.040 & 4.94 & 15.05 \\
\hline $6-\mathrm{N}\left(\mathrm{CH}_{3}\right)_{2}, 9-\mathrm{N}\left(\mathrm{CH}_{3}\right)_{2}$ & 3.11 & 0.15 & -0.034 & -0.040 & 4.70 & 15.17 \\
\hline
\end{tabular}




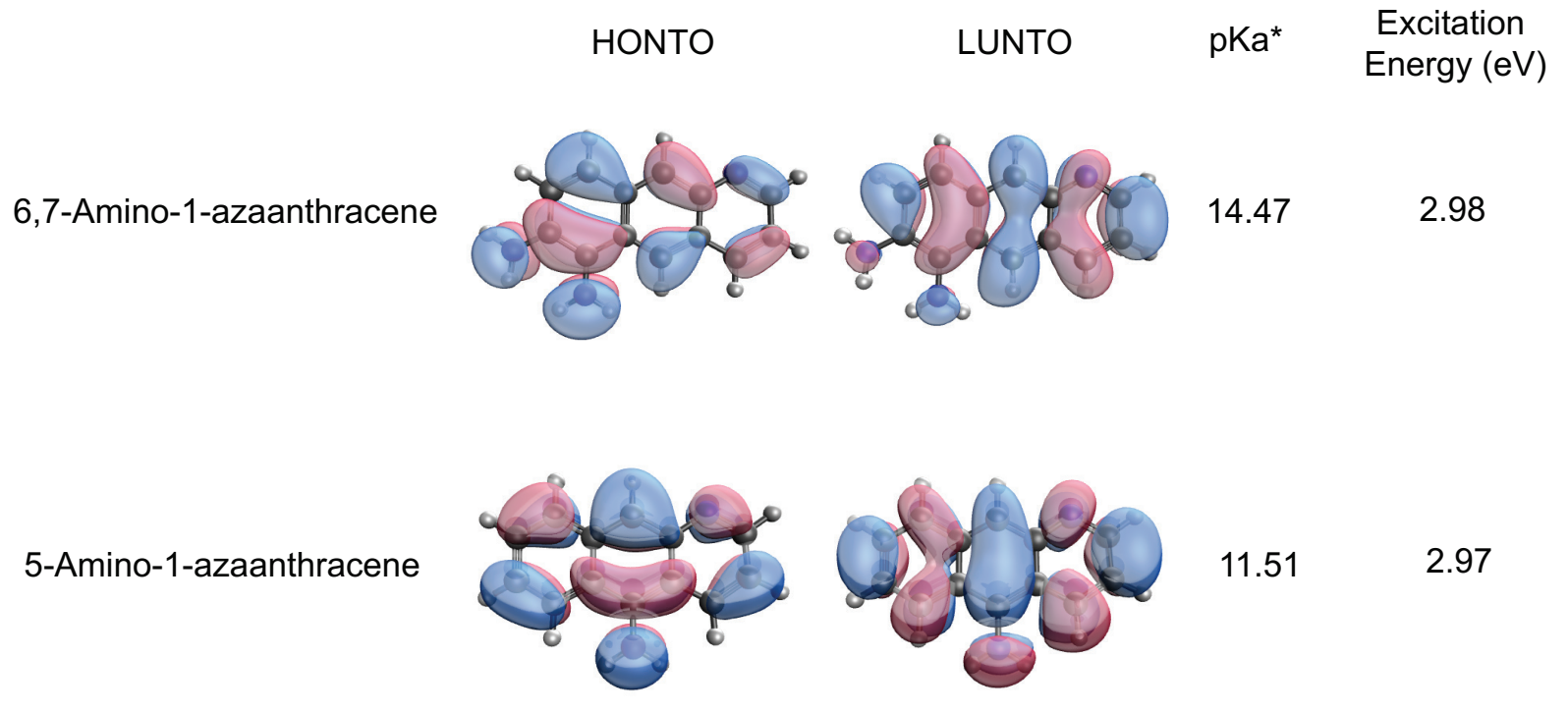

Figure S23: The highest occupied natural transition orbital (HONTO) and lowest unoccupied natural transition orbitas (LUNTO) at the excited state optimized geometry, along with the $\mathrm{p} K_{\mathrm{a}}^{*}$ and vertical excitation energy, for 6,7-amino-1-azaanthracene and 5-amino-1-azaanthracene.

9-Amino-1-azaanthracene
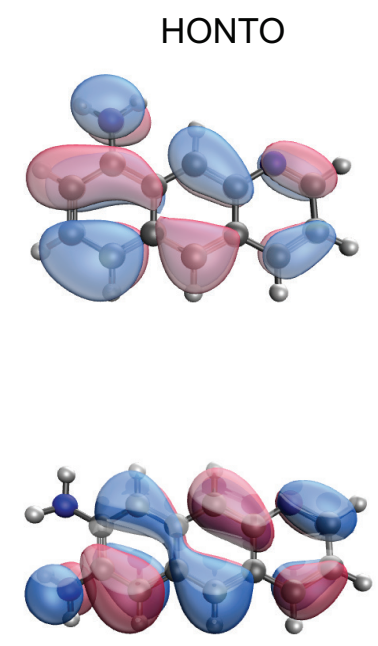

7,8-Amino-1-azaanthracene

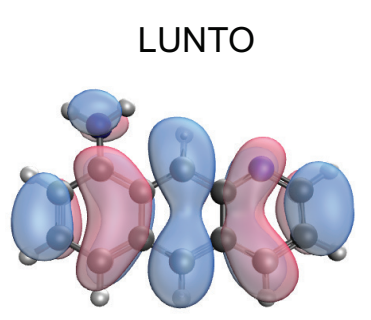

pKa*

13.96

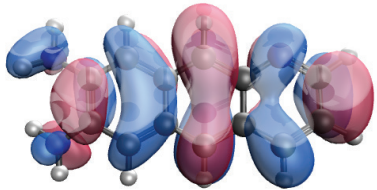

Excitation

Energy (eV)

Figure S24: The highest occupied natural transition orbital (HONTO) and lowest unoccupied natural transition orbitals (LUNTO) at the excited state optimized geometry, along with the $\mathrm{p} K_{\mathrm{a}}^{*}$ and vertical excitation energy, for 7,8-amino-1-azaanthracene and 9-amino-1-azaanthracene. 


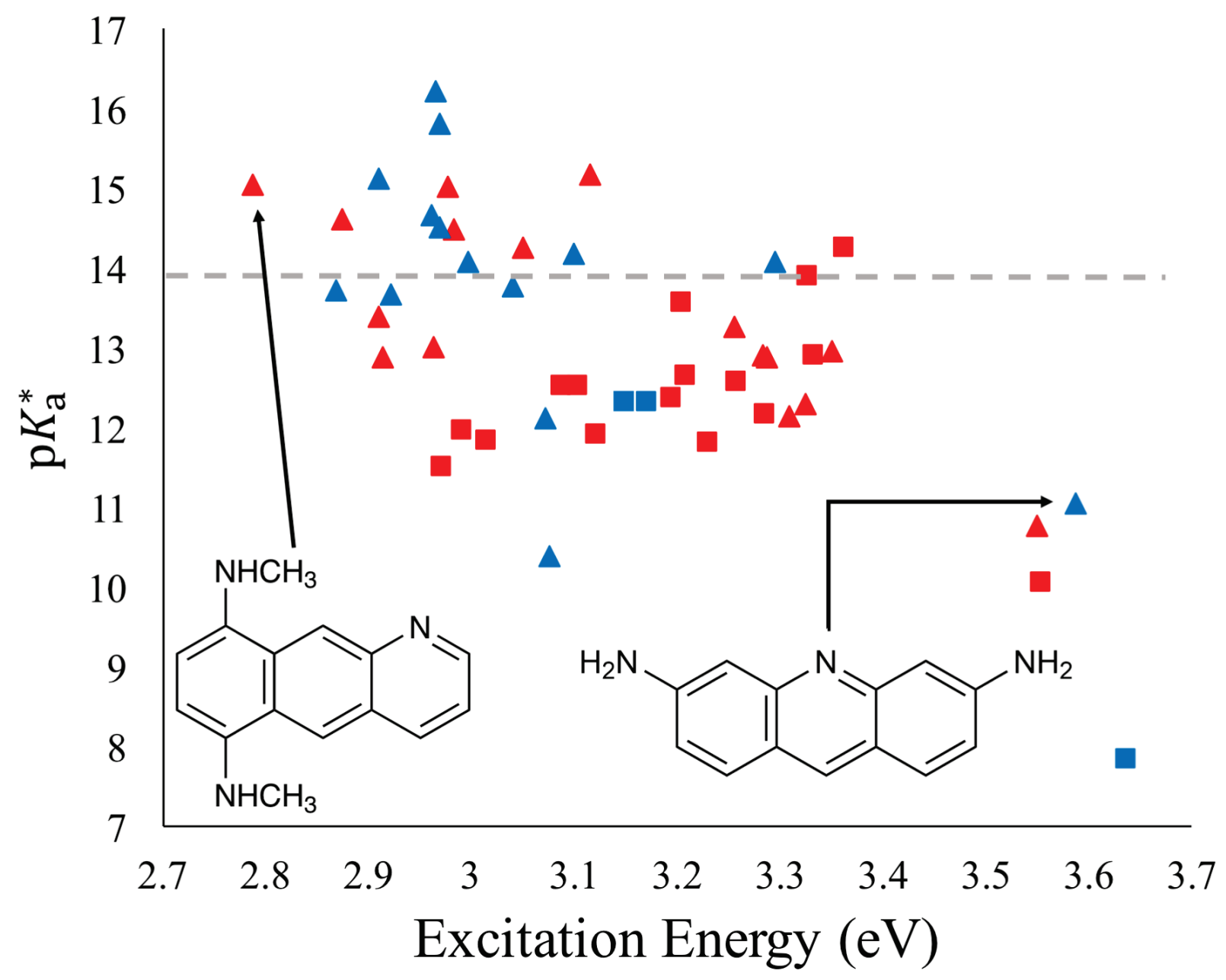

Figure S25: Plot of $\mathrm{p} K_{\mathrm{a}}^{*}$ versus vertical excitation energy for the acridine (blue data points) and 1-azaanthracene (red data points) compounds. The monosubstituted compounds are represented by squares while the disubstituted compounds are shown as triangles. Recall that all compounds with $\mathrm{p} K_{\mathrm{a}}^{*}>14$ are strong bases in the excited state. 


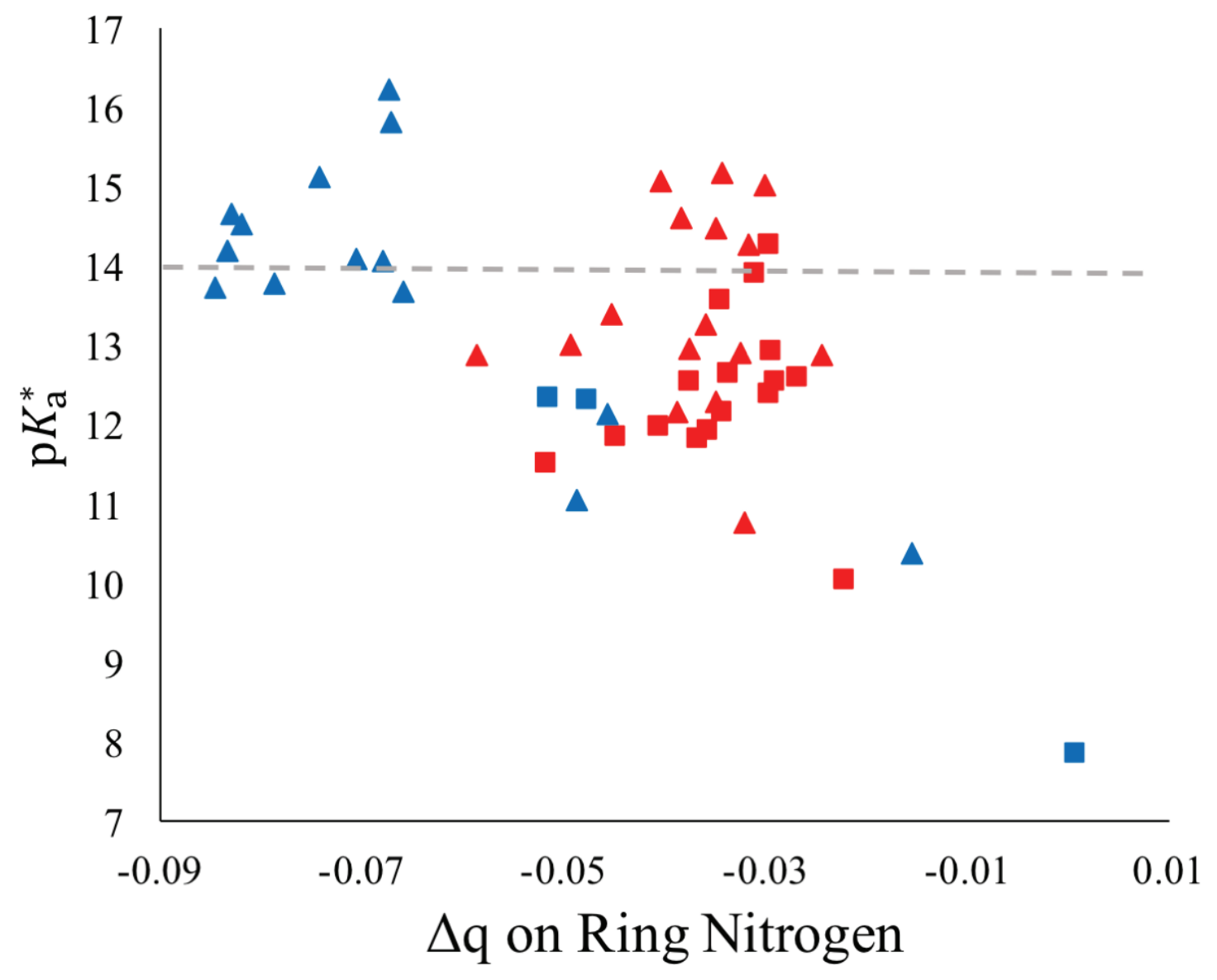

Figure S26: Plot of $\mathrm{p} K_{\mathrm{a}}^{*}$ versus change in charge $(\Delta \mathrm{q})$ on the ring nitrogen for the acridine (blue data points) and 1-azaanthracene (red data points) compounds. The monosubstituted compounds are represented by squares while the disubstituted compounds are shown as triangles. Note that the $\mathrm{p} K_{\mathrm{a}}^{*}$ are calculated using adiabatic energy gaps whereas the $\Delta \mathrm{q}$ on the ring $\mathrm{N}$ are calculated at the ground state geometry. While there is some correlation between $\mathrm{p} K_{\mathrm{a}}^{*}$ and $\Delta \mathrm{q}$ on the ring $\mathrm{N}$, the trend is too noisy to allow a calculated $\Delta \mathrm{q}$ on the ring $\mathrm{N}$ to accurately predict $\mathrm{p} K_{\mathrm{a}}^{*}$. 


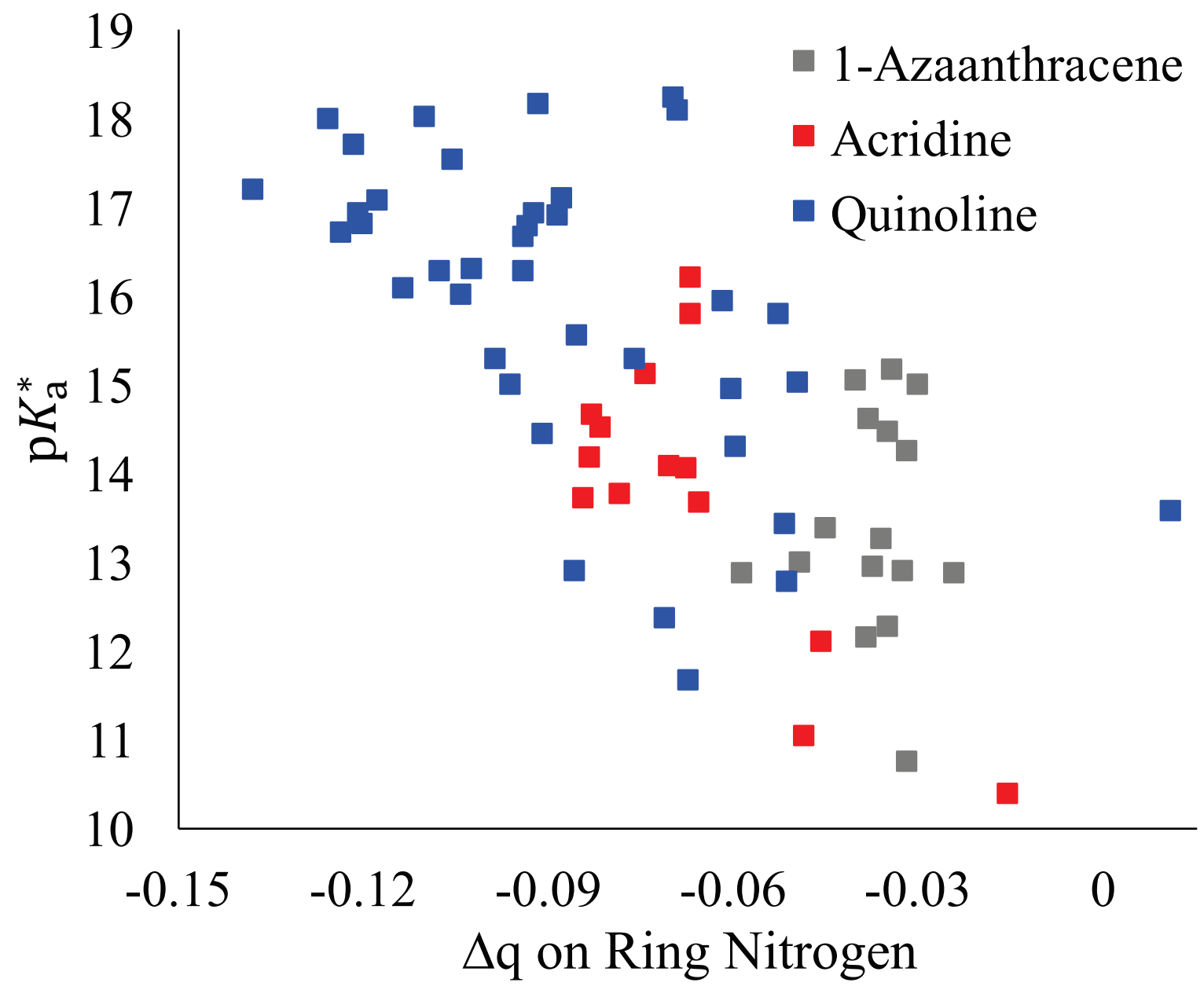

Figure S27: Plot of $\mathrm{p} K_{\mathrm{a}}^{*}$ versus change in charge $(\Delta \mathrm{q})$ on the ring nitrogen for the disubstituted 1-azaanthracene (gray squares), acridine (red squares), and quinoline (blue squares) compounds. Note that the $\mathrm{p} K_{\mathrm{a}}^{*}$ are calculated using adiabatic energy gaps whereas the $\Delta \mathrm{q}$ on the ring $\mathrm{N}$ are calculated at the ground state geometry. Linear regression analysis leads to $\mathrm{R}^{2}$ values of 0.004 , 0.56 , and 0.33 for the 1-azaanthracene, acridine, and quinoline compounds respectively. 
Table S13: Calculated $E_{\mathrm{SCT}}$ and $E_{\mathrm{T}}-E_{\mathrm{SCT}}$ between $\mathrm{S}_{\mathrm{CT}}$ and the two closest triplet states for representative 5-R and 6-R quinoline compounds at the $\mathrm{S}_{\mathrm{CT}}$ optimized geometries. Because the Tamm-Dancoff approximation (TDA) is known to minimize triplet instability problems that can appear in TDDFT calculations, all of these energies were calculated using TDA. ${ }^{2}$ The $E_{\mathrm{SCT}}$ is reported relative to the ground state.

\begin{tabular}{|cccc|}
\hline Compound & $\begin{array}{c}\boldsymbol{E}_{\mathbf{S C T}} \\
\mathbf{( e V})\end{array}$ & $\begin{array}{c}\text { Closest Triplet } \\
\boldsymbol{E}_{\mathbf{T}}-\boldsymbol{E}_{\mathbf{S C T}}(\mathbf{e V})\end{array}$ & $\begin{array}{c}\text { Second Closest } \\
\text { Triplet } \\
\boldsymbol{E}_{\mathbf{T}}-\boldsymbol{E}_{\mathbf{S C T}}(\mathbf{e V})\end{array}$ \\
\hline 5-methoxyquinoline & 3.75 & 0.16 & 0.26 \\
5-methoxyquinoline acid & 3.18 & 0.47 & 0.72 \\
5-aminoquinoline & 3.30 & 0.21 & 0.69 \\
5-aminoquinoline acid & 2.72 & 0.69 & -0.78 \\
5-methylaminoquinoline & 3.29 & 0.24 & 0.69 \\
5-methylaminoquinoline acid & 2.69 & 0.72 & -0.75 \\
5-dimethylaminoquinoline & 3.30 & 0.27 & 0.57 \\
5-dimethylaminoquinoline acid & 2.69 & 0.73 & -0.79 \\
6-aminoquinoline & 3.57 & -0.08 & 0.26 \\
6-aminoquinoline acid & 3.05 & 0.21 & 0.74 \\
6-methylaminoquinoline & 3.58 & -0.16 & 0.23 \\
6-methylaminoquinoline acid & 3.04 & 0.19 & 0.72 \\
6-dimethylaminoquinoline & 3.49 & -0.05 & 0.32 \\
6-methylaminoquinoline acid & 2.92 & 0.28 & 0.81 \\
\hline
\end{tabular}


Table S14: Calculated $E_{\mathrm{SCT}}$ and $E_{\mathrm{T}}-E_{\mathrm{SCT}}$ between $\mathrm{S}_{\mathrm{CT}}$ and the two closest triplet states for representative disubstituted quinoline compounds at the $\mathrm{S}_{\mathrm{CT}}$ optimized geometries. Because the Tamm-Dancoff approximation (TDA) is known to minimize triplet instability problems that can appear in TDDFT calculations, all of these energies were calculated using TDA. ${ }^{2}$ The $E_{\mathrm{SCT}}$ is reported relative to the ground state.

\begin{tabular}{|c|c|c|c|}
\hline Compound & $\begin{array}{l}E_{\mathrm{SCT}} \\
(\mathrm{eV})\end{array}$ & $\begin{array}{l}\text { Closest Triplet } \\
E_{\mathrm{T}}-E_{\mathrm{SCT}}(\mathrm{eV})\end{array}$ & $\begin{array}{c}\text { Second Closest } \\
\text { Triplet } \\
E_{\mathrm{T}}-E_{\mathrm{SCT}}(\mathrm{eV}) \\
\end{array}$ \\
\hline $3-\mathrm{NH}_{2}, 5-\mathrm{NH}_{2}$ & 3.23 & -0.0004 & 0.22 \\
\hline $3-\mathrm{NH}_{2}, 5-\mathrm{NH}_{2}$ acid & 2.61 & 0.21 & 0.82 \\
\hline $3-\mathrm{NH}_{2}, 6-\mathrm{NH}_{2}$ & 3.67 & 0.33 & 0.46 \\
\hline $3-\mathrm{NH}_{2}, 6-\mathrm{NH}_{2}$ acid & 3.06 & 0.67 & -0.73 \\
\hline $4-\mathrm{NH}_{2}, 5-\mathrm{NH}_{2}$ & 3.27 & 0.12 & 0.67 \\
\hline $4-\mathrm{NH}_{2}, 5-\mathrm{NH}_{2}$ acid & 2.93 & 0.43 & 0.66 \\
\hline $3-\mathrm{NC}_{2} \mathrm{H}_{6}, 5-\mathrm{NC}_{2} \mathrm{H}_{6}$ & 3.21 & -0.09 & 0.26 \\
\hline $3-\mathrm{NC}_{2} \mathrm{H}_{6}, 5-\mathrm{NC}_{2} \mathrm{H}_{6}$ acid & 2.57 & 0.09 & 0.83 \\
\hline $5-\mathrm{NC}_{2} \mathrm{H}_{6}, 8-\mathrm{NC}_{2} \mathrm{H}_{6}$ & 2.56 & 0.28 & -0.87 \\
\hline $5-\mathrm{NC}_{2} \mathrm{H}_{6}, 8-\mathrm{NC}_{2} \mathrm{H}_{6}$ acid & 1.81 & -0.63 & 0.85 \\
\hline $5-\mathrm{NC}_{2} \mathrm{H}_{6}, 8-\mathrm{OCH}_{3}$ & 2.88 & 0.21 & -0.95 \\
\hline $5-\mathrm{NC}_{2} \mathrm{H}_{6}, 8-\mathrm{OCH}_{3}$ acid & 2.19 & -0.69 & 0.73 \\
\hline $5-\mathrm{NH}_{2}, 8-\mathrm{OCH}_{3}$ & 2.80 & 0.19 & -0.93 \\
\hline $5-\mathrm{NH}_{2}, 8-\mathrm{OCH}_{3}$ acid & 2.13 & -0.68 & 0.74 \\
\hline $5-\mathrm{OCH}_{3}, 6-\mathrm{NH}_{2}$ & 3.38 & 0.10 & 0.32 \\
\hline $5-\mathrm{OCH}_{3}, 6-\mathrm{NH}_{2}$ acid & 2.50 & 0.70 & 0.88 \\
\hline 6- $\mathrm{NH}_{2}, 7-\mathrm{NH}_{2}$ & 3.73 & 0.21 & 0.49 \\
\hline $6-\mathrm{NH}_{2}, 7-\mathrm{NH}_{2}$ acid & 3.25 & -0.41 & 0.59 \\
\hline $5-\mathrm{NH}_{2}, 6-\mathrm{NH}_{2}$ & 2.87 & 0.40 & 0.70 \\
\hline 5- $\mathrm{NH}_{2}, 6-\mathrm{NH}_{2}$ acid & 2.13 & -0.74 & 0.92 \\
\hline $5-\mathrm{NH}_{2}, 7-\mathrm{NH}_{2}$ & 3.21 & 0.32 & 0.43 \\
\hline $5-\mathrm{NH}_{2}, 7-\mathrm{NH}_{2}$ acid & 2.80 & 0.29 & -0.72 \\
\hline $5-\mathrm{NH}_{2}, 6-\mathrm{OCH}_{3}$ & 3.05 & 0.42 & 0.73 \\
\hline $5-\mathrm{NH}_{2}, 6-\mathrm{OCH}_{3}$ acid & 2.37 & -0.77 & 0.88 \\
\hline $5-\mathrm{NH}_{2}, 7-\mathrm{OCH}_{3}$ & 3.37 & 0.30 & 0.43 \\
\hline $5-\mathrm{NH}_{2}, 7-\mathrm{OCH}_{3}$ acid & 2.85 & 0.53 & -0.71 \\
\hline
\end{tabular}


Table S15: Calculated $E_{\mathrm{SCT}}$ and $E_{\mathrm{T}}-E_{\mathrm{SCT}}$ between $\mathrm{S}_{\mathrm{CT}}$ and the two closest triplet states for representative disubstituted acridine compounds at the $\mathrm{S}_{\mathrm{CT}}$ optimized geometries. Because the Tamm-Dancoff approximation (TDA) is known to minimize triplet instability problems that can appear in TDDFT calculations, all of these energies were calculated using TDA. ${ }^{2}$ The $E_{\mathrm{SCT}}$ is reported relative to the ground state.

\begin{tabular}{|cccc|}
\hline Compound & $\begin{array}{c}\boldsymbol{E}_{\mathbf{S C T}} \\
(\mathbf{e V})\end{array}$ & $\begin{array}{c}\text { Closest Triplet } \\
\boldsymbol{E}_{\mathbf{T}}-\boldsymbol{E}_{\mathbf{S C T}}(\mathbf{e V})\end{array}$ & $\begin{array}{c}\text { Second Closest } \\
\text { Triplet } \\
\boldsymbol{E}_{\mathbf{T}}-\boldsymbol{E}_{\mathbf{S C T}}(\mathbf{e V})\end{array}$ \\
\hline $2-\mathrm{NC}_{2} \mathrm{H}_{6}, 7-\mathrm{NC}_{2} \mathrm{H}_{6}$ & 2.92 & 0.48 & -0.56 \\
$2-\mathrm{NC}_{2} \mathrm{H}_{6}, 7-\mathrm{NC}_{2} \mathrm{H}_{6}$ acid & 2.45 & -0.52 & 0.76 \\
$1-\mathrm{NH}_{2}, 2-\mathrm{NH}_{2}$ & 2.31 & 0.57 & 0.94 \\
$1-\mathrm{NH}_{2}, 2-\mathrm{NH}_{2}$ acid & 1.76 & -0.78 & 1.08 \\
$1-\mathrm{NH}_{2}, 2-\mathrm{OH}$ & 2.52 & 0.40 & 0.85 \\
$1-\mathrm{NH}_{2}, 2-\mathrm{OH}_{\text {acid }}$ & 2.07 & 0.75 & -0.81 \\
$1-\mathrm{NC}_{2} \mathrm{H}_{6}, 2-\mathrm{NC}_{2} \mathrm{H}_{6}$ & 2.35 & 0.42 & 0.76 \\
$1-\mathrm{NC}_{2} \mathrm{H}_{6}, 2-\mathrm{NC}_{2} \mathrm{H}_{6}$ acid & 1.75 & -0.74 & 0.88 \\
$1-\mathrm{NH}_{2}, 4-\mathrm{NC}_{2} \mathrm{H}_{6}$ & 1.94 & 0.80 & -0.84 \\
$1-\mathrm{NH}_{2}, 4-\mathrm{NC}_{2} \mathrm{H}_{6}$ acid & 1.52 & -0.69 & 1.22 \\
$1-\mathrm{NH}_{2}, 4-\mathrm{OCH}_{3}$ & 2.28 & 0.58 & 0.76 \\
$1-\mathrm{NH}_{2}, 4-\mathrm{OCH}_{3}$ acid & 1.88 & -0.74 & 0.89 \\
$1-\mathrm{NHCH}_{3}, 2-\mathrm{NHCH}_{3}$ & 2.30 & 0.55 & 0.94 \\
$1-\mathrm{NHCH}_{3}, 2-\mathrm{NHCH}_{3}$ acid & 1.70 & -0.81 & 1.12 \\
\hline
\end{tabular}


Table S16: Calculated $E_{\mathrm{SCT}}$ and $E_{\mathrm{T}}-E_{\mathrm{SCT}}$ between $\mathrm{S}_{\mathrm{CT}}$ and the two closest triplet states for representative 1-azaanthracene compounds at the $\mathrm{S}_{\mathrm{CT}}$ optimized geometries. Because the TammDancoff approximation (TDA) is known to minimize triplet instability problems that can appear in TDDFT calculations, all of these energies were calculated using TDA. ${ }^{2}$ The $E_{\mathrm{SCT}}$ is reported relative to the ground state.

\begin{tabular}{|cccc|}
\hline Compound & $\begin{array}{c}\boldsymbol{E}_{\mathbf{S C T}} \\
(\mathbf{e V})\end{array}$ & $\begin{array}{c}\text { Closest Triplet } \\
\boldsymbol{E}_{\mathbf{T}}-\boldsymbol{E}_{\mathbf{S C T}}(\mathbf{e V})\end{array}$ & $\begin{array}{c}\text { Second Closest } \\
\text { Triplet } \\
\boldsymbol{E}_{\mathbf{T}}-\boldsymbol{E}_{\mathbf{S C T}}(\mathbf{e V})\end{array}$ \\
\hline $6 \mathrm{NHCH}_{3}, 9 \mathrm{NHCH}_{3}$ & 2.03 & 0.67 & 0.75 \\
$6 \mathrm{NHCH}_{3}, 9 \mathrm{NHCH}_{3}$ acid & 1.43 & -0.63 & 1.00 \\
$6 \mathrm{NH}_{2}, 9 \mathrm{NH}_{2}$ & 2.01 & 0.62 & 0.80 \\
$6 \mathrm{NH}_{2}, 9 \mathrm{NH}_{2}$ acid & 1.44 & -0.70 & 0.96 \\
$6 \mathrm{NC}_{2} \mathrm{H}_{6}, 9 \mathrm{NC}_{2} \mathrm{H}_{6}$ & 2.12 & 0.61 & 0.66 \\
$6 \mathrm{NC}_{2} \mathrm{H}_{6}, 9 \mathrm{NC}_{2} \mathrm{H}_{6}$ acid & 1.46 & -0.65 & 0.99 \\
$6 \mathrm{NHCH}_{3}, 7 \mathrm{NHCH}_{3}$ & 2.22 & 0.53 & 0.86 \\
$6 \mathrm{NHCH}_{3}, 7 \mathrm{NHCH}_{3}$ acid & 1.60 & -0.72 & 0.97 \\
$6 \mathrm{NH}_{2}, 7 \mathrm{NH}_{2}$ & 2.47 & 0.29 & 0.75 \\
$6 \mathrm{NH}_{2}, 7 \mathrm{NH}_{2}$ acid & 1.83 & 0.73 & -0.73 \\
$6 \mathrm{NC}_{2} \mathrm{H}_{6}, 7 \mathrm{NC}_{2} \mathrm{H}_{6}$ & 2.39 & 0.48 & 0.77 \\
$6 \mathrm{NC}_{2} \mathrm{H}_{6}, 7 \mathrm{NC}_{2} \mathrm{H}_{6}$ acid & 1.79 & -0.76 & 0.90 \\
$6 \mathrm{NHCH}_{3}$ & 2.64 & 0.33 & 0.58 \\
$6 \mathrm{NHCH}_{3}$ acid & 2.15 & 0.68 & -0.84 \\
\hline
\end{tabular}


Table S16: Calculated excited state energy $\left(E_{\mathrm{SCT}}\right)$, radical anion energy $\left(E_{\text {radical anion }}\right)$, and exited state electron affinity $\left(E_{\text {radical anion }}-E_{\mathrm{SCT}}\right)$ for a range of nitrogen-containing heterocyclic compounds. All electronic energies are evaluated at the excited state optimized geometry. The excited state electron affinity should be compared with the ionization potential of liquid water, $6.5 \pm 0.5 \mathrm{eV}^{3}$

\begin{tabular}{|cccc|}
\hline Compound & $\begin{array}{c}\boldsymbol{E}_{\mathbf{S C T}} \\
\left(\mathbf{k c a l ~ m o l}^{\mathbf{- 1}} \mathbf{)}\right.\end{array}$ & $\begin{array}{c}\boldsymbol{E}_{\text {radical anion }} \\
\left(\mathbf{k c a l ~ m o l}^{\mathbf{1}} \mathbf{)}\right.\end{array}$ & $\begin{array}{c}\boldsymbol{E}_{\text {radical anion }}-\boldsymbol{E}_{\mathbf{S C T}} \\
(\mathbf{e V})\end{array}$ \\
\hline 5-cyanoquinoline & -310009.90 & -310163.47 & -6.66 \\
5-chloroquinoline & -540534.95 & -540678.26 & -6.21 \\
quinoline & -252121.26 & -252264.35 & -6.21 \\
5-methylquinoline & -276799.38 & -276937.60 & -5.99 \\
5-methoxyquinoline & -324004.80 & -324134.63 & -5.63 \\
5-aminoquinoline & -286887.59 & -287005.40 & -5.11 \\
5-dimethylaminoquinoline & -336213.02 & -336330.42 & -5.09 \\
5,6-aminoquinoline & -321637.97 & -321742.47 & -4.53 \\
1,2-amino-acridine & -418061.09 & -418165.45 & -4.53 \\
6,7-amino-1-azaanthracene & -418058.06 & -418162.18 & -4.51 \\
\hline
\end{tabular}


(1) Driscoll, E. W.; Hunt, J. R.; Dawlaty, J. M. Photobasicity in Quinolines: Origin and Tunability via the Substituents' Hammett Parameters. J. Phys. Chem. Lett. 2016, 7 (11), 2093-2099. https://doi.org/10.1021/acs.jpclett.6b00790.

(2) Peach, M. J. G.; Williamson, M. J.; Tozer, D. J. Influence of Triplet Instabilities in TDDFT. J. Chem. Theory Comput. 2011, 7 (11), 3578-3585. https://doi.org/10.1021/ct200651r.

(3) Roy, S.; Ardo, S.; Furche, F. 5-Methoxyquinoline Photobasicity Is Mediated by Water Oxidation. J. Phys. Chem. A 2019, 123 (31), 6645-6651.

https://doi.org/10.1021/acs.jpca.9b05341. 